CRWR Online Report 08-03

\title{
Stormwater Quality Benefits of a Permeable Friction Course
}

\author{
by \\ Christina E. Stanard, M.S.E. \\ Michael E. Barrett, Ph.D. \\ Randall J. Charbeneau, Ph.D.
}

May 2008

\author{
Center for Research in Water Resources \\ The University of Texas at Austin \\ J.J. Pickle Research Campus \\ Austin, TX 78712-4497
}

This document is available online via the World Wide Web at http://www.crwr.utexas.edu/online.shtml 



\section{Acknowledgements}

This research was funded by the Texas Department of Transportation under

project number 0-5220, "Investigation of Stormwater Quality Improvements Utilizing Permeable Pavement and/or the Porous Friction Course (PFC)". 


\section{Table of Contents}

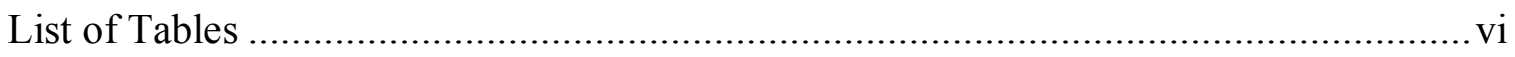

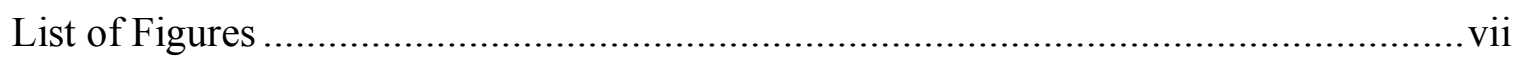

CHAPTER 1 INTRODUCTION ........................................................................................... 1

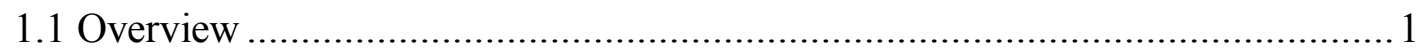

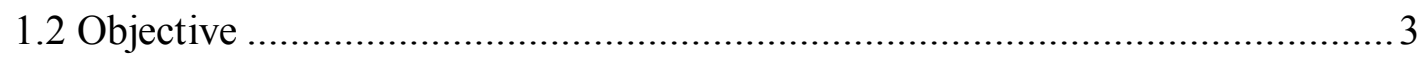

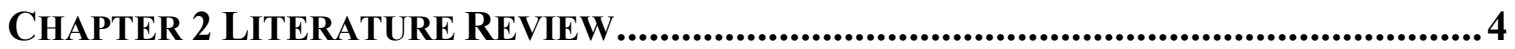

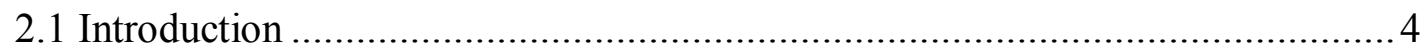

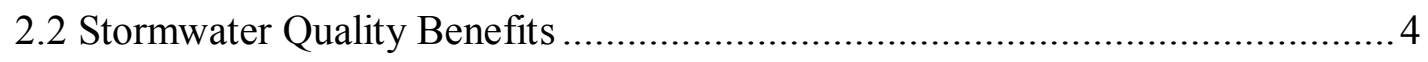

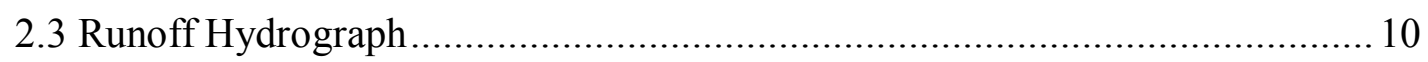

CHAPTER 3 MATERIALS AND METHODS ............................................................12

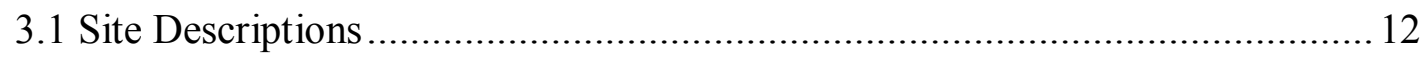

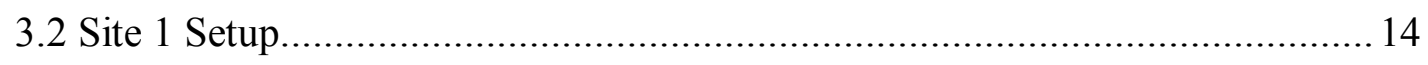

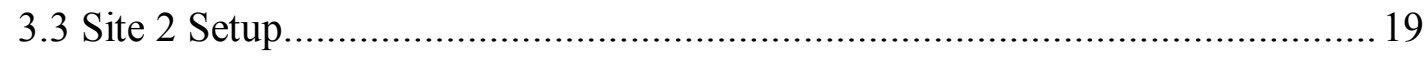

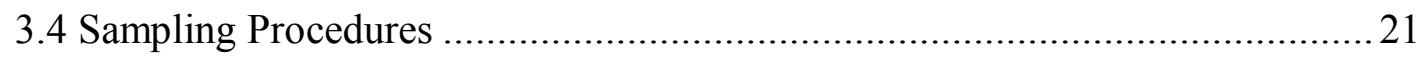

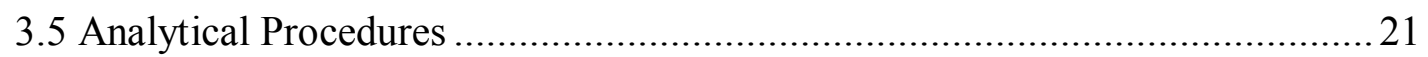

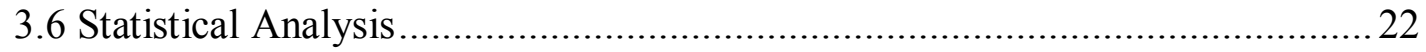

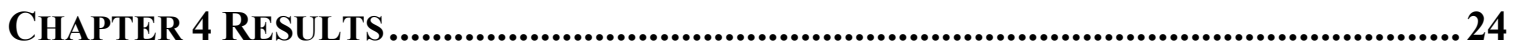

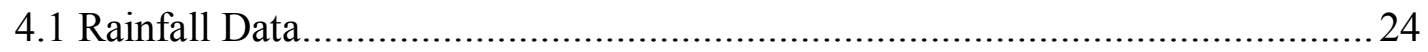

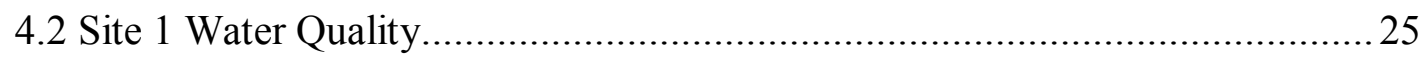

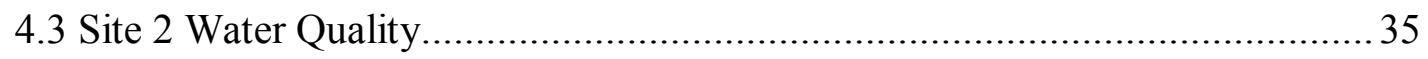

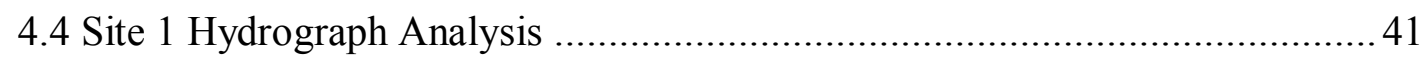

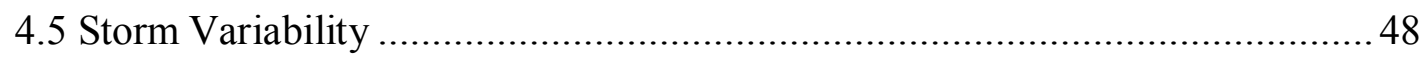


CHAPTER 5 SUMMARY AND CONCLUSIONS ...........................................................50

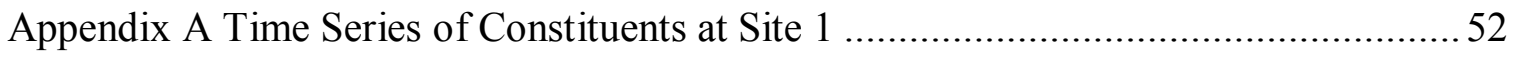

Appendix B Significant Trends for Constituents at Site 1 ....................................... 57

Appendix C Hydrographs for Each Monitored Rain Event.................................... 61

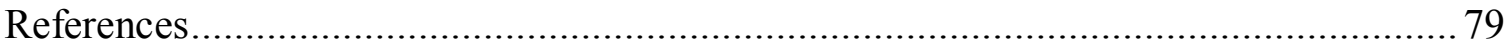




\section{List of Tables}

Table 1: Concentration range comparison from Berbee et al. (1999) ...............................5

Table 2: Concentration comparison from Pagotto et al. (2000)...................................6

Table 3: Clogging material concentrations from Colandini et al. (1995)........................ 7

Table 4: Concentration comparison from Ranchet (1995) ....................................... 9

Table 5: Summary of literature data of pollutant concentrations in highway runoff........ 10

Table 6: Parameters and methods for analysis by Environmental Laboratory Services ...22

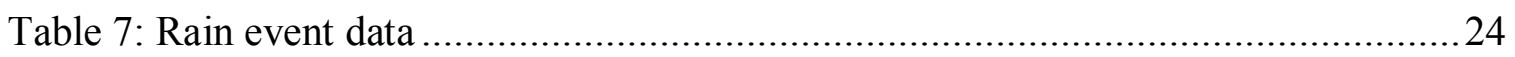

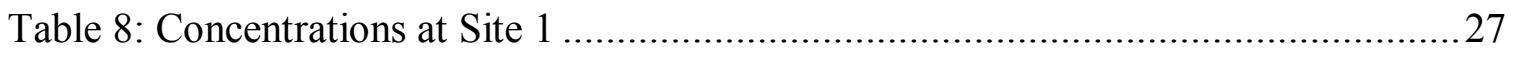

Table 9: Comparison of concentrations from conventional asphalt and PFC at Site $1 \ldots . .28$

Table 10: Comparison of mean concentrations from Barrett et al. (1995) ......................31

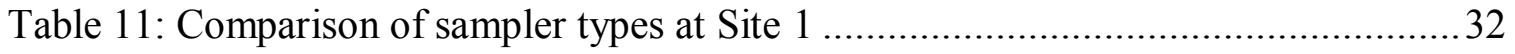

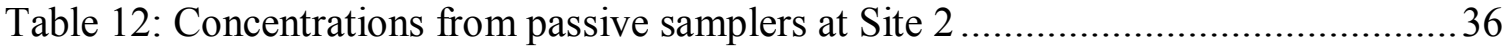

Table 13: Comparison of concentrations from passive samplers at Site 2 ..................... 37

Table 14: Percent dissolved form of total concentration........................................... 41 


\section{List of Figures}

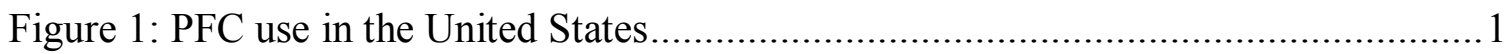

Figure 2: Satellite image of sites on Loop 360 (Google Maps, 2007) …........................ 12

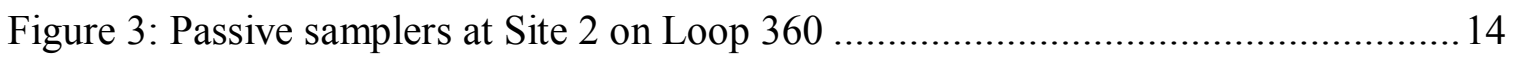

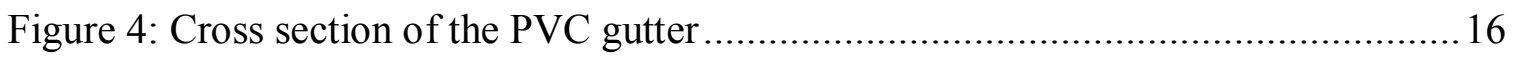

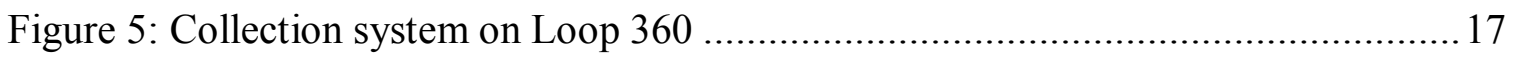

Figure 6: Flume, draining box and storage box setup ...............................................18

Figure 7: PFC and conventional pavement passive samplers ........................................20

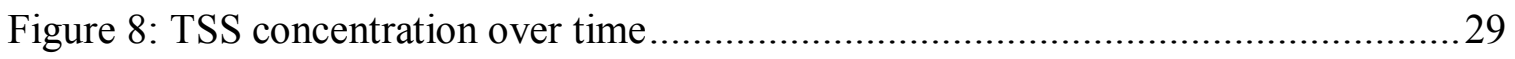

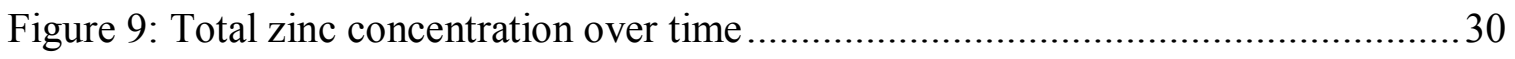

Figure 10: Total copper concentrations from passive sampler at Site 1 .........................33

Figure 11: Total copper concentrations from automatic sampler at Site 1.......................33

Figure 12: TSS concentrations from passive samplers ……............................................38

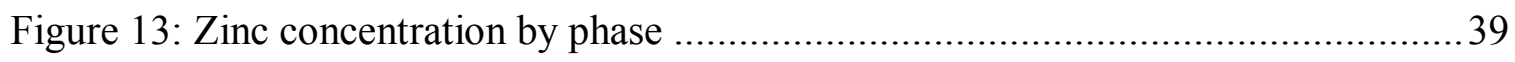

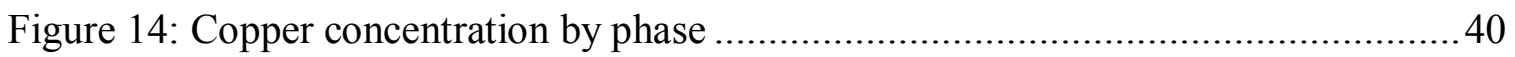

Figure 15: Hydrograph from sampled rain even on March 11, 2007 ............................42

Figure 16: Rainfall-runoff relationship from PFC at Site 1..........................................4 44

Figure 17: PFC storage curve for March 11, 2007 rain event ………...........................45

Figure 18: Runoff versus storage for March 11, 2007 rain event ...................................46

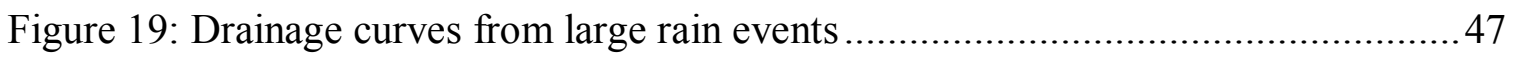




\section{CHAPTER 1 INTRODUCTION}

\subsection{OVERVIEW}

A permeable friction course (PFC) is a type of porous pavement that is applied over an impervious concrete or conventional asphalt base. The overlay is a bituminous mixture produced with course aggregate (and no fine aggregate) that is usually placed at a thickness of approximately $5 \mathrm{~cm}$ and a porosity of about $20 \%$. Porous asphalt overlays are sometimes referred to as open-graded friction course or, in Texas, permeable friction course (PFC) as described by the Texas Department of Transportation (TxDOT) specifications (TxDOT, 2004). PFC is different from fully porous pavements, which are sometimes used on parking lots, driveways and sidewalks to reduce runoff volume, because the porous overlay is applied over an impervious base. PFC is commonly used in the United States, Europe and Japan. Figure 1 shows the states currently using or testing PFC based on a survey of departments of transportation in the United States (Stanard et al., 2008).

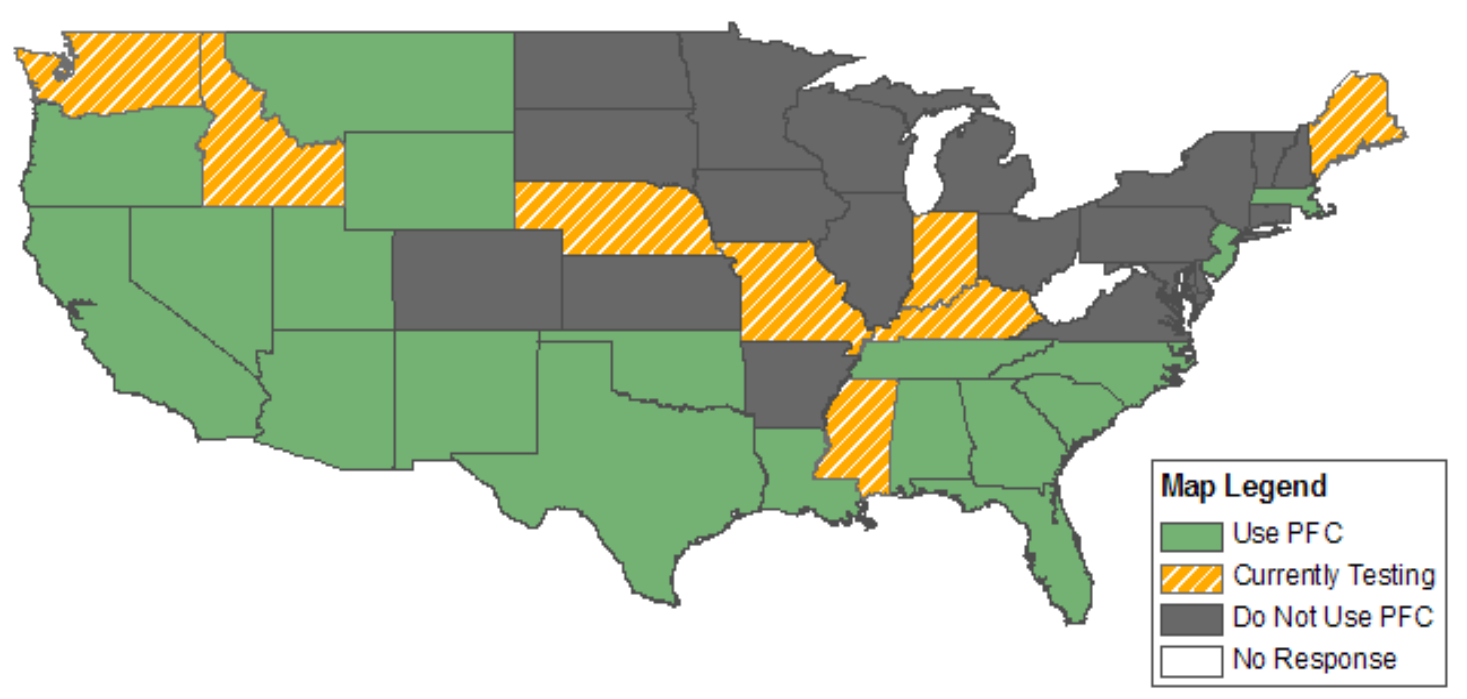

Figure 1: PFC use in the United States 
PFC is generally used to improve road safety in wet conditions and reduce noise from the roadway (Kandhal, 2004). The interconnected voids in the overlay allow rainwater to drain down into the pavement and then flow over the impervious base and out at the edge of the pavement. The removal of water from the roadway provides the following safety benefits in rain events: reduced hydroplaning, greater skid resistance at high speeds, less splash and spray from vehicles, and therefore, better visibility (Van der Zwan et al., 1990). In recent years, studies have also found that porous asphalt overlays reduce the concentrations of many pollutants in stormwater runoff (Berbee et al., 1999; Barrett and Shaw, 2007).

Due to the unique properties of $\mathrm{PFC}$, the overlay requires more maintenance, costs more to install, and usually has a shorter service life than conventional pavement. The most commonly noted problems with porous asphalt overlays are reduced performance due to clogging and the winter maintenance requirements (Van der Zwan et al., 1990). Particles from the roadway are collected in the pores of the pavement as runoff flows through the overlay. The particles are generally sand or debris from tires (Fwa et al., 1999). It is recommended that PFC is used on high-speed roadways since the tires create pressure and suction that has a cleaning effect which slows the clogging of the pores (Pagotto et al., 2000).

Stormwater runoff controls are becoming an important aspect of development and construction as concern for protecting the environment increases. TxDOT is required by the Texas Commission on Environmental Quality (TCEQ) to treat stormwater runoff over the Edwards Aquifer region. The regulations require $80 \%$ removal of TSS load created by construction projects over the Edwards Aquifer recharge zone (Texas Administrative Code, 2005). Structural treatment controls currently used, such as wet ponds, detention ponds and sedimentation/filtration basins, are often expensive to construct and maintain. 
Right-of-way for control structures can be very difficult to obtain particularly in road expansion projects. The pollutant reduction in runoff from PFC may allow stormwater treatment to be incorporated into the pavement itself which would be extremely costeffective.

A previous study monitored stormwater runoff from conventional asphalt at a site on Loop 360 in Austin, Texas to evaluate the performance of vegetative buffer strips (Kearfott et al., 2005). Seven months into monitoring, a PFC overlay was installed on Loop 360. When monitoring resumed, the runoff was found to be much cleaner. The monitoring continued at the site over the next two years (Barrett and Shaw, 2007).

\subsection{OBJECTIVE}

The purpose of this project was to determine the degree and longevity of the stormwater quality benefits of PFC. The scope of this project included:

- Design and installation of a collection system with a flow meter and automatic sampler for continued monitoring at the original site on Loop 360

- Selection of another site for monitoring and installation of two passive samplers

- Monitoring of both sites and collection of runoff samples for a period of 15 months

- Laboratory analysis of all runoff samples

- Compilation of results from laboratory analysis into a database

- Statistical and graphical analysis of results to establish any trends in data

- Compilation and analysis of flow meter data for each rain event 


\section{CHAPTER 2 LITERATURE REVIEW}

\subsection{INTRODUCTION}

This chapter provides a review of the limited literature from around the world on the stormwater quality benefits of PFC. It also includes a section about the runoff hydrograph created by porous asphalt overlays. The majority of the cited articles are from online databases and journals.

\subsection{STORMWATER QUALITY BENEFITS}

In the Netherlands, polluted highway runoff is a problem that has drawn attention over the years. Berbee et al. (1999) studied the effects of impervious and pervious asphalt on the water quality of highway runoff. The study involved analyzing runoff from a conventional (impervious) asphalt highway and a highway with a porous asphalt overlay. The highways had similar characteristics (4-lanes, hard shoulders, North-South orientation) although the porous asphalt highway had greater traffic intensity. The porous asphalt overlay was approximately $50-\mathrm{mm}$ thick and three-years old at the start of the study in 1994. The highway runoff samples were collected in a gutter over 1-week periods and then analyzed for pollutant concentrations. The results showed that the pollutant concentrations in the runoff from porous asphalt were significantly lower than in the runoff from the impervious asphalt. The concentrations of heavy metals (lead, copper, and zinc) in the porous asphalt runoff were much lower than in the runoff from impervious asphalt. The ranges of concentration values found in this study are compared in Table 1. The greatest pollutant reduction was the suspended solids concentration being reduced by a factor of 10 . 
Table 1: Concentration range comparison from Berbee et al. (1999)

\begin{tabular}{|l|c|c|}
\hline Pollutant (units) & Impervious & Pervious \\
\hline Suspended Solids (mg/L) & $153-354$ & $2-70$ \\
Nitrogen, Kjeldahl, Total (mg/L) & $2-3$ & $0.3-0.5$ \\
Chemical Oxygen Demand $(\mathrm{mg} / \mathrm{L})$ & $143-149$ & $16-18$ \\
Chlorine $(\mathrm{mg} / \mathrm{L})$ & $<1$ & $<1$ \\
Copper $(\mu \mathrm{g} / \mathrm{L})$ & $91-163$ & $14-107$ \\
Lead $(\mu \mathrm{g} / \mathrm{L})$ & $51-106$ & $2-22$ \\
Zinc $(\mu \mathrm{g} / \mathrm{L})$ & $225-493$ & $18-133$ \\
Cadmium $(\mu \mathrm{g} / \mathrm{L})$ & $0.8-0.9$ & 0.1 \\
\hline
\end{tabular}

Berbee et al. (1999) also investigated the effect of particle settling in runoff from both types of asphalt. Settling provides significant reduction of heavy metal concentrations usually found in highway runoff. Due to the decrease in suspended solids in the porous asphalt runoff, settling had a greater effect on the runoff from impervious asphalt.

Pagotto et al. (2000) also compared the quality of highway runoff from different pavement types. The site of the experiment was a section of highway in France that originally had conventional pavement but was resurfaced with a $30-\mathrm{mm}$ thick porous asphalt overlay one year into the study. Keeping the parameters as constant as possible, the data collected over the different pavement time periods could be compared so any differences could be attributed to the type of asphalt. The datasets were compared for the same length time periods with similar total rainfall. Due to the difference in variables that would affect the water quality over the two time periods, the concentrations were reported as flow-weighted averages. The results showed a significant reduction in suspended solids and particulate metals. Total suspended solids (TSS) was reduced from a mean value of $46 \mathrm{mg} / \mathrm{L}$ to $8.7 \mathrm{mg} / \mathrm{L}$ (an $81 \%$ reduction) and total metals were also 
reduced. Lead decreased by $78 \%$, cadmium by $69 \%$, zinc by $66 \%$ and copper by $35 \%$. The concentration values are shown in Table 2. All of these metals had high retention in the particulate form, which is expected because all of the metals, except for copper, are present mainly in the particulate form. Some dissolved metals (zinc and cadmium) were also reduced by about $60 \%$.

Table 2: Concentration comparison from Pagotto et al. (2000)

\begin{tabular}{|l|c|c|}
\hline Pollutant (units) & Impervious & Pervious \\
\hline Total Suspended Solids $(\mathrm{mg} / \mathrm{L})$ & 46 & 8.7 \\
Nitrogen, Kjeldahl, Total $(\mathrm{mg} / \mathrm{L})$ & 2.1 & 1.2 \\
Chemical Oxygen Demand $(\mathrm{mg} / \mathrm{L})$ & 80 & 80 \\
Chlorine $(\mathrm{mg} / \mathrm{L})$ & 18 & 16 \\
Hydrocarbons, Total $(\mathrm{mg} / \mathrm{L})$ & 1.2 & 0.09 \\
Copper, Total $(\mu \mathrm{g} / \mathrm{L})$ & 30 & 20 \\
Lead, Total $(\mu \mathrm{g} / \mathrm{L})$ & 40 & 8.7 \\
Zinc, Total $(\mu \mathrm{g} / \mathrm{L})$ & 228 & 77 \\
Cadmium, Total $(\mu \mathrm{g} / \mathrm{L})$ & 0.88 & 0.28 \\
Copper, Dissolved $(\mu \mathrm{g} / \mathrm{L})$ & 19 & 16 \\
Lead, Dissolved $(\mu \mathrm{g} / \mathrm{L})$ & 3.3 & 2.2 \\
Zinc, Dissolved $(\mu \mathrm{g} / \mathrm{L})$ & 140 & 54 \\
Cadmium, Dissolved $(\mu \mathrm{g} / \mathrm{L})$ & 0.32 & 0.13 \\
\hline
\end{tabular}

Pagotto et al. (2000) assume that all of the removed solids are retained in the porous asphalt. The removal of particulate pollution is attributed to the filtering function of the pavement. The mechanisms for removal of dissolved species could be adsorption onto the pavement or the clogging materials in the pores. Biological processes might also occur, such as biosorption of heavy metals.

Legret et al. (1999) investigated the ability of porous asphalt overlays to retain heavy metals found in stormwater. A laboratory experiment was conducted by spraying 
highway runoff water over artificially clogged porous asphalt cores to imitate rain events. The concentration of lead in the runoff was reduced after infiltrating the cores, and the heavy metals (lead, copper, cadmium, and zinc) were retained by the clogging material particles.

An earlier study on porous pavement focused on the pollutant particles that were retained in the pavement. Colandini et al. (1995) analyzed the clogging material of porous pavement to determine the pollutant concentrations and particle size distribution. The clogging material, consisting of mostly fine and course sand, was removed through a cleaning process of high-pressure water spray and immediate suction of the resulting sludge. The clogging material was found to have high concentrations of the heavy metals copper, zinc, cadmium, and especially lead. These concentrations reported in $\mathrm{mg} / \mathrm{kg}$ are shown in Table 3.

Table 3: Clogging material concentrations from Colandini et al. (1995)

\begin{tabular}{|l|c|c|}
\hline \multirow{2}{*}{ Pollutant } & \multicolumn{2}{|c|}{ Average Concentration by particle size $(\mathrm{mg} / \mathrm{kg})$} \\
\cline { 2 - 3 } & less than $2 \mathrm{~mm}$ & less than $125 \mu \mathrm{m}$ \\
\hline Copper & 320 & 438 \\
Lead & 1258 & 1474 \\
Zinc & 796 & 975 \\
Cadmium & 2.01 & 3.25 \\
\hline
\end{tabular}

This study also found that course particles were less contaminated than fine particles (sizes less than $40 \mu \mathrm{m}$ ). The fine particles represented $25 \%$ of the mass of clogging particles but contained $40-50 \%$ of the total heavy metal contents.

One of the initial investigations on the water quality of runoff from porous asphalt overlays was documented by Stotz and Krauth (1994). This study analyzed runoff from a section of $40-\mathrm{mm}$ thick porous asphalt in Germany for one year. The pollutant loadings 
found in the runoff were compared to calculated yearly loads in runoff from an impervious highway section determined by a previous project (Stotz, 1987). The filterable solid loads from the porous asphalt were found to be approximately $50 \%$ of the loads from the impervious highway. Stotz and Krauth also assumed that the pollutant particles were detained by the porous asphalt overlay.

Stotz and Krauth (1994) also compared the summer and winter pollutant concentrations in the porous asphalt runoff. All pollutants, except lead and solid iron, had higher concentrations in the winter than in the summer. Some of these concentration increases could be attributed to winter maintenance procedures. As described by Legret and Pagotto (1999), these pollutants are considered "seasonal" and generally include suspended solids, chlorides, sulfates, and heavy metals from deicing salt.

In France, Ranchet (1995) studied the impact of porous asphalt overlays on water quality by monitoring an urban site and freeway site for a two-year period. The urban site had both porous asphalt sections and impervious stone-matrix. Upon comparison to the impervious pavement, the porous asphalt runoff reduced concentrations of lead by $87 \%$ and hydrocarbons by $43 \%$. The other site consisted of a divided freeway with porous asphalt in one direction and conventional pavement on the other direction. The concentrations found at this site are compared in Table 4. The greatest reductions were zinc, copper, and hydrocarbons. For this site, the orientation of the freeway must be considered as the wind blows across the highway and is likely to transfer pollutants from the impervious lanes onto the pervious asphalt pavement. 
Table 4: Concentration comparison from Ranchet (1995)

\begin{tabular}{|l|c|c|}
\hline Pollutant (units) & Impervious & Pervious \\
\hline Total Suspended Solids $(\mathrm{mg} / \mathrm{L})$ & 61 & 57 \\
Nitrogen, Kjeldahl, Total $(\mathrm{mg} / \mathrm{L})$ & 1.4 & 2.3 \\
Hydrocarbons, Total $(\mathrm{mg} / \mathrm{L})$ & 3.2 & 1.7 \\
Copper $(\mu \mathrm{g} / \mathrm{L})$ & 16 & 6 \\
Lead $(\mu \mathrm{g} / \mathrm{L})$ & $<2$ & $<1$ \\
Zinc $(\mu \mathrm{g} / \mathrm{L})$ & 190 & 63 \\
Cadmium $(\mu \mathrm{g} / \mathrm{L})$ & $<0.1$ & $<0.1$ \\
\hline
\end{tabular}

A recent stormwater quality study in Israel (Pacific Water Resources, 2004) was conducted over a 10-month period on a highway with sections of porous asphalt located near populated areas. The highway has a channel that runs between the edge of the pavement and the barriers on the side of the road. The channel overflows into containment basins. The water quality monitoring sites were located at porous asphalt runoff areas and traditional pavement areas for comparison. The samples were taken at the edge of pavement, top of the channel spillway, and the containment basin outlet. A comparison of TSS concentrations at the edge of pavement sampler and the channel spillway show a decrease in TSS over the spillway due to settling in the channel. Dissolved zinc and copper concentrations were similar at both locations. Due to particle settling, only dissolved species are accurately compared in this study. Upon comparison of washoff concentrations from both pavement types, there was not a significant reduction in concentrations from the porous asphalt. This was attributed to the channel that runs next to the roadway which easily collects and transports sediment.

Another part of this study (Pacific Water Resources, 2004) included road dirt accumulation comparisons and cleaning practice effects. The road dirt testing was performed by hand-vacuuming areas of pavement to collect the dirt in the pavement. 
While there was not much difference in the accumulated road dirt in the two types of pavement, there was a difference in the particle size distribution. Particles from porous asphalt were coarser than particles on traditional pavement. As expected, runoff from cleaned pavements of both types had lower pollutant concentrations than pavements that were not cleaned. The statistical difference is not significant as the average values are only slightly lower, but the results suggest that cleaning the pavements reduced the frequency of high concentrations.

While all of these studies were conducted on roadways of different types and traffic loads, some trends are noticed. Overall, total suspended solids were reduced from the runoff from porous asphalt by up to a factor of 10 . Heavy metals concentrations were also consistently lower from the porous asphalt. A summary of pollutant concentration ranges found in the literature is provided in Table 5.

Table 5: Summary of literature data of pollutant concentrations in highway runoff

\begin{tabular}{|l|c|c|}
\hline Pollutant (units) & Impervious & Pervious \\
\hline Total Suspended Solids $(\mathrm{mg} / \mathrm{L})$ & $46-354$ & $2-70$ \\
Nitrogen, Kjeldahl, Total $(\mathrm{mg} / \mathrm{L})$ & $1.4-3.0$ & $0.3-2.3$ \\
Chemical Oxygen Demand $(\mathrm{mg} / \mathrm{L})$ & $80-149$ & $16-80$ \\
Hydrocarbons, Total $(\mathrm{mg} / \mathrm{L})$ & $1.2-3.2$ & $0.09-1.7$ \\
Copper, Total $(\mu \mathrm{g} / \mathrm{L})$ & $16-163$ & $6-107$ \\
Lead, Total $(\mu \mathrm{g} / \mathrm{L})$ & $<2-106$ & $<1-22$ \\
Zinc, Total $(\mu \mathrm{g} / \mathrm{L})$ & $190-493$ & $18-133$ \\
Cadmium, Total $(\mu \mathrm{g} / \mathrm{L})$ & $<0.1-0.9$ & $<0.1-0.28$ \\
\hline
\end{tabular}

\subsection{RUNOFF HYDROGRAPH}

Some of the water quality studies discussed in the previous section also investigated the hydraulic behavior of highway runoff from porous asphalt. Pagotto et al. 
(2000) compared the hydraulic behavior of highway runoff from conventional and porous asphalt with a flow meter located at the site. These experiments found that porous asphalt had response times about twice as long as the conventional pavement under similar conditions. The response time is the time between the first rainfall and beginning of flow. It was also shown that the porous asphalt had smaller peak discharges and longer total discharge time. The results are experimental and only the difference in response times was statistically significant.

Stotz and Krauth (1994) also found that peak effluent flows were lower from the porous asphalt. Ranchet (1995) found similar results from his comparison of porous asphalt and conventional pavement. Porous asphalt had longer runoff times of 12 to 23 hours. Hydrographs revealed that the peak flows from the porous asphalt ranged from $25 \%$ to $79 \%$ of the peak flow from conventional pavement.

The runoff coefficient is the fraction of rainwater runoff that actually flows off of a drainage surface. Pagotto et al. (2000) determined runoff coefficients over the one-year study periods of the conventional and porous asphalt. Porous asphalt had a greater average runoff coefficient of 0.98 compared to the runoff coefficient of 0.84 measured for conventional asphalt pavement. Pagotto et al. found that higher volumes of water came from the porous asphalt than the conventional pavement as there were consistently higher runoff coefficients. This could be attributed to the decrease of water spray from the porous asphalt, and therefore, less evaporation and wind losses.

Stotz and Krauth (1994) found the opposite that lower volumes of water came from the porous asphalt than the impermeable runoff volumes. Ranchet (1995) similarly found that porous asphalt had an average runoff volume reduction of $20 \%$. These results could explain the reduced peak flows previously discussed. 


\section{CHAPTER 3 MATERIALS AND METHODS}

\subsection{SITE DESCRIPTIONS}

\subsubsection{Overview}

The two sites used in this study are located on North Loop 360 near Bull Creek north of the intersection with RM 2222 in Austin, Texas. A satellite image of the sites is presented in Figure 2.

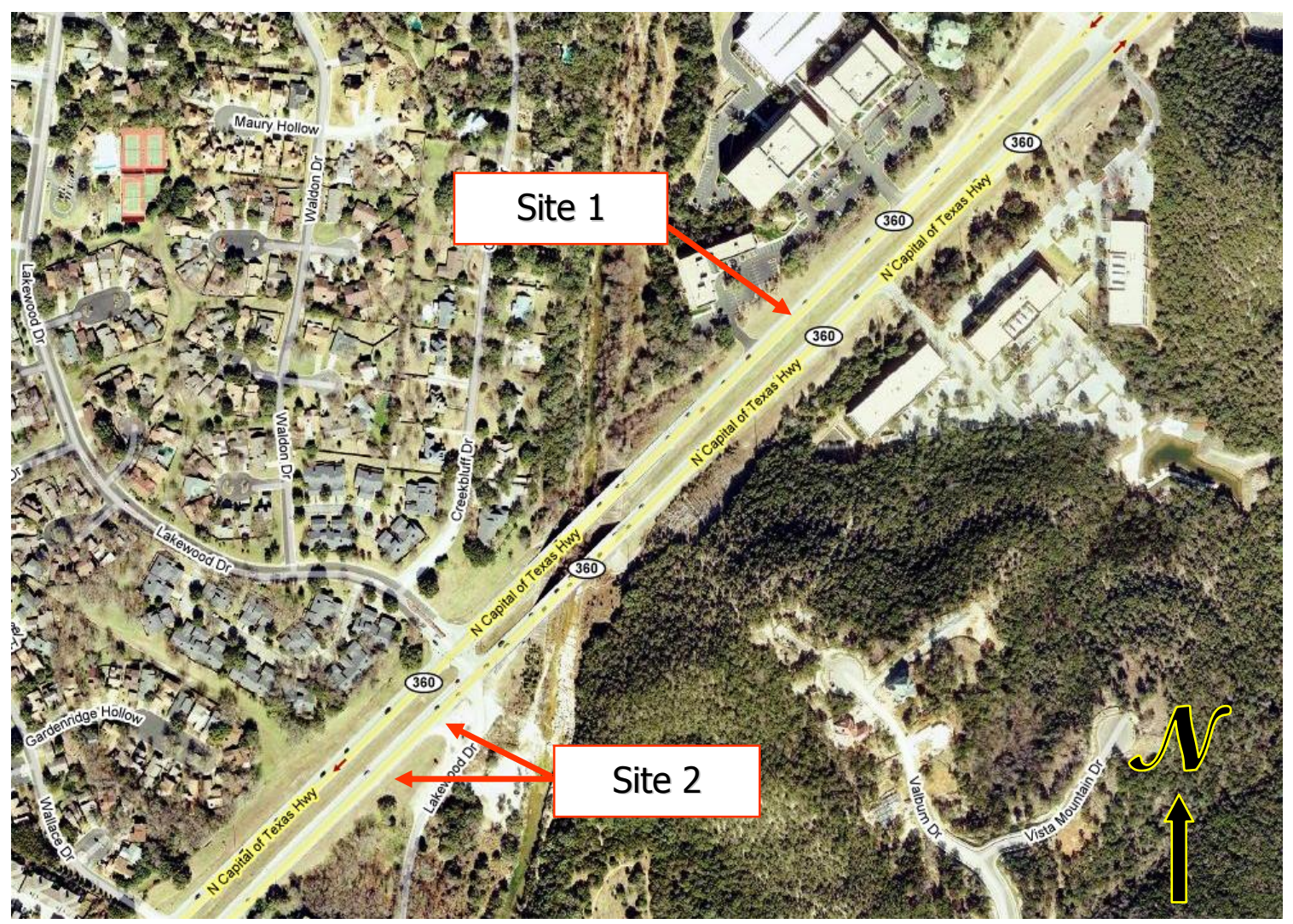

Figure 2: Satellite image of sites on Loop 360 (Google Maps, 2007)

Loop 360 is paved with a 50-mm thick PFC overlay from the Loop 360 bridge over Lake Austin to US Hwy 183, except for segments at intersections with traffic signals 
and over bridges. The 2005 TxDOT estimate of the annual average daily traffic count (AADT) for this segment of Loop 360 from Spicewood Springs Road to RM 2222 was 48,000 (CAMPO, 2007).

\subsubsection{Site 1}

Site 1 is located on the shoulder of the southbound lanes of Loop 360 to the north of the intersection with Lakewood Avenue. The stormwater runoff at this site has been monitored since March 2004 when Loop 360 was paved with conventional hot mix asphalt. A PFC overlay was applied to Loop 360 in October 2004. The site is located in front of an office complex parking lot which allows the researchers to safely park their vehicles while at the site.

\subsubsection{Site 2}

Two passive samplers are located on the edge of the pavement of the northbound lanes of Loop 360 just south of the intersection with Lakewood Avenue. The samplers, approximately 200 feet apart, are installed on either side of a transition from PFC to conventional asphalt. TxDOT used conventional asphalt instead of PFC at intersections with traffic signals to avoid deterioration of the overlay associated with vehicles stopping and accelerating. These samplers provide paired samples of runoff from rain events with the same conditions, such as traffic, rainfall intensity and antecedent dry period (ADP). A photograph of the passive sampler locations is presented in Figure 3. 


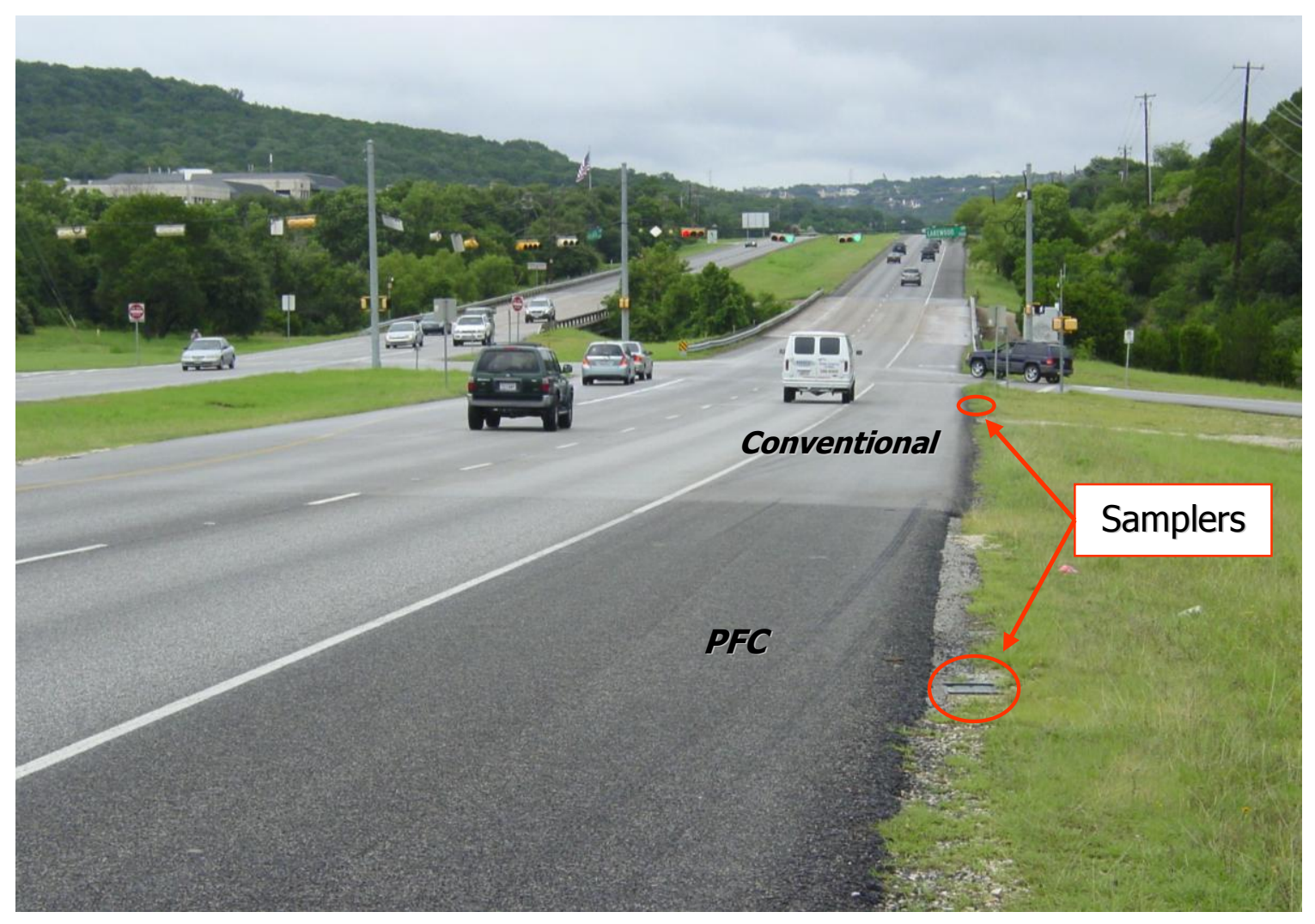

Figure 3: Passive samplers at Site 2 on Loop 360

\subsection{SITE 1 SETUP}

When stormwater monitoring began in March 2004, a GKY FirstFlush Stormwater Sampler, or passive sampler, was used to collect highway runoff samples. In December 2006, a new collection system was installed at the site to monitor water quantity as well as water quality.

\subsubsection{Design}

A 60-foot long, 4-inch diameter PVC pipe system was installed at the edge of the pavement to act as a gutter to collect the pavement runoff. A 90-degree section was cut lengthwise out of the PVC pipe segments with a table saw to create an opening for runoff to enter the gutter. The pipe sizing was designed according to the runoff expected from 
the catchment area during the design storm. A pipe length of 60 feet with a diameter of 4 inches could convey a 2 -year storm with a 20 minute time of concentration. The rational method was used to obtain the peak flow rate and the pipe was designed to flow half-full at this flow rate to prevent water from overflowing. Manning's equation was used to calculate the required diameter under these circumstances.

\subsubsection{Installation}

A shallow trench was dug out adjacent to the roadway to contain the pipe system. The trench was made as level as possible with a slight downward slope parallel to the roadway. The 10-foot PVC pipe segments are connected by rigid PVC connectors and PVC glue. The upstream end of the pipe has a cap to prevent other runoff from entering the pipe. At this location, the impervious pavement base extends laterally beyond the PFC overlay. Plastic flashing (TufTex "deck drain") was attached to the edge of the underlying impervious pavement to allow the runoff to flow out of the edge of the PFC into the pipe gutter. Plastic flashing was used instead of a metal flashing because the zinc used for galvanizing the metal would affect the water quality results. The flashing is 5 " wide with a 1" overhang. The flashing was placed slightly overlapping the pavement edge and attached with silicon. The overhang part of the flashing was placed within the PVC pipe opening and more silicon was applied to attach the flashing to the edge of the opening. A drawing of the side-view of the gutter is shown in Figure 4. 


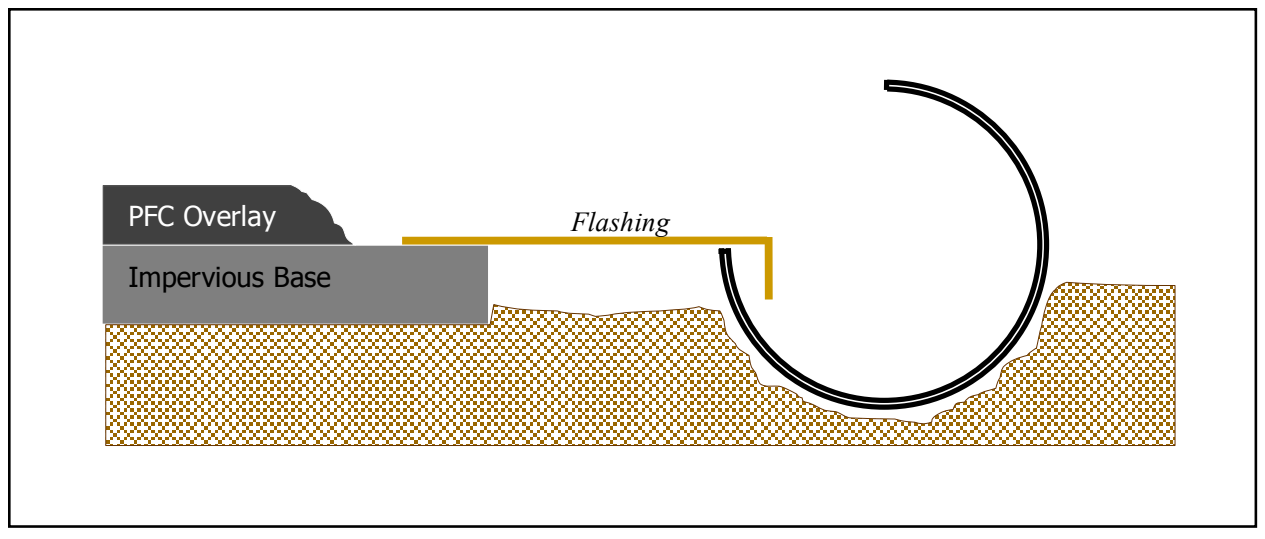

Figure 4: Cross section of the PVC gutter

At the downstream end of the 60 -foot PVC pipe gutter, a rigid elbow is used to turn the pipe 90-degress away from the roadway. Fully-enclosed pipe then flows downhill for about 20 feet. These sections of pipe are connected with rubber gaskets to allow the pipes to angle downhill. The pipe levels out and then connects to an H-flume. This connection consists of a waterproofed piece of wood with a circular hole cut to fit the end the pipe and a 4" flange screwed into the wood and glued to the end of the pipe. The H-flume has a depth of 0.5 feet and a recommended minimum head of 0.02 feet (ISCO, 2006). The flume is screwed onto 4 threaded rods that are set in concrete which allow for the flume to be leveled easily.

An ISCO 4230 Bubbler Flow Meter is used to measure the water level in the flume and calculate the corresponding flow rate. The flume has a built-in bubble line fitting where the bubble line attaches from the flow meter.

The water flows unimpeded from the flume into a draining box from which samples are drawn using an ISCO 3700 Portable Sampler. The samples are drawn through Teflon suction line which is attached to the pump tubing in the sampler. A stainless steel strainer is attached to the suction line intake to prevent debris from 
clogging the tubing. Flow-weighted composite samples are collected in a 10 Liter bottle inside of the sampler.

A locked storage box onsite houses the bubbler flow meter and the automatic sampler. A solar panel and a 12-volt marine battery in the storage box power the equipment. An ISCO 674 Rain Gauge is located nearby and connected to the flow meter. The ISCO 674 is a tipping bucket rain gauge which measures rainfall in 0.01 inch increments. All tubing and wires from the equipment to the storage box are buried in conduit to protect them. Photographs of the site and flume setup are presented in Figure 5 and Figure 6.

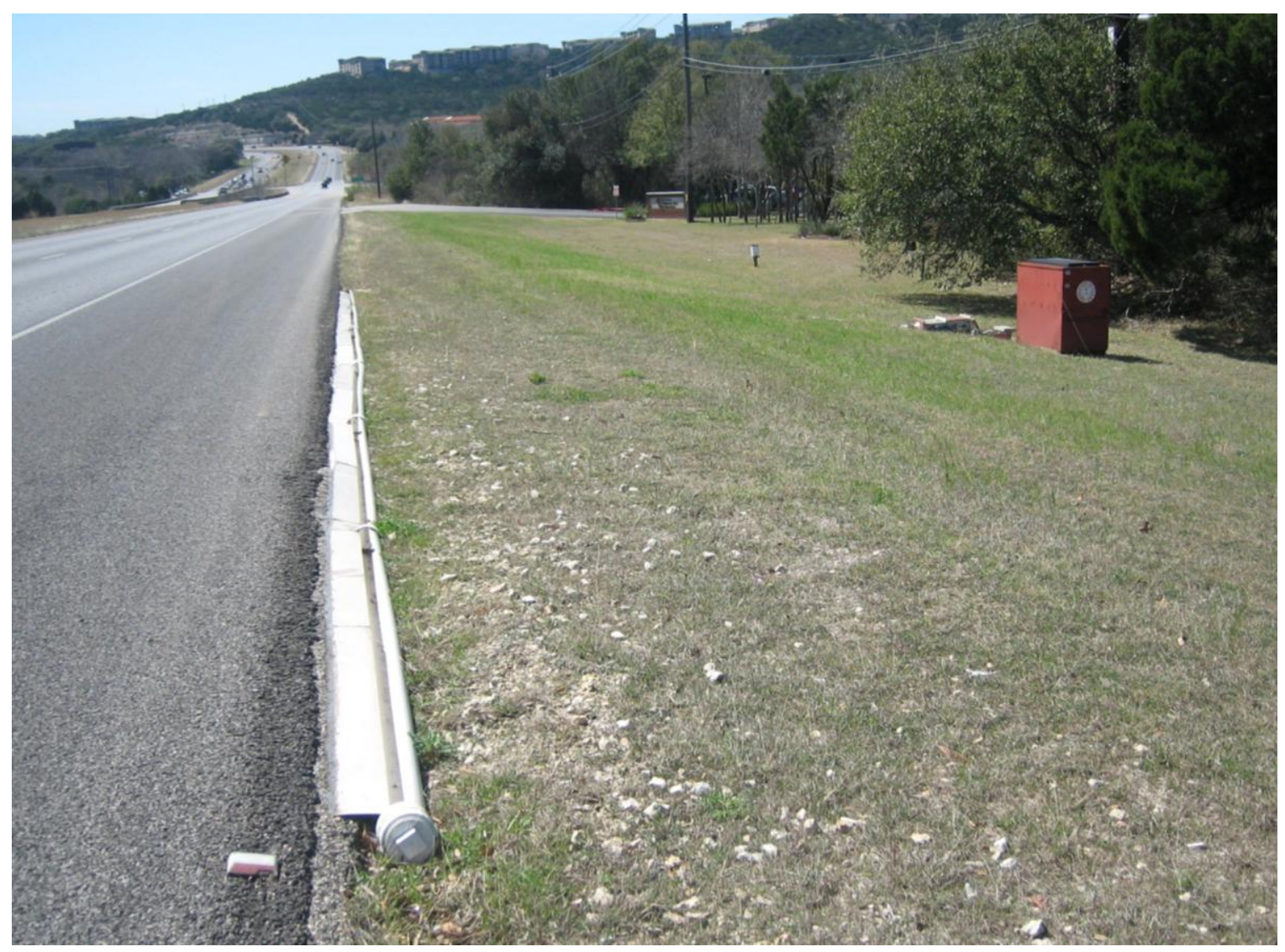

Figure 5: Collection system on Loop 360 


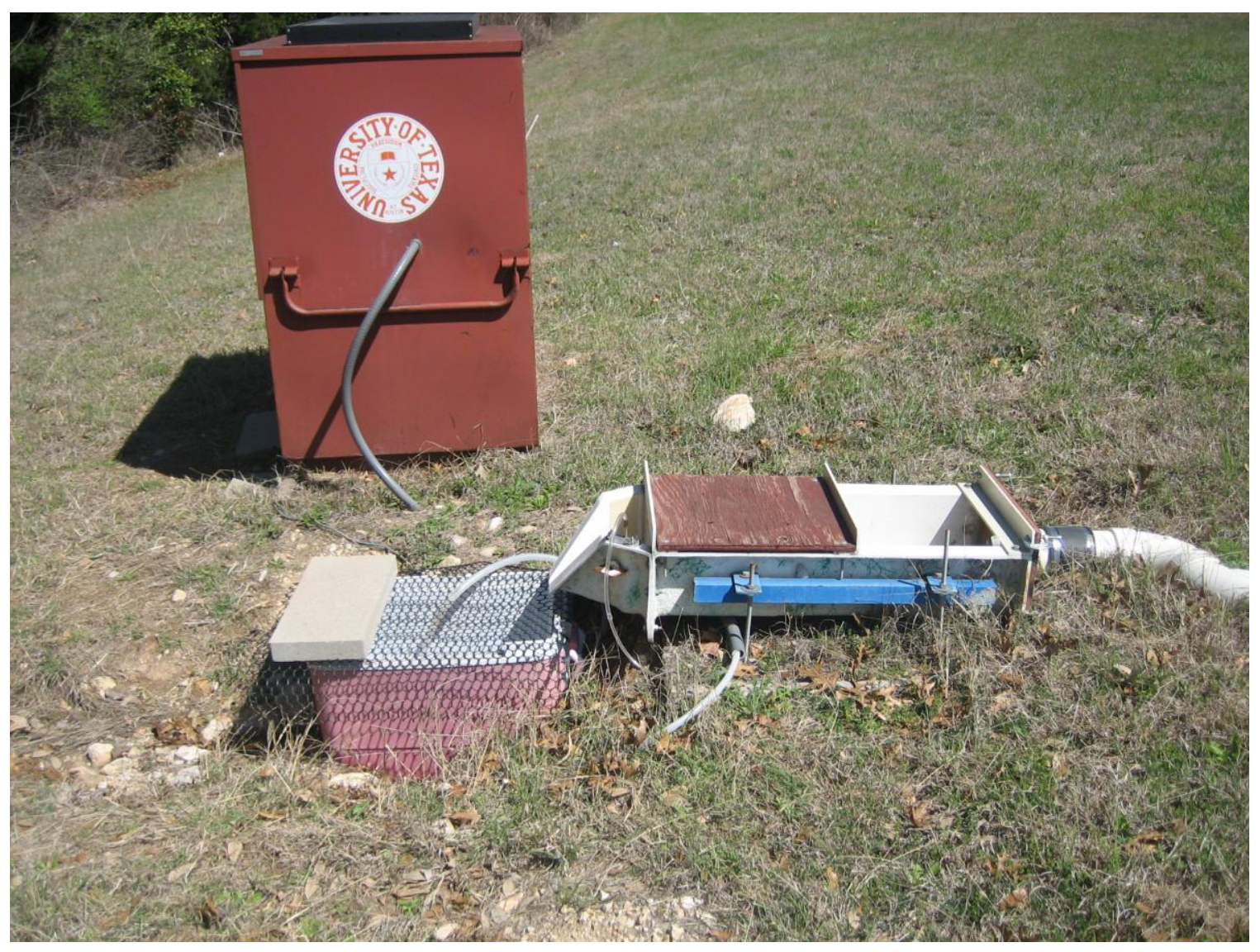

Figure 6: Flume, draining box and storage box setup

\subsubsection{Equipment Programming}

The ISCO 4230 flow meter measures and records depth of runoff (mm), velocity $(\mathrm{m} / \mathrm{s})$, flow rate $(\mathrm{L} / \mathrm{s})$ and rainfall (inches). A reading is taken for each of these parameters every 5 minutes. The data is stored in the flow meter until the memory is full, which takes approximately one month. The data was downloaded monthly to a computer using ISCO Flowlink software.

The ISCO 3700 sampler collects flow-weighted composite samples of the runoff. The sampler was set to enable when the depth of runoff in the flume reached $10 \mathrm{~mm}$. Originally, the sampler intake was located along the bottom edge of the flume and the 
sampler enabling ensured that the intake strainer was submerged in the flume. This setup did not provide adequate samples, so the sampler intake was moved to a draining box. The sampler enable was still used to ensure adequate flows to avoid sampling rain events that were much smaller than the minimum design storm size. The volume of runoff that passes through the flume is used to pace the sampler. The volume pacing was programmed according to the estimated catchment area and the minimum design storm in Austin, Texas. The bottle used to collect the composite samples has a volume of 10 Liters; however, the minimum sample volume required by the LCRA Laboratory to perform analysis is 3 Liters. The number of aliquots chosen for the minimum design storm was 10 aliquots of $320 \mathrm{~mL}$. The volume pacing was determined with the following calculations.

Road width $=34 \mathrm{ft}$ (which entirely slopes toward outside shoulder)

Estimated catchment area $=60 \mathrm{ft} \times 34 \mathrm{ft}=2040 \mathrm{ft}^{2}$

Minimum storm size $=0.25$ inches

Minimum runoff volume $=0.25$ inches $/ 12 \times 2040 \mathrm{ft}^{2}=42.5 \mathrm{ft}^{3}=1203 \mathrm{~L}$

Volume of runoff per aliquot $=1203 \mathrm{~L} / 10$ aliquots $=120 \mathrm{~L} /$ aliquot

The largest storm that could be completely sampled would be 3720 Liters (31 aliquots of $320 \mathrm{~mL}$ each) which corresponds to a rain event with 0.8 inches of rainfall. Storms larger than 0.8 inches would have a front-weighted sample.

\subsection{SITE 2 SETUP}

Two GKY FirstFlush Stormwater Samplers were installed at the edge of the pavement on Loop 360 in March 2007. The GKY FirstFlush sampler has five holes in 
the top that allow water to drain inside the sampler into a removable 5-Liter plastic container. Once the collection container is full, buoyant flaps float up and cover the holes to prevent any more water from running into the sample. The sampler collects runoff from a one foot wide section of roadway. Since the total road width is 34 feet, the estimated catchment area is $34 \mathrm{ft}^{2}$. The passive samplers are shown in Figure 7.

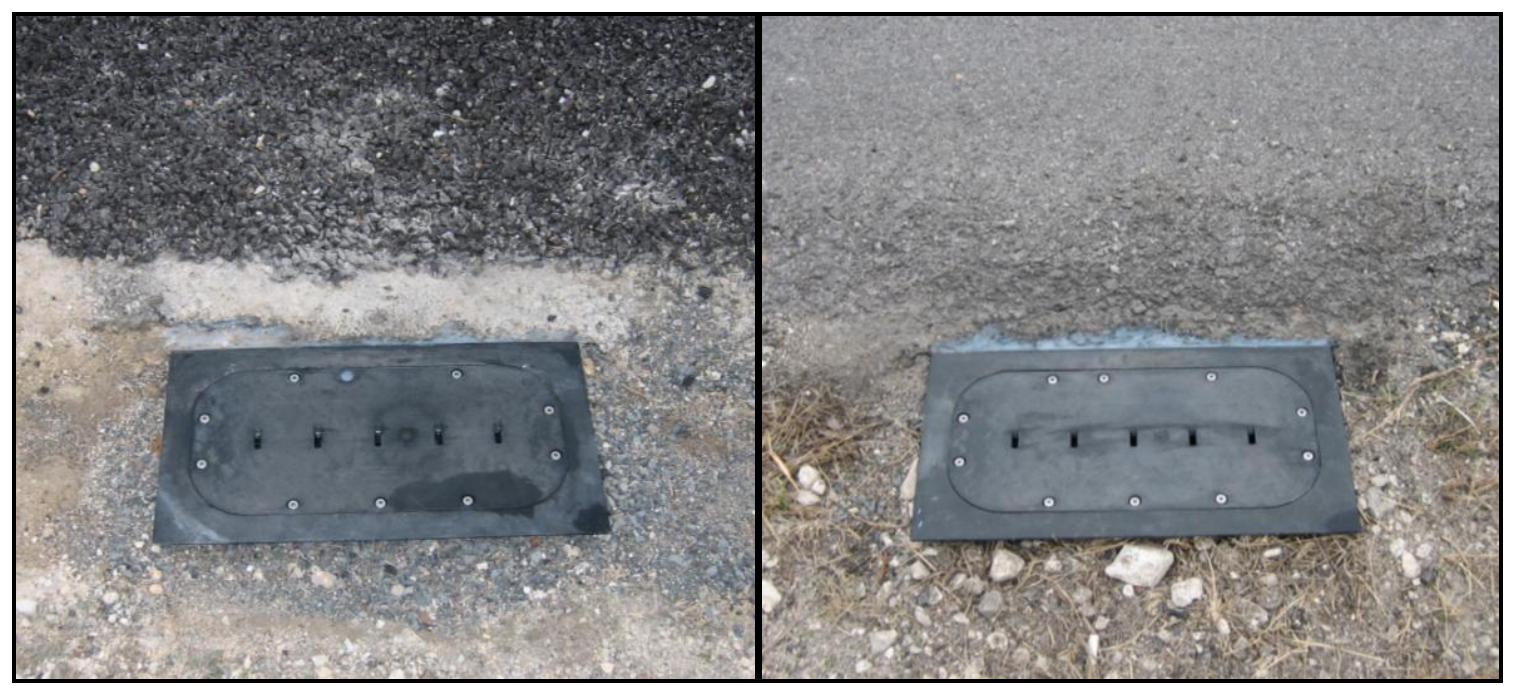

Figure 7: PFC and conventional pavement passive samplers

The location for the PFC pavement sampler was chosen because of the exposed impervious asphalt base and sufficient drainability of the surrounding PFC. The location for the conventional pavement sampler was chosen at a distance far enough away from the pavement transition so that the PFC pavement would not affect the runoff from the conventional pavement. The passive samplers were installed by digging out a hole at the edge of the pavement and setting the samplers into concrete while ensuring they are level. The edge of the sampler was attached to the edge of the pavement with silicone. 


\subsection{SAMPLing PROCEDURES}

Due to the disturbance of the soil around the sites during installation, sampling did not begin immediately. Sampling began after a few rain events had occurred to allow the sites to return to normal, undisturbed conditions. During the first 5 months, as many rain events were sampled as possible to check for consistency and fix any sampling issues. After that time, approximately one storm per month was sampled if possible.

Periodically and prior to expected rain events, the collection system and the passive samplers were cleaned to remove any dirt and debris that had accumulated since the previous storm. Clean sampling containers were put inside each sampler. The pipe collection system was cleaned using an air blower and the draining box was always emptied and wiped clean. The passive samplers were wiped off and any water within the sampler was removed. The rain gauge was also kept free of any dirt and debris that may have collected in the top.

After a storm event, the sample containers were removed from the samplers and sealed with lids. If sufficient volume was collected, the samples were transported to the Lower Colorado River Authority (LCRA) laboratory for analysis.

The sites were observed during a few storms to verify that the runoff was flowing into the collection system and passive samplers as expected. Maintenance on the collection system and passive samplers was performed when necessary. This included replacing cracked passive samplers, flashing and rigid PVC connectors, as well as applying additional silicon to prevent leaking.

\subsection{Analytical Procedures}

The samples were taken to the LCRA's Environmental Laboratory Services for analysis as soon as possible after a rain event. If the samples could not be delivered 
immediately, they were stored in a refrigeration room at $4{ }^{\circ} \mathrm{C}$ until they could be delivered. The parameters and methods for analysis are shown in Table 1.

Table 6: Parameters and methods for analysis by Environmental Laboratory Services

\begin{tabular}{|l|c|c|c|}
\hline Parameter & Units & Method & $\begin{array}{c}\text { Practical } \\
\text { Quantification Limit }\end{array}$ \\
\hline Total Suspended Solids (TSS) & $\mathrm{mg} / \mathrm{L}$ & $\mathrm{E} 160.2$ & 1.0 \\
\hline Total Kjeldahl Nitrogen $(\mathrm{TKN})$ & $\mathrm{mg} / \mathrm{L}$ & $\mathrm{E} 351.2$ & 0.400 \\
\hline Nitrate and Nitrite as N $\left(\mathrm{NO}_{3}{ }^{+} / \mathrm{NO}_{2}\right)$ & $\mathrm{mg} / \mathrm{L}$ & $\mathrm{E} 353.2$ & 0.04 \\
\hline Total Phosphate as P in water & $\mathrm{mg} / \mathrm{L}$ & $\mathrm{E} 365.4$ & 0.02 \\
\hline Dissolved Phosphate as P in water & $\mathrm{mg} / \mathrm{L}$ & $\mathrm{E} 365.4$ & 0.02 \\
\hline Chemical Oxygen Demand (COD) & $\mathrm{mg} / \mathrm{L}$ & $\mathrm{E} 410.4$ & 70 \\
\hline Total Copper $(\mathrm{Cu})$ & $\mu \mathrm{g} / \mathrm{L}$ & $\mathrm{E} 200.8$ & 2.00 \\
\hline Dissolved Copper & $\mu \mathrm{g} / \mathrm{L}$ & $\mathrm{E} 200.8$ & 1.02 \\
\hline Total Lead $(\mathrm{Pb})$ & $\mu \mathrm{g} / \mathrm{L}$ & $\mathrm{E} 200.8$ & 1.00 \\
\hline Dissolved Lead & $\mu \mathrm{g} / \mathrm{L}$ & $\mathrm{E} 200.8$ & 1.02 \\
\hline Total Zinc $(\mathrm{Zn})$ & $\mu \mathrm{g} / \mathrm{L}$ & $\mathrm{E} 200.8$ & 5.00 \\
\hline Dissolved Zinc & $\mu \mathrm{g} / \mathrm{L}$ & $\mathrm{E} 200.8$ & 4.08 \\
\hline
\end{tabular}

The Practical Quantification Limit (PQL) is the minimum concentration that can be detected with the analysis, and constituents with concentration less than the PQL had "Not Detected" (ND) as the result.

\subsection{STATiSTiCAL ANALYSIS}

The laboratory analysis results were compiled in a Microsoft Excel spreadsheet. Each set of results was checked for apparent errors or missing data. The data was statistically analyzed in Excel using the t-tests in the data analysis pack. The passive sampler data from Site 2 could be compared using a paired t-test, while the time-series data from Site 1 were compared with two sample t-test assuming unequal variance. For 
all of the statistical analysis, any values with "Not Detected" were replaced with the PQL concentration. The t-test returns the P-value for the one-tail and two-tail test, which is twice the P-value of the one-tail test. The P-value, which ranges from 0 to 1 , represents the probability that the data sets are the same. When the P-value is 1 , there is no difference between the data sets, and the difference increases as the P-value approaches 0. For this study, statistically significant differences in concentrations from the two types of pavement were considered to be constituents with P-values less than 0.10 . The twotail P-value is used to establish if data sets are significantly different from one another. The one-tail P-value is used when testing if one data set's values are higher or lower than the other data set's. The P-value from the more conservative two-tail test is used in this study.

Linear regression of the PFC data was used to determine if any trends exist in the water quality since the overlay was applied. To test the regression line slope for significance, 95\% confidence intervals were calculated. The regression line was considered significant if the interval was entirely positive (did not include negative values or zero).

More in-depth statistical analysis was performed on the water quality results from the passive samplers and corresponding traffic data using Minitab Statistical Software. Multiple regressions were performed to determine the significant predictor variables for stormwater runoff concentrations. Daily traffic data for Loop 360 was estimated using the daily traffic diurnal curve for a nearby highway (MoPac at West $35^{\text {th }}$ Street) traffic data (Irish et al., 1995) and the annual average daily traffic count for MoPac in 1994 and then scaling the curve to the AADT count on Loop 360. The AADT for Loop 360 between Spicewood Springs Road and RM 2222 in 2007 was estimated to be 55,000 based on linear regression of AADT data from 1990-2005 (CAMPO, 2007). 


\section{CHAPTER 4 RESULTS}

\subsection{RAINFALL DATA}

Since the collection system at Site 1 was installed in December 2006, 17 rain events have been successfully sampled and analyzed. Flow and rainfall data for 27 other rain events were also used in the hydrograph analysis. Since the passive samplers were installed at Site 2 in March 2007, 14 rain events have been sampled. The date, total rainfall, total runoff (if available), duration and sample location for each rain event are presented in Table 7.

Table 7: Rain event data

\begin{tabular}{|c|c|c|c|c|}
\hline Storm Date & Rainfall (in.) & Runoff (L) & Duration (hr.) & $\begin{array}{l}\text { Sample } \\
\text { Location }\end{array}$ \\
\hline $1 / 13 / 2007$ & 2.43 & $12,118^{\star \star}$ & 15 & 1 \\
\hline $1 / 14 / 2007$ & 0.59 & $3,349^{* *}$ & 25 & 1 \\
\hline $3 / 11 / 2007$ & 1.79 & 8,381 & 15 & $1 \& 2$ \\
\hline $3 / 13 / 2007$ & 0.95 & 4,328 & 6 & $1 \& 2$ \\
\hline $3 / 26 / 2007$ & 1.36 & $11,099^{* *}$ & 9 & $1 \& 2$ \\
\hline $3 / 30 / 2007$ & $0.68^{*}$ & $1,871^{* *}$ & 5 & 1 \\
\hline 4/7/2007 & 0.65 & 2,342 & 18 & \\
\hline $4 / 13 / 2007$ & 0.17 & 470 & 5 & \\
\hline $4 / 17 / 2007$ & 0.28 & 1,008 & 10 & \\
\hline 4/24/2007 & 0.37 & 1,530 & 3 & $1 \& 2$ \\
\hline $4 / 30 / 2007$ & 0.42 & 1,660 & 10 & $1 \& 2$ \\
\hline $5 / 2 / 2007$ & 1.33 & 6,338 & 6 & $1 \& 2$ \\
\hline $5 / 9 / 2007$ & 0.22 & 975 & 2 & \\
\hline $5 / 16 / 2007$ & 0.46 & 1,742 & 3 & $1 \& 2$ \\
\hline $5 / 22 / 2007$ & $0.22^{*}$ & 705 & 2 & \\
\hline $5 / 24 / 2007$ & $1.06^{*}$ & 3,613 & 21 & $1 \& 2$ \\
\hline $5 / 28 / 2007$ & $2.23^{*}$ & 8,776 & 6 & \\
\hline $6 / 3 / 2007$ & 1.43 & 6,305 & 4 & $1 \& 2$ \\
\hline $6 / 14 / 2007$ & 0.26 & 830 & 2 & \\
\hline $6 / 16 / 2007$ & 0.40 & 1,646 & 2.5 & \\
\hline $6 / 20 / 2007$ & 0.72 & 2,967 & 4 & \\
\hline
\end{tabular}




\begin{tabular}{|c|c|c|c|c|}
\hline Storm Date & Rainfall (in.) & Runoff (L) & Duration (hr.) & $\begin{array}{c}\text { Sample } \\
\text { Location }\end{array}$ \\
\hline $7 / 2 / 2007$ & 0.72 & 3,042 & 24 & \\
\hline $7 / 4 / 2007$ & 0.19 & 797 & 7.5 & \\
\hline $7 / 5 / 2007$ & 0.32 & 1,618 & 7 & \\
\hline $7 / 18 / 2007$ & 0.39 & 1,698 & 2 & \\
\hline $7 / 20 / 2007$ & 1.90 & 9,350 & 4.5 & $1 \& 2$ \\
\hline $7 / 21 / 2007$ & 1.21 & 5,704 & 5 & \\
\hline $7 / 23 / 2007$ & 0.35 & 1,215 & 4 & \\
\hline $7 / 25 / 2007$ & 1.11 & 5,642 & 3 & \\
\hline $7 / 27 / 2007$ & 0.24 & 987 & 2.5 & \\
\hline $8 / 3 / 2007$ & 0.19 & 653 & 0.5 & \\
\hline $8 / 16 / 2007$ & 0.64 & 2,585 & 3 & \\
\hline $8 / 21 / 2007$ & 0.16 & 437 & 1 & \\
\hline $8 / 31 / 2007$ & 0.35 & 1,260 & 2 & \\
\hline $9 / 2 / 2007$ & 0.16 & 582 & 3 & \\
\hline $9 / 3 / 2007$ & 0.42 & 1,822 & 1 & \\
\hline $9 / 11 / 2007$ & 1.11 & 4,995 & 3 & \\
\hline $9 / 29 / 2007$ & 0.22 & 747 & 2.5 & \\
\hline $10 / 22 / 2007$ & 0.47 & $* *$ & 5 & 2 \\
\hline $11 / 24 / 2007$ & 1.00 & 4,787 & 26 & $1 \& 2$ \\
\hline $12 / 11 / 2007$ & 0.96 & 4,210 & 4 & $1 \& 2$ \\
\hline $1 / 18 / 2007$ & 0.27 & 1,436 & 16 & \\
\hline $3 / 3 / 2008$ & 0.30 & 1,222 & 4 & \\
\hline $3 / 6 / 2007$ & 0.20 & 914 & 4 & 2.5 \\
\hline $3 / 18 / 2008$ & 1.3 & 5,763 & & \\
\hline
\end{tabular}

*USGS rain gauge values (LCRA, 2008)

**Storms not used in hydrograph analysis due to flow meter data errors

\subsection{SITE 1 WATER QUALITY}

Stormwater monitoring began in March 2004 when Loop 360 was paved with conventional hot mix asphalt. Five storms were sampled with the GKY FirstFlush Sampler prior to the application of the PFC overlay in October 2004. Twenty-one more rain events were sampled from the PFC overlay with the passive sampler before the collection system was installed in December 2006 and monitoring for this project began. A total of 38 rain events were monitored since the PFC overlay was applied. The water 
quality data from the previous projects (Kearfott et al., 2005; Barrett and Shaw, 2007) is used to establish differences and trends in water quality runoff from conventional asphalt and PFC overlays. The concentrations in the runoff from Site 1 prior to the installation of the collection system are reported by Barrett and Shaw (2007).

The concentrations in the runoff at Site 1 from the 17 sampled rain events since the collection system was installed are presented in Table 8. Concentrations lower than the PQL are reported as less than the PQL in the table. 
Table 8: Concentrations at Site 1

\begin{tabular}{|c|c|c|c|c|c|c|c|c|c|c|c|c|c|}
\hline Date & $\begin{array}{c}\text { Rainfall } \\
\text { (in.) }\end{array}$ & $\begin{array}{c}\text { TSS } \\
\text { (mg/L) }\end{array}$ & $\begin{array}{c}\text { TKN } \\
(\mathrm{mg} / \mathrm{L})\end{array}$ & $\begin{array}{c}\mathbf{N O}_{3}{ }^{+} / \mathbf{N O}_{2} \\
(\mathrm{mg} / \mathrm{L})\end{array}$ & $\begin{array}{c}\mathbf{P}_{\text {Total }} \\
(\mathrm{mg} / \mathrm{L})\end{array}$ & $\begin{array}{c}\text { P }_{\text {Dissolved }} \\
(\mathrm{mg} / \mathrm{L})\end{array}$ & $\begin{array}{l}\text { COD } \\
(\mathrm{mg} / \mathrm{L})\end{array}$ & $\begin{array}{l}\mathbf{C u}_{\text {Total }} \\
(\mu \mathrm{g} / \mathrm{L})\end{array}$ & $\begin{array}{c}\text { Cu }_{\text {Dissolved }} \\
(\mu \mathrm{g} / \mathrm{L})\end{array}$ & $\begin{array}{l}\text { Pb }_{\text {Total }} \\
(\mu \mathrm{g} / \mathrm{L})\end{array}$ & $\begin{array}{c}\mathbf{P b}_{\text {Dissolved }} \\
(\mu \mathrm{g} / \mathrm{L})\end{array}$ & $\begin{array}{l}\mathbf{Z n}_{\text {Total }} \\
(\mu \mathrm{g} / \mathrm{L})\end{array}$ & $\begin{array}{c}\mathbf{Z n}_{\text {Dissolved }} \\
(\mu \mathrm{g} / \mathrm{L})\end{array}$ \\
\hline $1 / 13 / 07$ & 2.43 & 11 & 0.163 & 0.08 & $<0.02$ & $<0.02$ & 30 & 5.89 & 3.47 & $<1$ & $<1$ & 11.8 & 9.63 \\
\hline $1 / 14 / 07$ & 0.56 & 2 & 1.180 & 0.26 & $<0.02$ & $<0.02$ & 63 & 5.49 & 4.40 & $<1$ & $<1$ & 25.8 & 23.20 \\
\hline $3 / 11 / 07$ & 1.79 & 11 & 0.434 & 0.25 & $<0.02$ & $<0.02$ & 42 & 11.20 & 8.31 & 1.01 & $<1$ & 27.4 & 18.90 \\
\hline $3 / 13 / 07$ & 0.95 & 4 & 0.261 & 0.05 & $<0.02$ & $<0.02$ & 32 & 6.60 & 4.46 & 1.17 & $<1$ & 17.8 & 12.90 \\
\hline $3 / 26 / 07$ & 1.37 & 2 & 5.450 & 0.14 & 0.052 & $<0.02$ & 25 & 8.53 & 7.06 & $<1$ & $<1$ & 20.9 & 16.40 \\
\hline $3 / 30 / 07$ & 0.68 & 8 & 0.692 & 0.10 & 0.063 & $<0.02$ & 49 & 12.50 & 8.03 & 1.45 & $<1$ & 28.1 & 17.90 \\
\hline $4 / 25 / 07$ & 0.37 & 3 & 0.462 & 0.52 & 0.074 & 0.045 & 61 & 15.30 & 11.50 & $<1$ & $<1$ & 15.9 & 11.50 \\
\hline $4 / 30 / 07$ & 0.42 & 8 & 0.555 & 0.32 & 0.055 & $<0.02$ & 80 & 17.60 & 12.50 & $<1$ & $<1$ & 22.0 & 18.20 \\
\hline $5 / 3 / 07$ & 1.33 & 6 & 0.390 & 0.18 & 0.024 & $<0.02$ & 23 & 7.51 & 5.01 & $<1$ & $<1$ & 8.09 & 6.17 \\
\hline $5 / 16 / 07$ & 0.46 & 2 & 1.290 & 0.72 & 0.069 & 0.03 & 86 & 17.80 & 16.10 & $<1$ & $<1$ & 13.4 & 17.20 \\
\hline $5 / 24 / 07$ & 0.64 & 4 & 0.482 & 0.12 & $<0.02$ & $<0.02$ & 57 & 10.20 & 8.40 & $<1$ & $<1$ & 24.9 & 12.70 \\
\hline $6 / 4 / 07$ & 1.43 & 8 & 0.479 & 0.21 & 0.038 & $<0.02$ & 35 & 8.96 & 5.95 & $<1$ & $<1$ & 10.5 & 5.44 \\
\hline $7 / 20 / 07$ & 1.90 & 13 & 0.114 & 0.03 & 0.062 & $<0.02$ & 37 & 7.45 & 4.05 & $<1$ & $<1$ & 18.7 & 8.02 \\
\hline $11 / 26 / 07$ & 1.00 & 3 & 0.586 & 0.43 & 0.064 & 0.046 & 66 & 14.20 & 12.50 & $<1$ & $<1$ & 14.8 & 9.72 \\
\hline $12 / 12 / 07$ & 0.96 & 10 & 0.865 & 0.28 & $<0.02$ & $<0.02$ & 42 & 14.40 & 10.40 & 1.33 & $<1$ & 19.4 & 8.31 \\
\hline $3 / 3 / 08$ & 0.30 & 7 & 1.370 & 0.97 & 0.053 & 0.042 & 93 & 20.90 & 17.80 & $<1$ & $<1$ & 21.2 & 12.00 \\
\hline 3/18/08 & 1.34 & 29 & 0.791 & 0.22 & 0.052 & $<0.02$ & 50 & 16.70 & 8.39 & 1.42 & $<1$ & 35.2 & 6.9 \\
\hline
\end{tabular}


The mean concentrations before and after the installation of the PFC overlay are compared in Table 9. The percent reduction and P-values are also reported for comparison.

Table 9: Comparison of concentrations from conventional asphalt and PFC at Site 1

\begin{tabular}{lcccc}
\hline Constituent & $\begin{array}{c}\text { Conventional } \\
\text { Asphalt }\end{array}$ & PFC & $\begin{array}{c}\text { Reduction } \\
\%\end{array}$ & P-Value \\
\hline TSS $(\mathrm{mg} / \mathrm{L})$ & 117.80 & 8.95 & 92 & 0.017 \\
$\mathrm{TKN}(\mathrm{mg} / \mathrm{L})$ & 1.13 & 1.02 & 10 & 0.631 \\
$\mathrm{NO}_{3}{ }^{+} / \mathrm{NO}_{2}(\mathrm{mg} / \mathrm{L})$ & 0.43 & 0.40 & 8 & 0.894 \\
$\mathrm{Total}^{\mathrm{P}}(\mathrm{mg} / \mathrm{L})$ & 0.13 & 0.06 & 51 & 0.031 \\
Dissolved P $(\mathrm{mg} / \mathrm{L})$ & 0.044 & 0.035 & 20 & 0.564 \\
COD $(\mathrm{mg} / \mathrm{L})$ & 64.00 & 59.24 & 7 & 0.735 \\
Total Copper $(\mu \mathrm{g} / \mathrm{L})$ & 26.84 & 13.09 & 51 & 0.005 \\
Dissolved Copper $(\mu \mathrm{g} / \mathrm{L})$ & 5.94 & 9.97 & -68 & 0.100 \\
Total Lead $(\mu \mathrm{g} / \mathrm{L})$ & 12.57 & 1.13 & 91 & 0.025 \\
Dissolved Lead $(\mu \mathrm{gg} / \mathrm{L})$ & $<1.0$ & $<1.0$ & $\mathrm{NA}$ & $\mathrm{NA}$ \\
Total Zinc $(\mu \mathrm{gg} / \mathrm{L})$ & 167.40 & 31.54 & 81 & 0.003 \\
Dissolved Zinc $(\mu \mathrm{g} / \mathrm{L})$ & 47.06 & 23.71 & 50 & 0.179 \\
\hline
\end{tabular}

The concentrations of TSS, total phosphate, copper, lead and zinc are found to be significantly lower in the runoff generated from the PFC overlay than the runoff from conventional asphalt. There is an overall reduction in all of the constituents except for dissolved copper, which increased by $68 \%$. The TKN concentration from the rain event on March 26, 2007 was unusually high, although the samples collected at Site 2 from that event also had high TKN values. When this value (and another outlier from the previous data set) was removed from the statistical analysis, TKN was found to be significantly reduced (P-value of 0.061). The concentrations in the runoff from conventional asphalt and $\mathrm{PFC}$ are $1.13 \mathrm{mg} / \mathrm{L}$ and $0.78 \mathrm{mg} / \mathrm{L}$, respectively, which is a $31 \%$ reduction. 
As an example, the concentrations of TSS in the runoff from each monitored event are shown in Figure 8. The five concentration values reported before 11/1/2004 are from conventional asphalt runoff. The mean concentration of TSS from the monitored events after the PFC overlay was applied was $92 \%$ lower than the concentration of TSS from the conventional asphalt runoff.

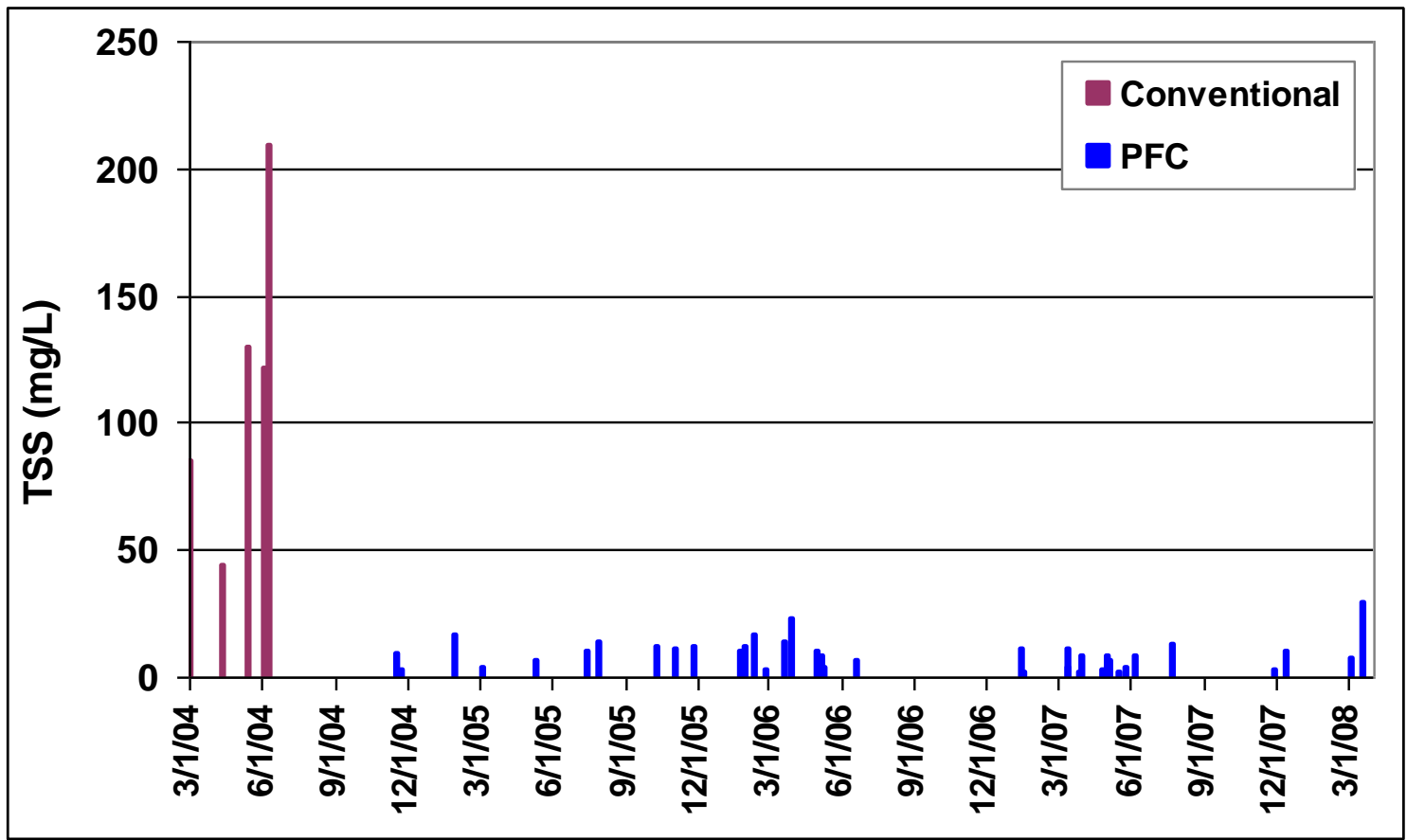

Figure 8: TSS concentration over time

As another example, total zinc concentrations were significantly reduced in the runoff from the PFC. The time-series trend for total zinc, presented in Figure 9, shows the $81 \%$ reduction of mean concentration in the runoff from PFC. Time-series graphs for all of the stormwater constituents are presented in Appendix A. 


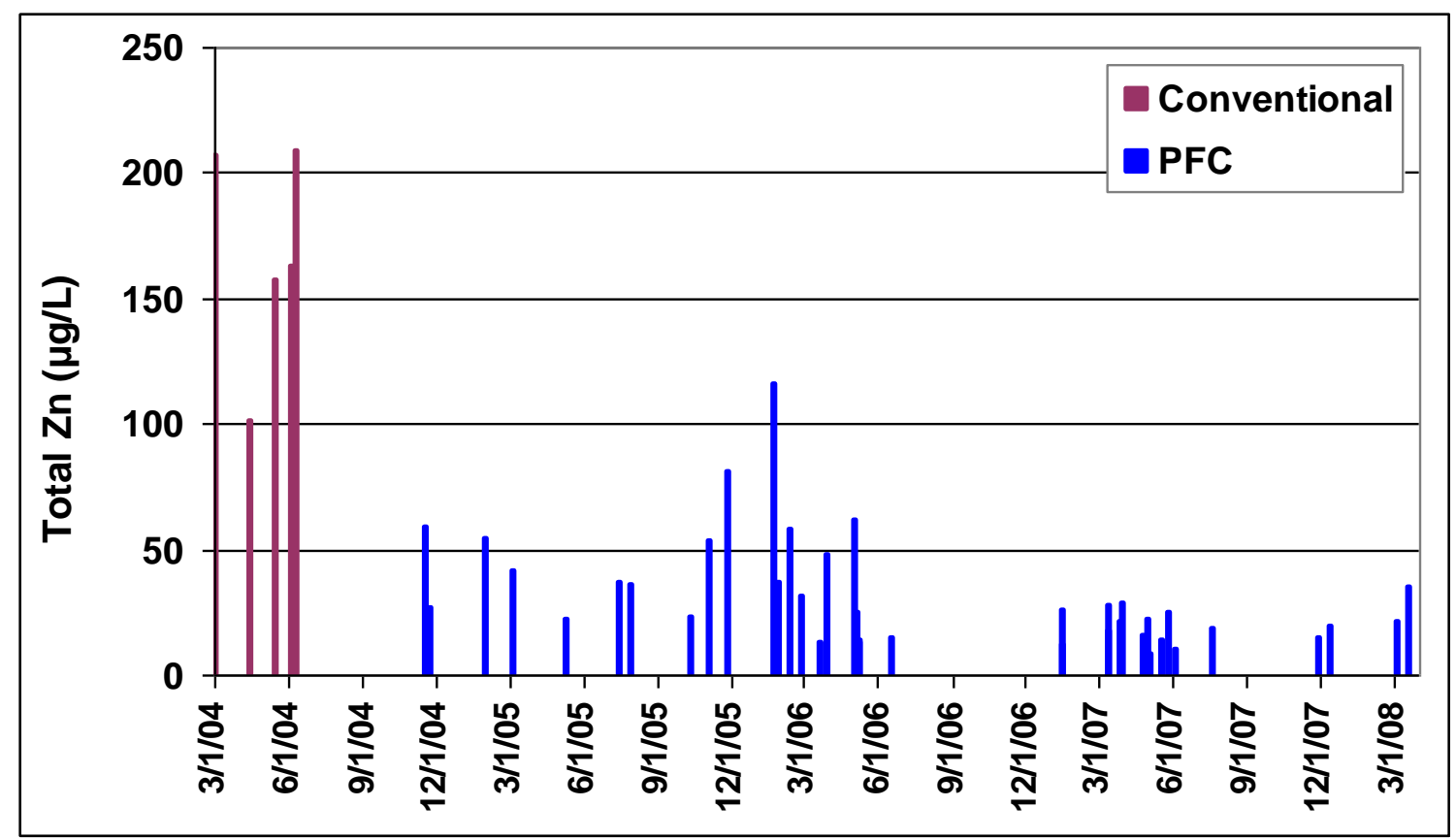

Figure 9: Total zinc concentration over time

The original results in Kearfott et al. (2005) found the same constituents, except for total phosphate, to be significantly lower in the runoff from PFC. The PFC overlay was five months old when this analysis was performed. At that time, TKN and COD were also found to be significantly lower in the PFC runoff.

Various studies have dealt with the water quality of highway runoff from impervious surfaces. Barrett et al. (1995) characterized highway runoff in Austin, Texas at a high-traffic $(60,000$ vehicles per day) and low-traffic site (8,800 vehicles per day). The results from this study are comparable to the concentrations found in the runoff from the conventional asphalt on Loop 360. In 1994, Loop 360 had an average daily traffic count of 47,000. The mean concentrations from Loop 360 fall between the high and low traffic site mean concentrations or are slightly lower than the low traffic site. The drainage area from the Loop 360 site was much smaller than the drainage areas 
monitored in Barrett et al. (1995). A comparison of the impervious asphalt mean concentrations is presented in Table 10 .

Table 10: Comparison of mean concentrations from Barrett et al. (1995)

\begin{tabular}{|l|c|c|c|}
\hline Constituent & $\begin{array}{c}\text { High-traffic } \\
\text { Site }\end{array}$ & $\begin{array}{c}\text { Low-traffic } \\
\text { Site }\end{array}$ & $\begin{array}{c}\text { Loop 360 } \\
\text { Site 1 }\end{array}$ \\
\hline TSS $(\mathrm{mg} / \mathrm{L})$ & 202 & 142 & 117.8 \\
Total P $(\mathrm{mg} / \mathrm{L})$ & 0.42 & 0.13 & 0.13 \\
COD $(\mathrm{mg} / \mathrm{L})$ & 149 & 48 & 64 \\
Total Copper $(\mu \mathrm{g} / \mathrm{L})$ & 38 & 10 & 26.84 \\
Total Lead $(\mu \mathrm{g} / \mathrm{L})$ & 99 & 41 & 12.57 \\
Total Zinc $(\mu \mathrm{g} / \mathrm{L})$ & 237 & 77 & 167.4 \\
\hline
\end{tabular}

The concentrations reported in Chapter 2 from studies on runoff from porous asphalt compare well to the mean concentrations found in the runoff since the PFC overlay was applied on Loop 360. Table 5 presents a summary of the concentrations found in the literature. The mean concentrations of the pollutants found on loop 360 are within the ranges of values found in the literature.

A comparison of the water quality data from PFC at Site 1 from the passive sampler (prior to December 2006) and the collection system (since December 2006) with the automatic sampler found that the average concentrations from the collection system were lower than the passive sampler. However, total and dissolved zinc were the only constituents with significantly lower concentrations from the collection system. The mean concentrations, percent reduction, and $\mathrm{P}$-value from a two-tail test are presented in Table 11. 
Table 11: Comparison of sampler types at Site 1

\begin{tabular}{lcccc}
\hline Constituent & $\begin{array}{c}\text { Passive } \\
\text { Sampler }\end{array}$ & $\begin{array}{c}\text { Automatic } \\
\text { Sampler }\end{array}$ & $\begin{array}{c}\text { Reduction } \\
\%\end{array}$ & P-Value \\
\hline TSS $(\mathrm{mg} / \mathrm{L})$ & 9.95 & 7.71 & 23 & 0.253 \\
$\mathrm{TKN}(\mathrm{mg} / \mathrm{L})$ & 1.10 & 0.92 & 17 & 0.618 \\
$\mathrm{NO}_{3}{ }^{+} / \mathrm{NO}_{2}(\mathrm{mg} / \mathrm{L})$ & 0.49 & 0.29 & 42 & 0.128 \\
Total P $(\mathrm{mg} / \mathrm{L})$ & 0.08 & 0.04 & 49 & 0.188 \\
Dissolved P $(\mathrm{mg} / \mathrm{L})$ & 0.04 & 0.02 & 43 & 0.180 \\
COD $(\mathrm{mg} / \mathrm{L})$ & 66.05 & 51.24 & 22 & 0.449 \\
Total Copper $(\mu \mathrm{gg} / \mathrm{L})$ & 14.11 & 11.84 & 16 & 0.530 \\
Dissolved Copper $(\mu \mathrm{g} / \mathrm{L})$ & 10.98 & 8.73 & 21 & 0.477 \\
Total Lead $(\mu \mathrm{gg} / \mathrm{L})$ & 1.17 & 1.08 & 8 & 0.351 \\
Dissolved Lead $(\mu \mathrm{g} / \mathrm{L})$ & $<1.0$ & $<1.0$ & $\mathrm{NA}$ & $\mathrm{NA}$ \\
Total Zinc $(\mu \mathrm{g} / \mathrm{L})$ & 41.08 & 19.76 & 52 & 0.0012 \\
Dissolved Zinc $(\mu \mathrm{g} / \mathrm{L})$ & 32.66 & 12.65 & 61 & 0.0005 \\
\hline
\end{tabular}

Due to the difference in concentrations for the two sampler types, linear regression on all of the PFC data could not be used to establish a trend. That would show an overall decrease in the concentration due to the lower concentrations found with the automatic sampler. Therefore, separate linear regressions were performed on the data from the passive sampler and the automatic sampler to establish any trends in water quality. For total copper, both sampler data sets show trends of slightly increasing concentrations over time and are presented in Figure 10 and Figure 11, respectively. A decline in water quality is expected as the pores in the overlay clog. 


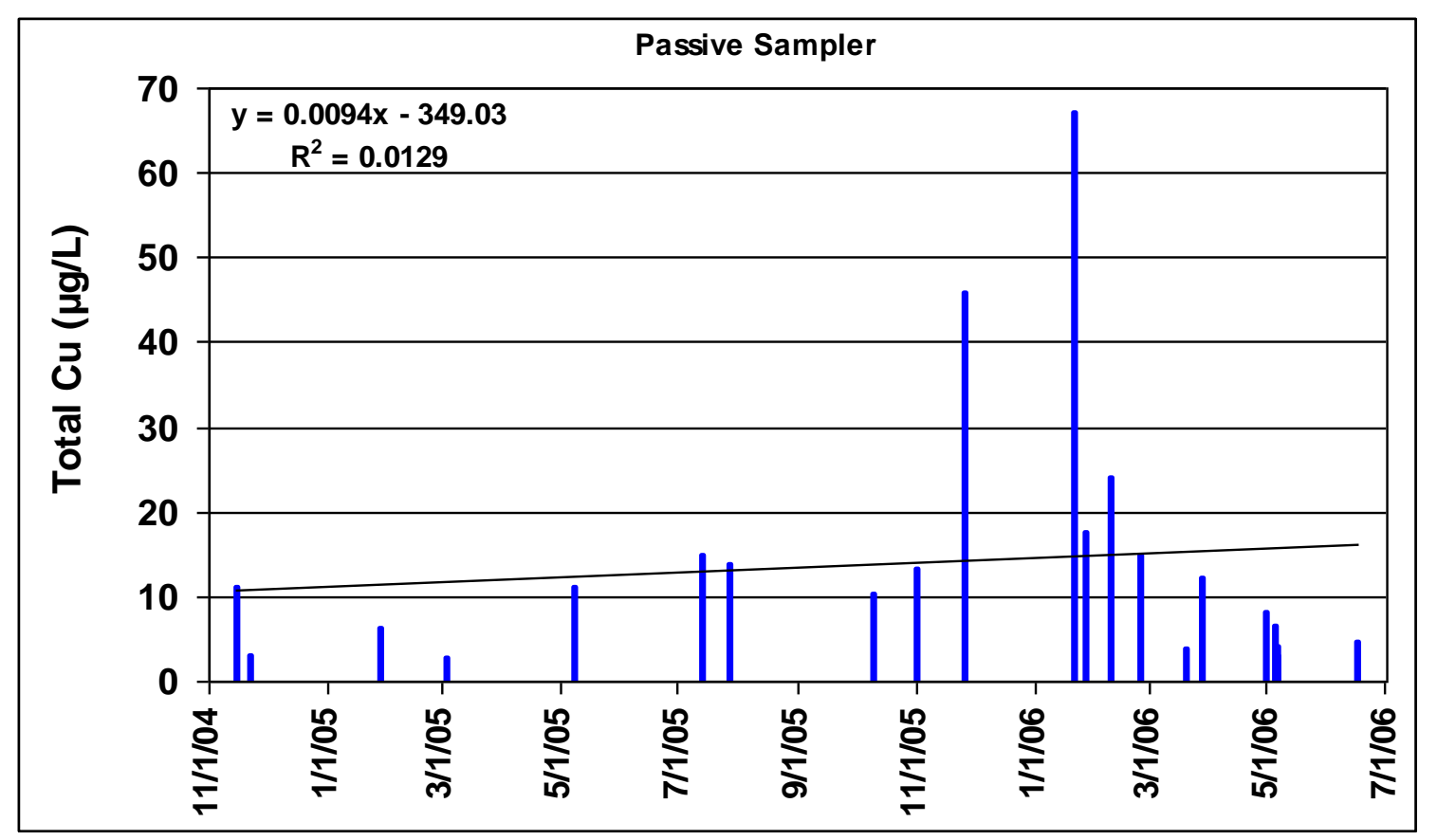

Figure 10: Total copper concentrations from passive sampler at Site 1

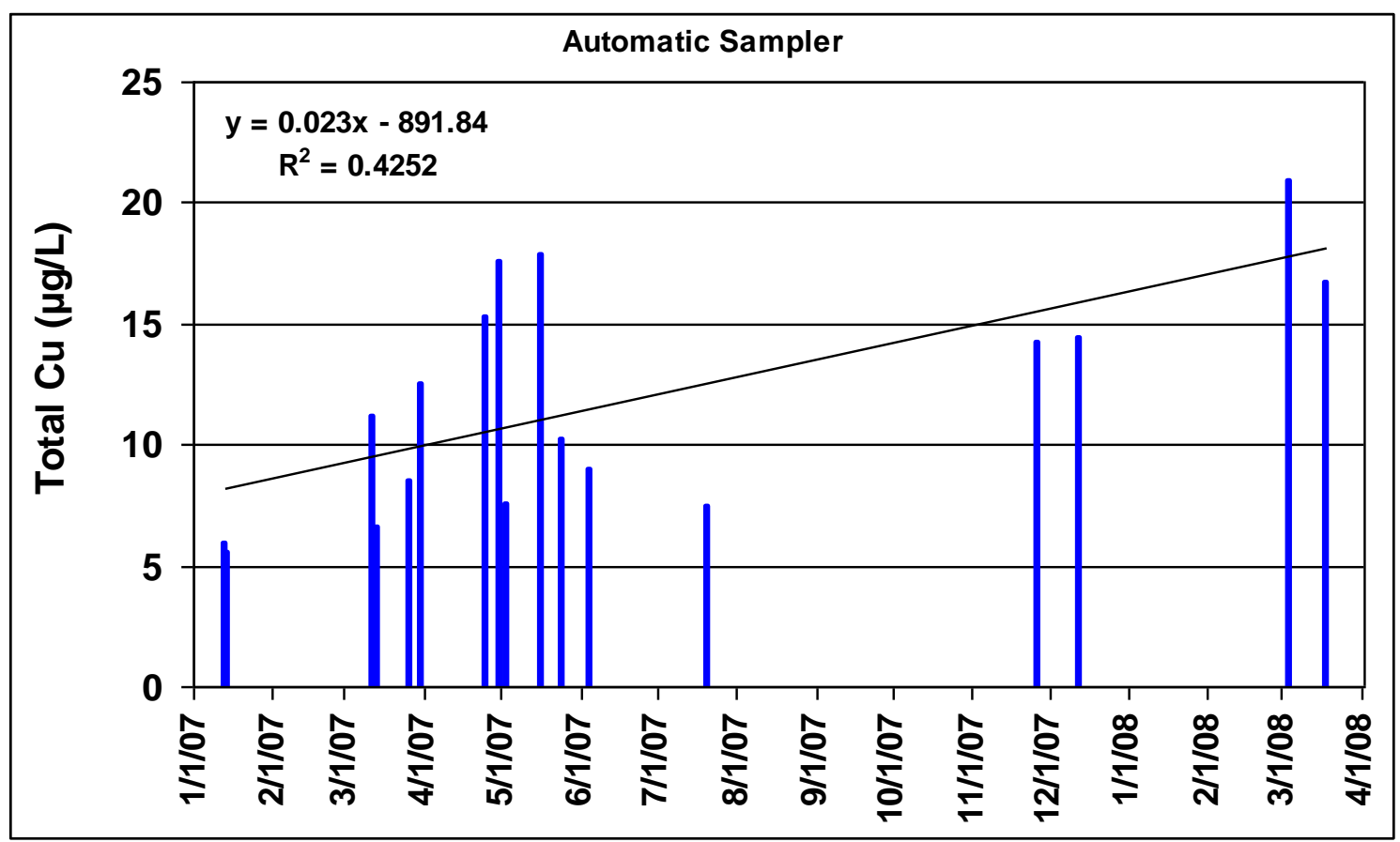

Figure 11: Total copper concentrations from automatic sampler at Site 1 
To establish the significance of regression slope, a $95 \%$ confidence interval was calculated for each slope. The $95 \%$ confidence intervals for the slopes of the total copper regression lines indicate that only the concentrations from the automatic sampler were significantly increasing. The P-value for the regression slope from the automatic sampler is 0.004 .

The other constituents with positive trends from both sampler types are dissolved copper, TSS, and COD. Dissolved copper concentrations from the automatic sampler increased significantly with a $95 \%$ confidence interval with a P-value of 0.031 . TSS concentrations from the automatic sampler were found to increase significantly; however, the significance of the trend is associated with one data point. The last rain event, on March 18, 2008, had a much higher TSS concentration than the previous sampled events from the automatic sampler. Without this value in the linear regression analysis, the regression slope is not significantly increasing. Sampling of additional storms would be required to confirm that the trend is significantly increasing. The slopes of the regression lines for COD were not significant for either sampler type. Dissolved zinc concentrations from the automatic sampler decreased significantly. The significant linear regression trendlines and confidence intervals are presented in Appendix B.

The time-series data could be used to establish the functional life of the pavement. The functional life of PFC is when the pavement clogs and no longer provides the benefits associated with the porosity of the overlay. At this point, it will perform like conventional asphalt. The functional life is different than the service life, which is when the pavement deteriorates, usually by raveling.

The regression equations for total copper were used to estimate the amount of time until the concentrations in the PFC runoff equaled the average concentration from the conventional asphalt. The average total copper concentration is predicted to reach a 
concentration of $29.4 \mu \mathrm{g} / \mathrm{L}$ in approximately 1.4 years from the last sampled rain event. Using the unconfirmed trend for TSS including the last storm, TSS is predicted to reach a concentration of $118 \mathrm{mg} / \mathrm{L}$ in approximately 12 years from the last sampled rain event.

\subsection{SITE 2 WATER QUALITY}

The water quality analysis for the passive samplers at Site 2 provides direct comparison of the runoff from the two pavement types, conventional hot mix asphalt and PFC. The concentrations in the runoff from each monitored rain event are shown in Table 12. 
Table 12: Concentrations from passive samplers at Site 2

\begin{tabular}{|c|c|c|c|c|c|c|c|c|c|c|c|c|c|}
\hline Date & $\begin{array}{l}\text { Rainfall } \\
\text { (in.) }\end{array}$ & $\begin{array}{c}\text { TSS } \\
\text { (mg/L) }\end{array}$ & $\begin{array}{c}\text { TKN } \\
\text { (mg/L) }\end{array}$ & $\begin{array}{c}\mathbf{N O}_{3}{ }^{+} / \mathbf{N O}_{2} \\
(\mathrm{mg} / \mathrm{L})\end{array}$ & $\begin{array}{c}\mathbf{P}_{\text {Total }} \\
(\mathrm{mg} / \mathrm{L})\end{array}$ & $\begin{array}{c}\mathbf{P}_{\text {Dissolved }} \\
(\mathrm{mg} / \mathrm{L})\end{array}$ & $\begin{array}{l}\text { COD } \\
(\mathrm{mg} / \mathrm{L})\end{array}$ & $\begin{array}{l}\mathbf{C u}_{\text {Total }} \\
(\mu \mathrm{g} / \mathrm{L})\end{array}$ & $\begin{array}{c}\text { Cu }_{\text {Dissolved }} \\
(\mu \mathrm{g} / \mathrm{L})\end{array}$ & $\begin{array}{l}\mathbf{P b}_{\text {Total }} \\
(\mu \mathrm{g} / \mathrm{L})\end{array}$ & $\begin{array}{c}\mathbf{P b}_{\text {Dissolved }} \\
(\mu \mathrm{g} / \mathrm{L})\end{array}$ & $\begin{array}{l}\mathbf{Z n}_{\text {Total }} \\
(\mu \mathrm{g} / \mathrm{L})\end{array}$ & $\begin{array}{c}\mathbf{Z n}_{\text {Dissolved }} \\
(\mu \mathrm{g} / \mathrm{L})\end{array}$ \\
\hline \multicolumn{14}{|c|}{ Conventional Asphalt } \\
\hline $3 / 11 / 07$ & 1.79 & 223 & 0.996 & 0.10 & 0.12 & 0.02 & 79 & 27.7 & 2.70 & 12.7 & $<1$ & 169.0 & 8.53 \\
\hline $3 / 13 / 07$ & 0.95 & 172 & 1.210 & 0.17 & 0.113 & 0.02 & 75 & 49.8 & 7.95 & 9.45 & $<1$ & 135.0 & 11.30 \\
\hline $3 / 26 / 07$ & 1.37 & 286 & 4.520 & 0.06 & 0.337 & 0.02 & 129 & 42.1 & 6.63 & 14.9 & 1.09 & 215.0 & 26.20 \\
\hline $4 / 24 / 07$ & 0.37 & 127 & 0.348 & 0.22 & 0.135 & 0.155 & 55 & 16.9 & 5.50 & 13.2 & $<1$ & 79.2 & 16.30 \\
\hline $4 / 30 / 07$ & 0.42 & 102 & 1.490 & 0.31 & 0.147 & 0.052 & 110 & 31.7 & 10.90 & 6.79 & $<1$ & 138.0 & 28.60 \\
\hline $5 / 3 / 07$ & 1.33 & 136 & 1.020 & 0.20 & 0.476 & 0.02 & 50 & 22.2 & 1.75 & 9.53 & $<1$ & 95.1 & 8.67 \\
\hline $5 / 16 / 07$ & 0.46 & 22 & 1.000 & 0.36 & 0.06 & 0.036 & 55 & 11.7 & 7.70 & 3.36 & $<1$ & 61.7 & 36.50 \\
\hline $5 / 24 / 07$ & 0.64 & 197 & 0.799 & 0.15 & 0.106 & $<0.02$ & 65 & 28.4 & 4.48 & 13.9 & $<1$ & 133.0 & 8.57 \\
\hline $6 / 3 / 07$ & 1.43 & 83 & 0.414 & 0.20 & 0.085 & $<0.02$ & 40 & 16.9 & 3.54 & 6.95 & $<1$ & 66.0 & 4.33 \\
\hline $7 / 20 / 07$ & 1.9 & 81 & 0.210 & 0.06 & 0.063 & 0.021 & 38 & 14.3 & 3.12 & 3.74 & $<1$ & 56.2 & 4.08 \\
\hline $10 / 22 / 07$ & 0.47 & 93 & 0.657 & 0.10 & 0.097 & $<0.02$ & 85 & 43.6 & 10.70 & 10.2 & $<1$ & 175.0 & 25.00 \\
\hline $11 / 24 / 07$ & 1 & 137 & 0.681 & 0.16 & 0.115 & 0.023 & 122 & 36.4 & 7.68 & 14.8 & $<1$ & 209.0 & 26.40 \\
\hline $12 / 11 / 07$ & 0.96 & 409 & 1.190 & 0.06 & 0.124 & $<0.02$ & 92 & 42.2 & 4.24 & 23.3 & $<1$ & 184.0 & 7.06 \\
\hline $3 / 18 / 08$ & 1.34 & 80 & 0.650 & 0.10 & 0.07 & $<0.02$ & 37 & 28.3 & 4.45 & 10.2 & $<1$ & 111.0 & $<4.00$ \\
\hline \multicolumn{14}{|c|}{ PFC } \\
\hline $3 / 11 / 07$ & 1.79 & 36 & 0.474 & 0.21 & 0.02 & 0.02 & 60 & 13.6 & 8.91 & 1.99 & $<1$ & 30.1 & 14.80 \\
\hline $3 / 13 / 07$ & 0.95 & 46 & 0.462 & 0.08 & 0.037 & 0.02 & 40 & 8.94 & 4.89 & 1.88 & $<1$ & 23.1 & 8.48 \\
\hline $3 / 26 / 07$ & 1.37 & 19 & 4.030 & 0.29 & 0.08 & 0.024 & 69 & 13.5 & 10.10 & 1.49 & $<1$ & 28.9 & 19.00 \\
\hline $4 / 24 / 07$ & 0.37 & 7 & 0.706 & 0.43 & 0.143 & 0.092 & 68 & 12.4 & 10.00 & $<1$ & $<1$ & 14.9 & 13.50 \\
\hline $4 / 30 / 07$ & 0.42 & 10 & 0.761 & 0.21 & 0.075 & 0.039 & 89 & 19.7 & 13.10 & $<1$ & $<1$ & 27.1 & 13.80 \\
\hline $5 / 3 / 07$ & 1.33 & 21 & 0.504 & 0.21 & 0.048 & 0.02 & 26 & 6.36 & 3.30 & $<1$ & $<1$ & 15.4 & 8.54 \\
\hline $5 / 16 / 07$ & 0.46 & 6 & 1.880 & 0.91 & 0.071 & $<0.02$ & 124 & 21.5 & 19.80 & $<1$ & $<1$ & 15.5 & 13.90 \\
\hline $5 / 24 / 07$ & 0.64 & 12 & 0.456 & 0.10 & 0.023 & $<0.02$ & 58 & 9.25 & 7.52 & $<1$ & $<1$ & 16.1 & 10.30 \\
\hline $6 / 3 / 07$ & 1.43 & 13 & 0.369 & 0.17 & 0.039 & $<0.02$ & 39 & 7.05 & 4.64 & $<1$ & $<1$ & 12.3 & 4.47 \\
\hline $7 / 20 / 07$ & 1.9 & 11 & 0.092 & $<0.02$ & 0.03 & $<0.02$ & 33 & 4.85 & 3.26 & $<1$ & $<1$ & 13.5 & 4.88 \\
\hline $10 / 22 / 07$ & 0.47 & 8 & 0.797 & 0.30 & 0.045 & $<0.02$ & 110 & 25.6 & 18.30 & 2.15 & $<1$ & 33.4 & 18.40 \\
\hline $11 / 24 / 07$ & 1 & 9 & 0.445 & 0.33 & 0.055 & 0.034 & 62 & 13.4 & 11.40 & $<1$ & $<1$ & 17.3 & 10.00 \\
\hline $12 / 11 / 07$ & 0.96 & 23 & 1.110 & 0.13 & $<0.02$ & $<0.02$ & 32 & 10.3 & 5.93 & 1.07 & $<1$ & 21.9 & 5.95 \\
\hline 3/18/08 & 1.34 & 30 & 0.463 & 0.07 & 0.045 & $<0.02$ & 19 & 8.62 & 2.74 & 1.66 & $<1$ & 24.8 & $<4.00$ \\
\hline
\end{tabular}


The mean concentrations from both pavement types, percent reduction and $\mathrm{p}$ values for each constituent are presented in Table 13.

Table 13: Comparison of concentrations from passive samplers at Site 2

\begin{tabular}{lcccc}
\hline Constituent & $\begin{array}{c}\text { Conventional } \\
\text { Asphalt }\end{array}$ & PFC & $\begin{array}{c}\text { Reduction } \\
\%\end{array}$ & P-Value \\
\hline TSS $(\mathrm{mg} / \mathrm{L})$ & 153.43 & 17.93 & 88 & $<0.000$ \\
$\mathrm{TKN}(\mathrm{mg} / \mathrm{L})$ & 1.08 & 0.90 & 17 & 0.134 \\
$\mathrm{NO}_{3}{ }^{+} / \mathrm{NO}_{2}(\mathrm{mg} / \mathrm{L})$ & 0.16 & 0.25 & -54 & 0.090 \\
Total P $(\mathrm{mg} / \mathrm{L})$ & 0.15 & 0.05 & 64 & 0.009 \\
Dissolved P $(\mathrm{mg} / \mathrm{L})$ & 0.033 & 0.028 & 17 & 0.261 \\
$\mathrm{COD}(\mathrm{mg} / \mathrm{L})$ & 73.71 & 59.21 & 20 & 0.151 \\
Total Copper $(\mu \mathrm{g} / \mathrm{L})$ & 29.44 & 12.51 & 58 & $<0.000$ \\
Dissolved Copper $(\mu \mathrm{g} / \mathrm{L})$ & 5.81 & 8.85 & -52 & 0.011 \\
Total Lead $(\mu \mathrm{g} / \mathrm{L})$ & 10.93 & 1.30 & 88 & $<0.000$ \\
Dissolved Lead $(\mu \mathrm{g} / \mathrm{L})$ & $<1.0$ & $<1.0$ & $\mathrm{NA}$ & $\mathrm{NA}$ \\
Total Zinc $(\mu \mathrm{g} / \mathrm{L})$ & 130.51 & 21.02 & 84 & $<0.000$ \\
Dissolved $\mathrm{Zinc}(\mu \mathrm{g} / \mathrm{L})$ & 15.40 & 10.72 & 30 & 0.049 \\
\hline
\end{tabular}

The significantly lower constituents found at Site 1, TSS, total P, copper, lead and zinc, are also found to be significantly lower in the PFC passive sampler than the conventional asphalt passive sampler. Dissolved zinc is also significantly lower in runoff from the PFC overlay. $\mathrm{NO}_{3}{ }^{+} / \mathrm{NO}_{2}$ and dissolved copper are significantly greater in the runoff from PFC. Dissolved lead was not detected in any of the samples at Site 1 or Site 2. Linear regression on the concentrations from the PFC passive samplers found that none of the trends were significantly increasing.

As an example, the paired concentrations of TSS from each monitored rain event are shown in Figure 12. 


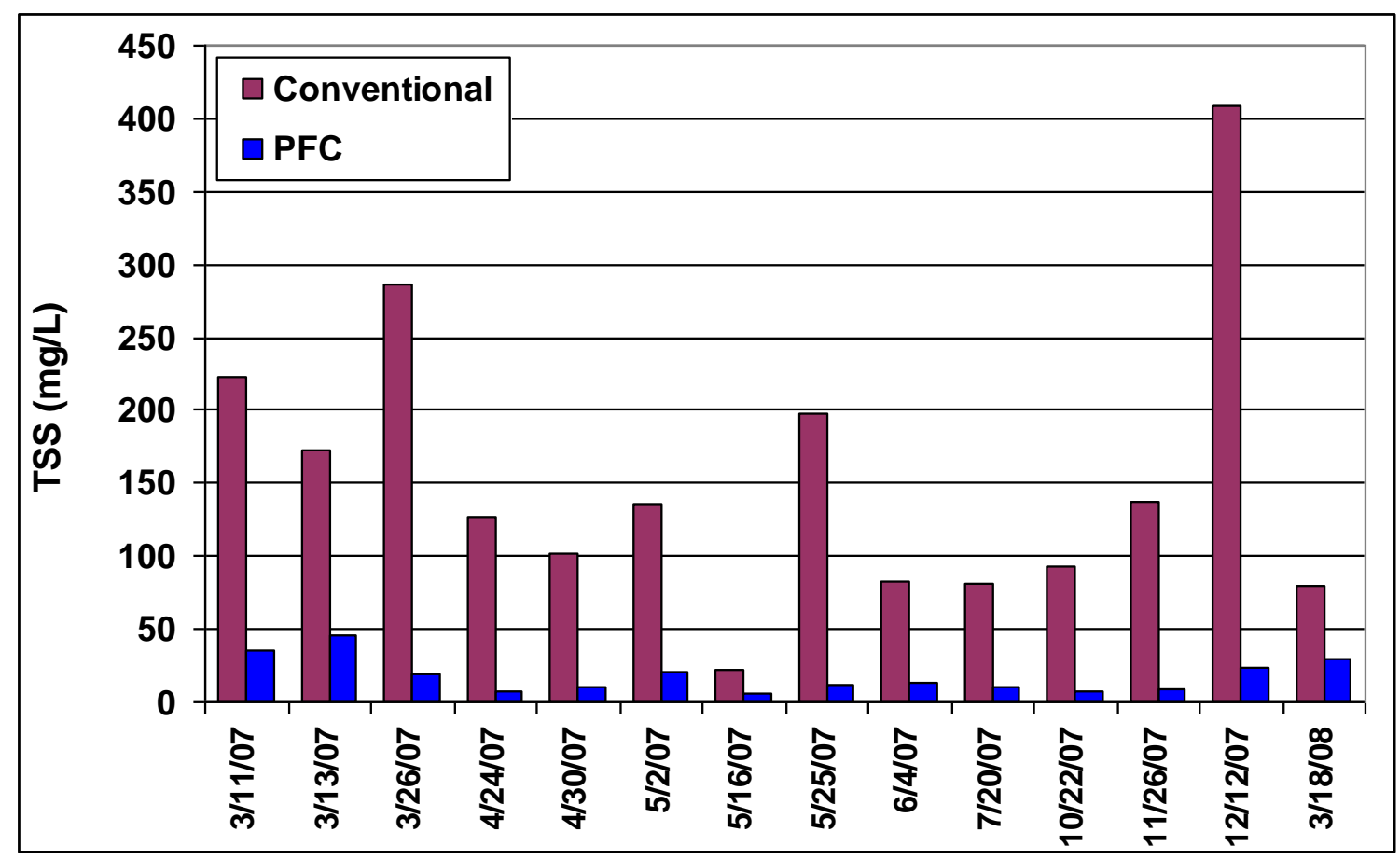

Figure 12: TSS concentrations from passive samplers

Pollutants in the particulate form experience the greatest reduction from the PFC overlay. As the runoff travels through the pavement, the majority of particles are removed by sedimentation, and some are trapped in the pores through filtration and other processes. Water velocities in the pore space are low and not likely to detach or transport the accumulated particles. These particle removal processes do not affect dissolved species in the runoff.

The heavy metals concentrations in the total and dissolved forms at Site 2 provide evidence for the particle removal processes. The particulate concentration is the difference between the total and dissolved concentrations. The reductions of particulate zinc, copper and phosphate are greater than the reductions of the total concentrations of those constituents. The mean particulate, dissolved, and total concentrations of zinc and copper found in the runoff are presented in Figure 13 and Figure 14, respectively. 
Zinc is present mainly in the particulate form (more than 85\%) and hence, experiences significant particulate and overall reduction from the PFC. Dissolved zinc is only slightly lower in the runoff from PFC.

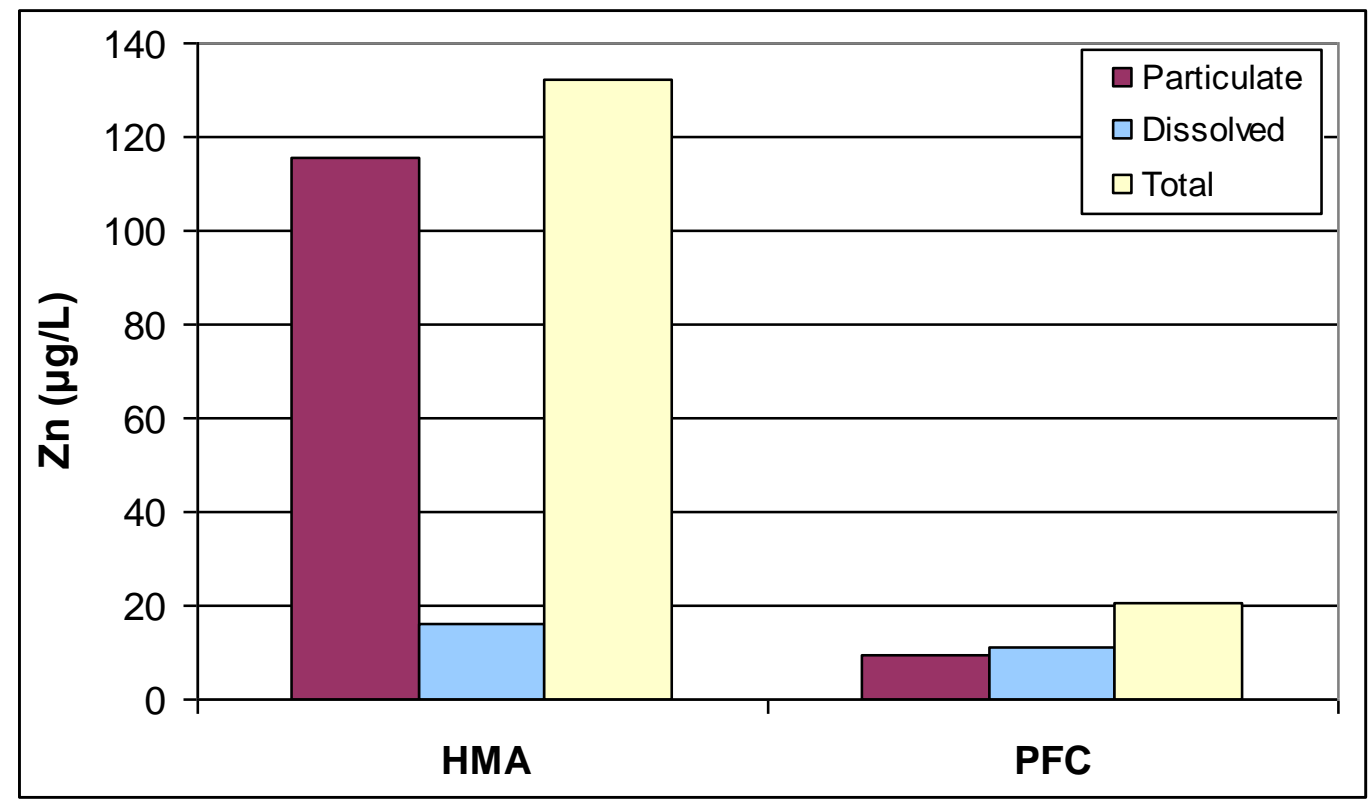

Figure 13: Zinc concentration by phase

Dissolved copper concentrations are greater in the runoff from PFC at Site 1 and Site 2. However, the particulate form of copper is reduced by $85 \%$, which is evident in Figure 14. Copper is present mainly in particulate form (approximately $80 \%$ ) which contributes to the significant overall reduction in concentration. 


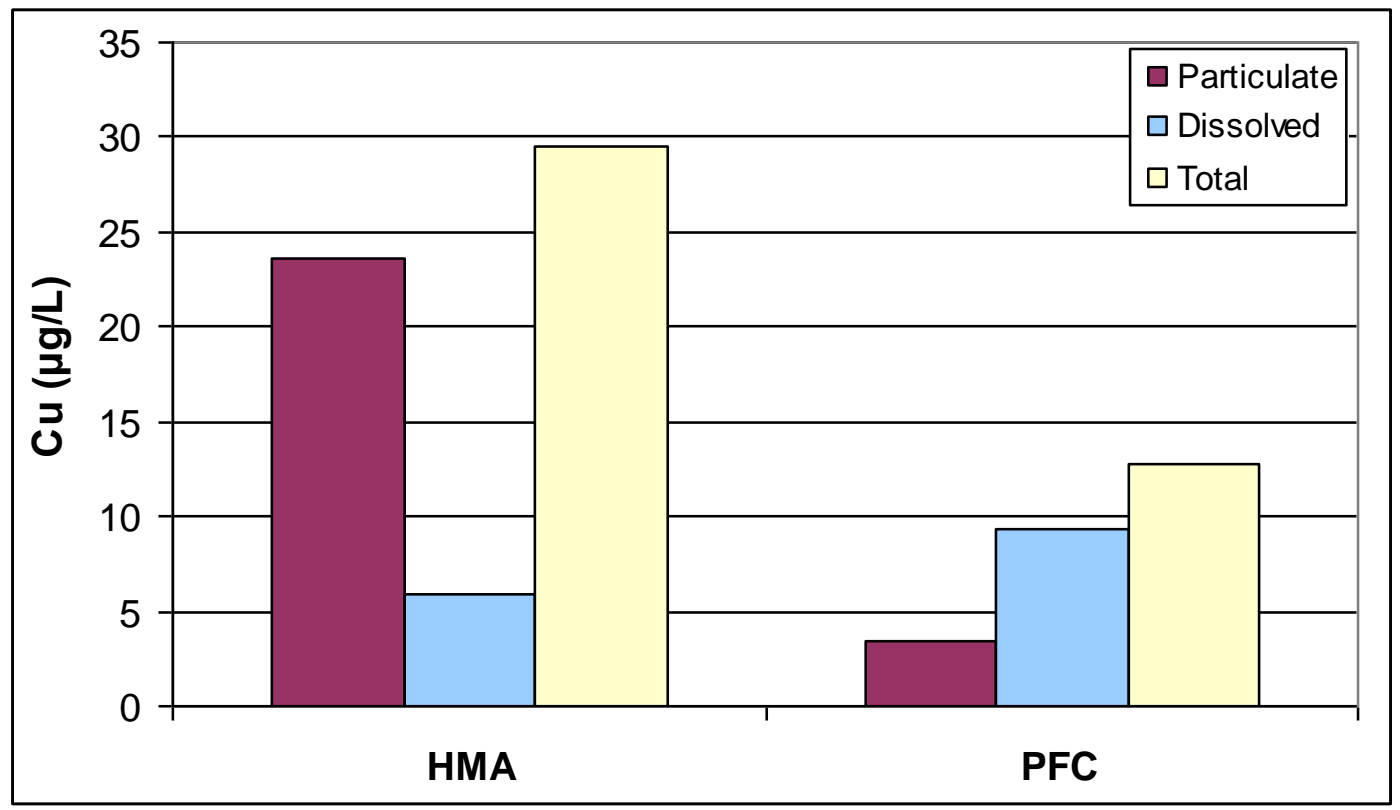

Figure 14: Copper concentration by phase

The average total lead concentration in the runoff from the conventional pavement is $11 \mu \mathrm{g} / \mathrm{L}$, while the total lead concentrations from PFC are near or below the detection limit $(1 \mu \mathrm{g} / \mathrm{L})$. Dissolved lead concentrations are below the detection limit in the runoff from both pavement types. Total lead is greatly reduced by PFC because lead is present primarily in the particulate form (more than $90 \%$ ).

Total phosphate is dominated by the particulate form (greater than $77 \%$ ) and also experiences significant reduction from PFC. The effect on the dissolved form cannot be determined because most of the values from the PFC are below the detection limit.

The dissolved percentages of the total concentrations are reported by pavement type in Table 14. The dissolved concentration makes up the majority of the total concentration in the runoff from the PFC. The values with asterisks $(*)$ are calculated with any "Not Detected" concentrations replaced by the PQL. The actual percentage is lower than the value reported. 
Table 14: Percent dissolved form of total concentration

\begin{tabular}{|l|c|c|}
\hline \multirow{2}{*}{ Constituent } & \multicolumn{2}{|c|}{$\%$ Dissolved } \\
\cline { 2 - 3 } & HMA & PFC \\
\hline Total P $(\mathrm{mg} / \mathrm{L})$ & $23^{*}$ & $54^{*}$ \\
Total Copper $(\mu \mathrm{g} / \mathrm{L})$ & 20 & 73 \\
Total Lead $(\mu \mathrm{g} / \mathrm{L})$ & $9^{*}$ & $78^{\star}$ \\
Total Zinc $(\mu \mathrm{g} / \mathrm{L})$ & 12 & 54 \\
\hline
\end{tabular}

\subsection{SITE 1 HYDROGRAPH ANALYSIS}

A runoff hydrograph for the PFC pavement at Site 1 is created from the flow meter data for each rain event. A typical storm hydrograph is presented in Figure 15. The figure shows the rainfall (in green) from the top using the left axis and flow rate (in blue) across the bottom using the right axis. The time at which samples were taken is shown by the red diamonds in the center of the figure. 


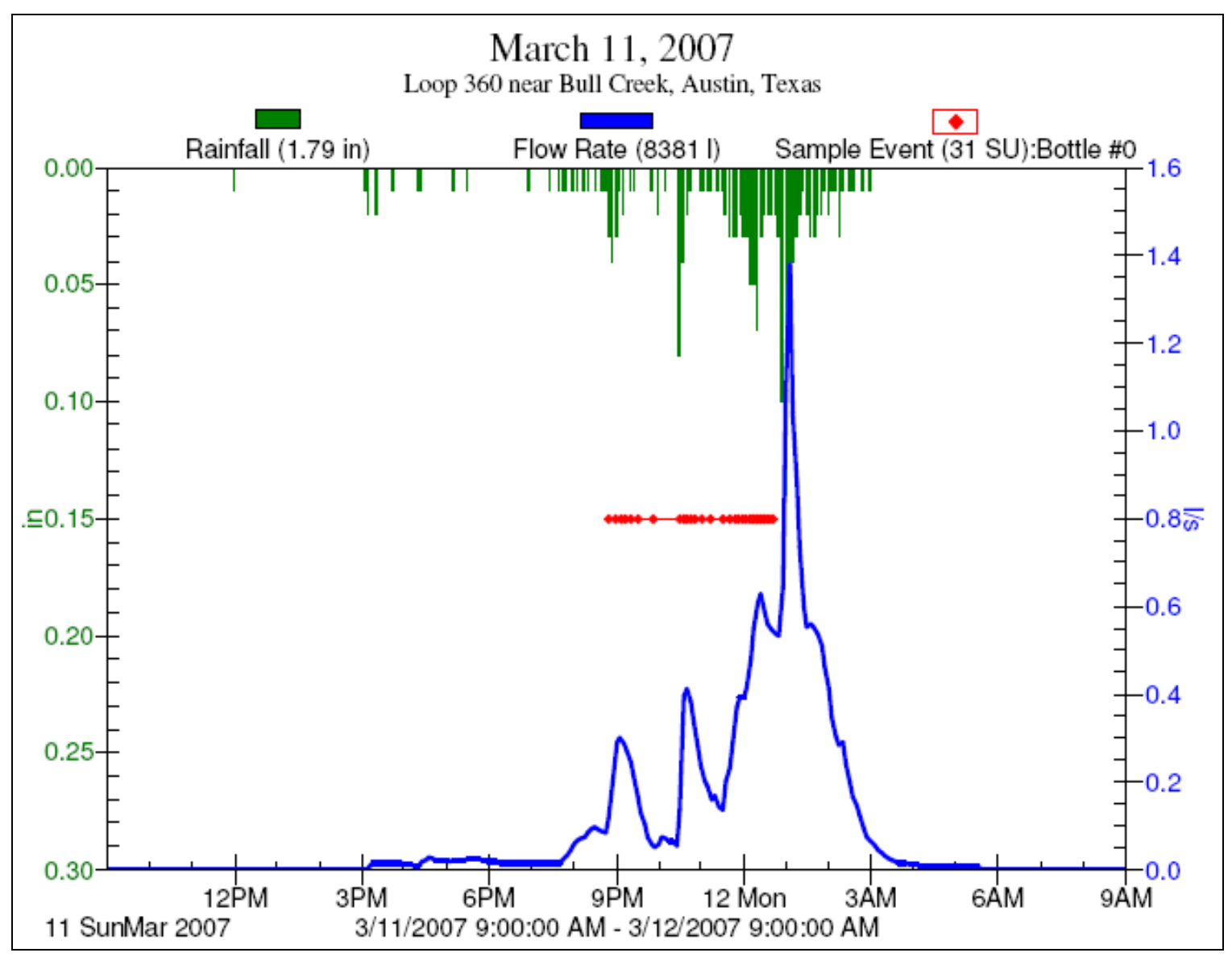

Figure 15: Hydrograph from sampled rain even on March 11, 2007

The storm on March 11, 2007 was a relatively large rain event. The samples were all taken in the first half of the storm. The delay in peak runoff from peak rainfall was less than five minutes. Smaller rain events had peak lags of up to 15 minutes. The hydrographs for all monitored rain events are presented in Appendix B.

The rain events and their characteristics are presented in Table 7. The rain events included in the analysis were storms with at least 0.15 inches of rainfall in approximately 6 hours. Some events were not included because of errors in the data. Rainfall data errors occurred because of the rain gauge being clogged by grass, dirt or bird droppings. For four events with rain gauge errors, the precipitation data from a nearby USGS Gauge 
(08154700 Bull Creek at Loop 360 near Austin, TX) operated by LCRA was used (LCRA, 2008). The flow meter data errors were caused by the bubbler line being disconnected, the sampler box overflowing and affecting the flume, and the zero level needing adjustment due to sitting water. The Flowlink software was used to determine the total flow for a rain event. When light rain, drizzle or high humidity occurred for many hours, the flume stayed wet and continued to measure a low flow rate. For these rain events the level was adjusted to zero after 3 hours, which is the expected draining time for the collection system.

The relationship between rainfall and runoff from the PFC is shown in Figure 16. The rainfall was converted to millimeters and the runoff depth was calculated by dividing the runoff volume by the drainage area. The runoff coefficient is the runoff volume divided by the rain volume. The slope of the linear regression trendline can be interpreted as the runoff coefficient for the pavement. The runoff coefficient for the overlay at Site 2 is 0.95 . The trendline also shows that a minimum of approximately 1 $\mathrm{mm}(0.04$ inches $)$ of rain must fall before there is any runoff. 


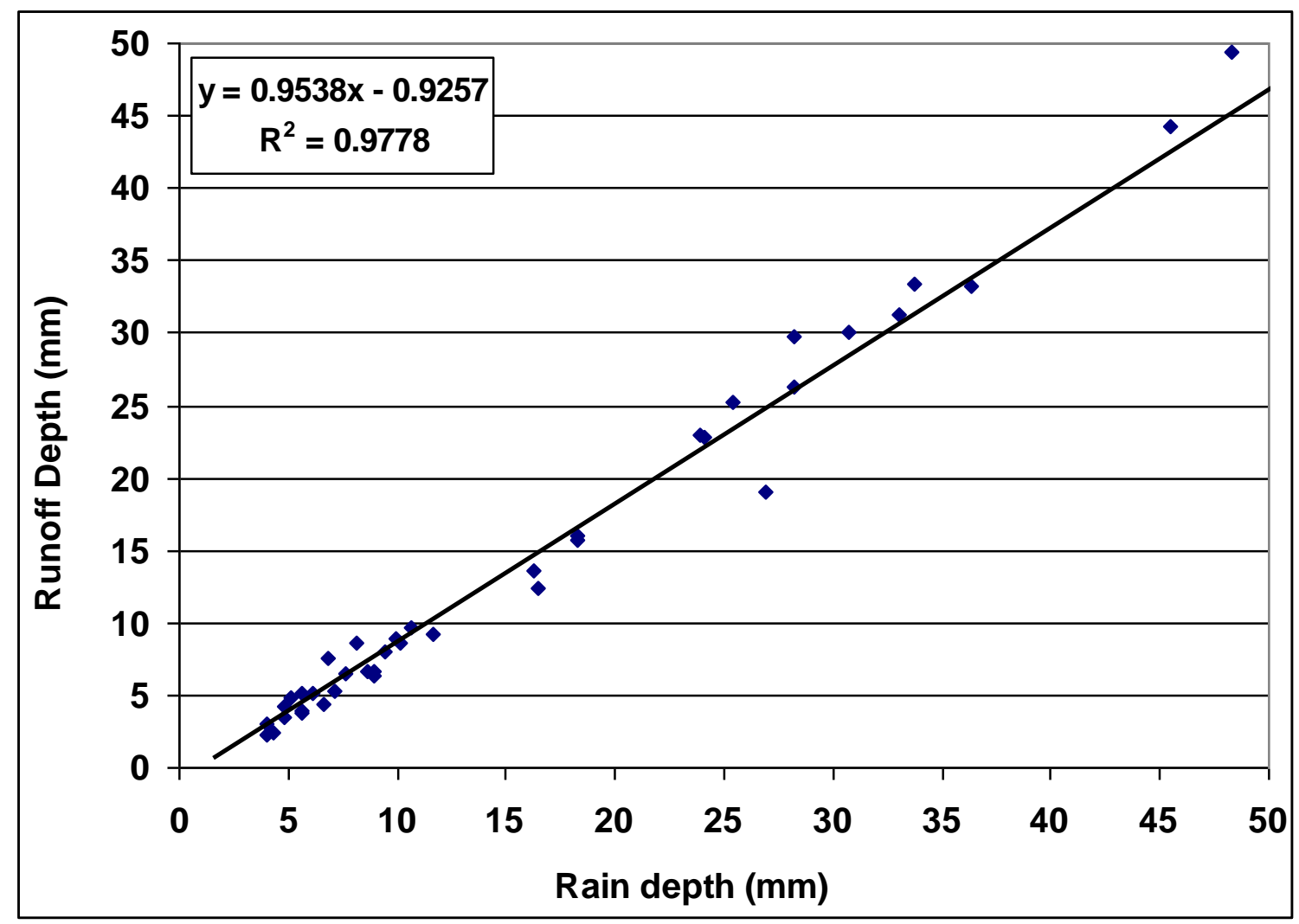

Figure 16: Rainfall-runoff relationship from PFC at Site 1

The PFC pavement storage was also analyzed using the flow meter data. Rainfall data was converted to a rain rate in the same units as flow rate $(\mathrm{L} / \mathrm{s})$ using the following equation.

Rain (ft) x Area $\left(\mathrm{ft}^{2}\right) \times 28.3\left(\mathrm{~L} / \mathrm{ft}^{3}\right) \times$ Runoff Coefficient / $300 \mathrm{~s}=$ Rain Rate $(\mathrm{L} / \mathrm{s})$

The cumulative rainfall and runoff were calculated from the previous cumulative value and the average rates over the time step. The difference between the cumulative rainfall and runoff curves represents the storage volume of the pavement. When the calculated storage exceeds the pavement storage, there is sheet flow over the pavement. 
The estimated pavement storage was determined with the following calculations assuming a pavement porosity at Site 1 of 0.20 .

Pavement thickness at Site $1=41 \mathrm{~mm}$ (determined from cores)

Total pavement volume $=34 \mathrm{ft} \times 60 \mathrm{ft} \times 41 \mathrm{~mm}=274 \mathrm{ft}^{3}$

Estimated pavement storage $=274 \mathrm{ft}^{3} \times 0.20=1,554 \mathrm{~L}$

The calculated pavement storage for the rain event on March 11, 2007 is shown in Figure 17. A plot of the runoff versus storage shows periods when the pavement is filling (solid lines) and draining (dotted lines). The runoff versus storage for March 11, 2007 is shown in Figure 18.

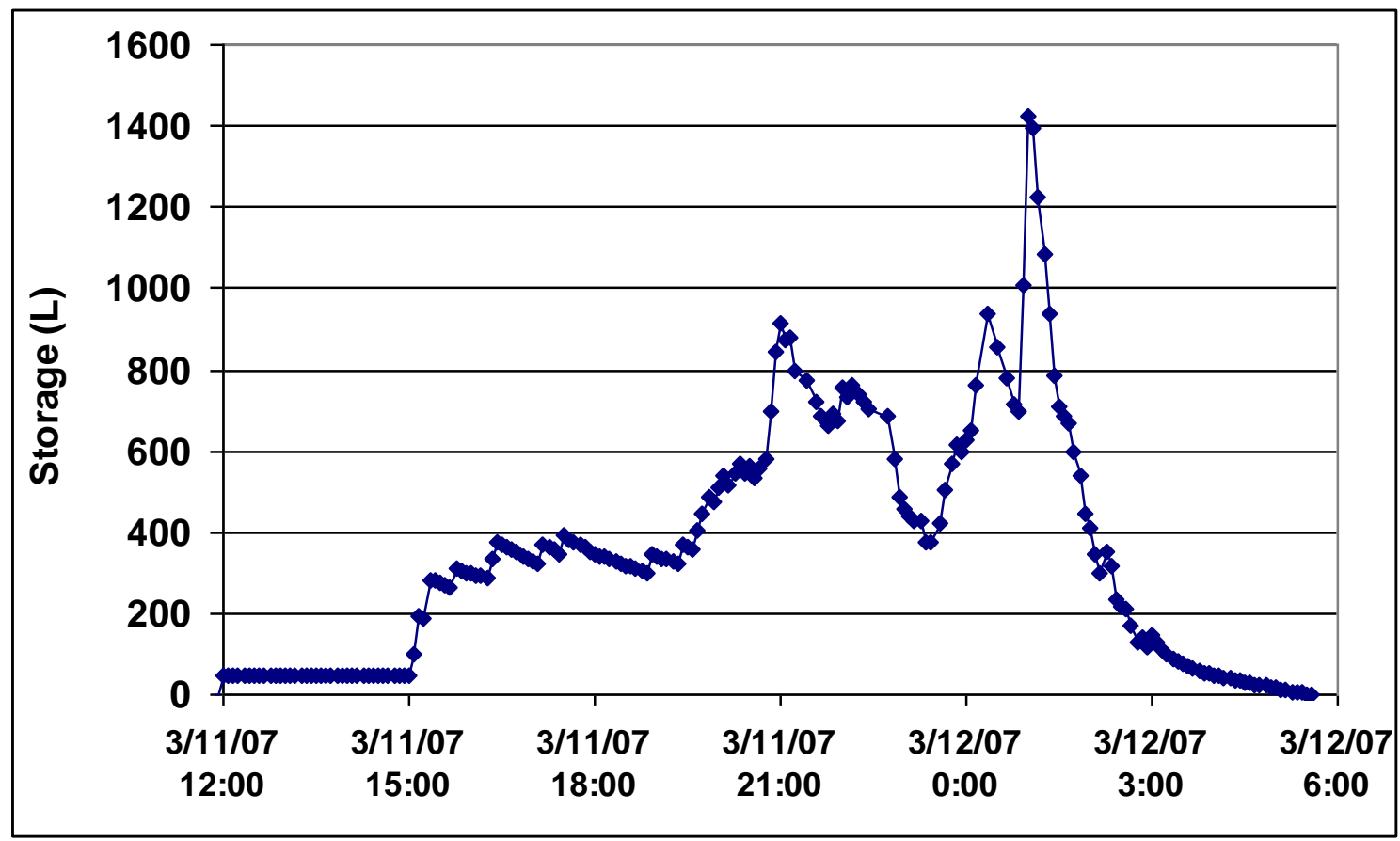

Figure 17: PFC storage curve for March 11, 2007 rain event 


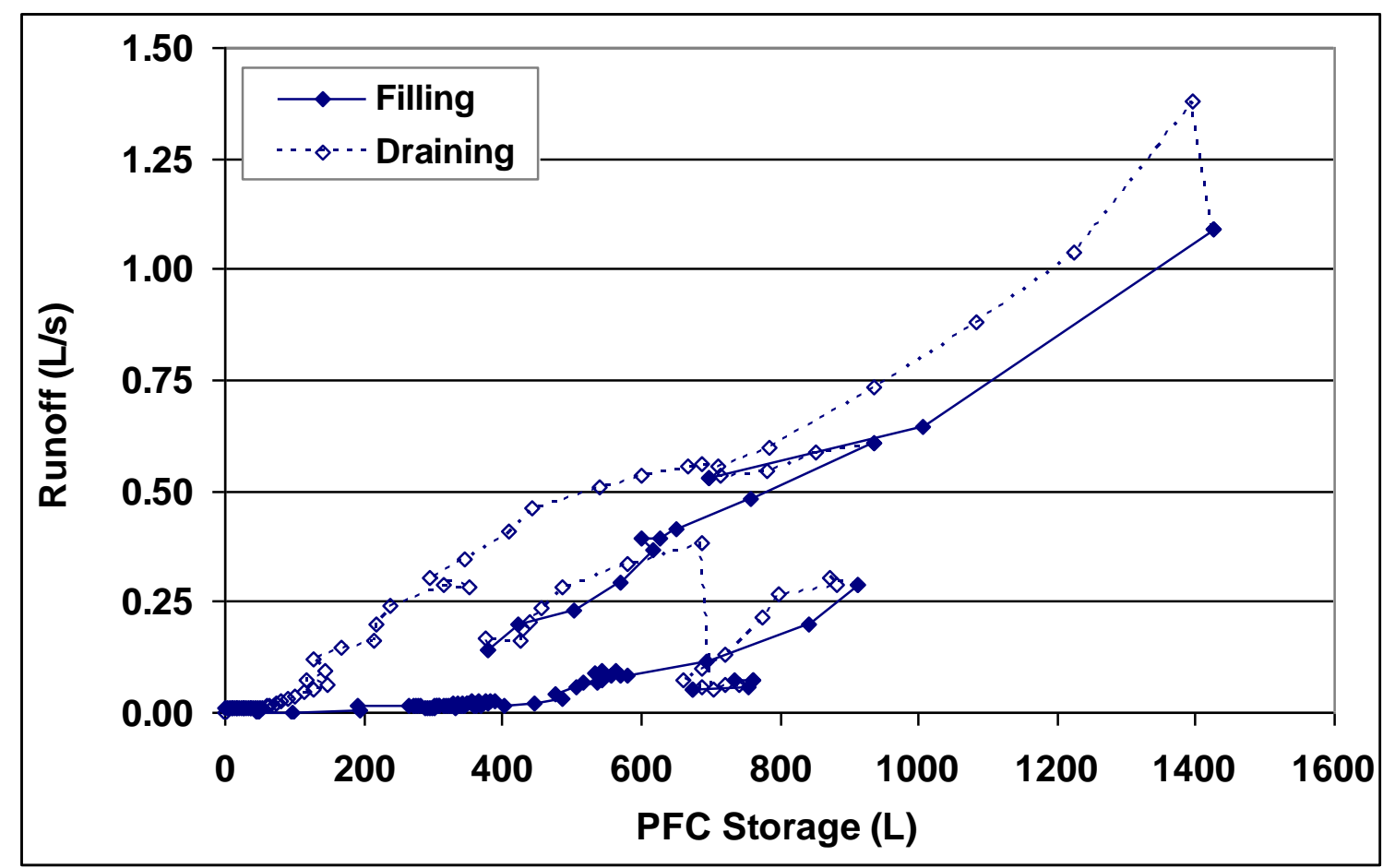

Figure 18: Runoff versus storage for March 11, 2007 rain event

The drainage curve at the end of the rain event is of interest because it will most likely change over time as the pores of the overlay clog. The drainage curves from large rain events (greater than 1-inch) were found to be very similar. These curves are shown in Figure 19. Large rain events were used in this analysis to ensure adequate rainfall intensity and pavement storage. 


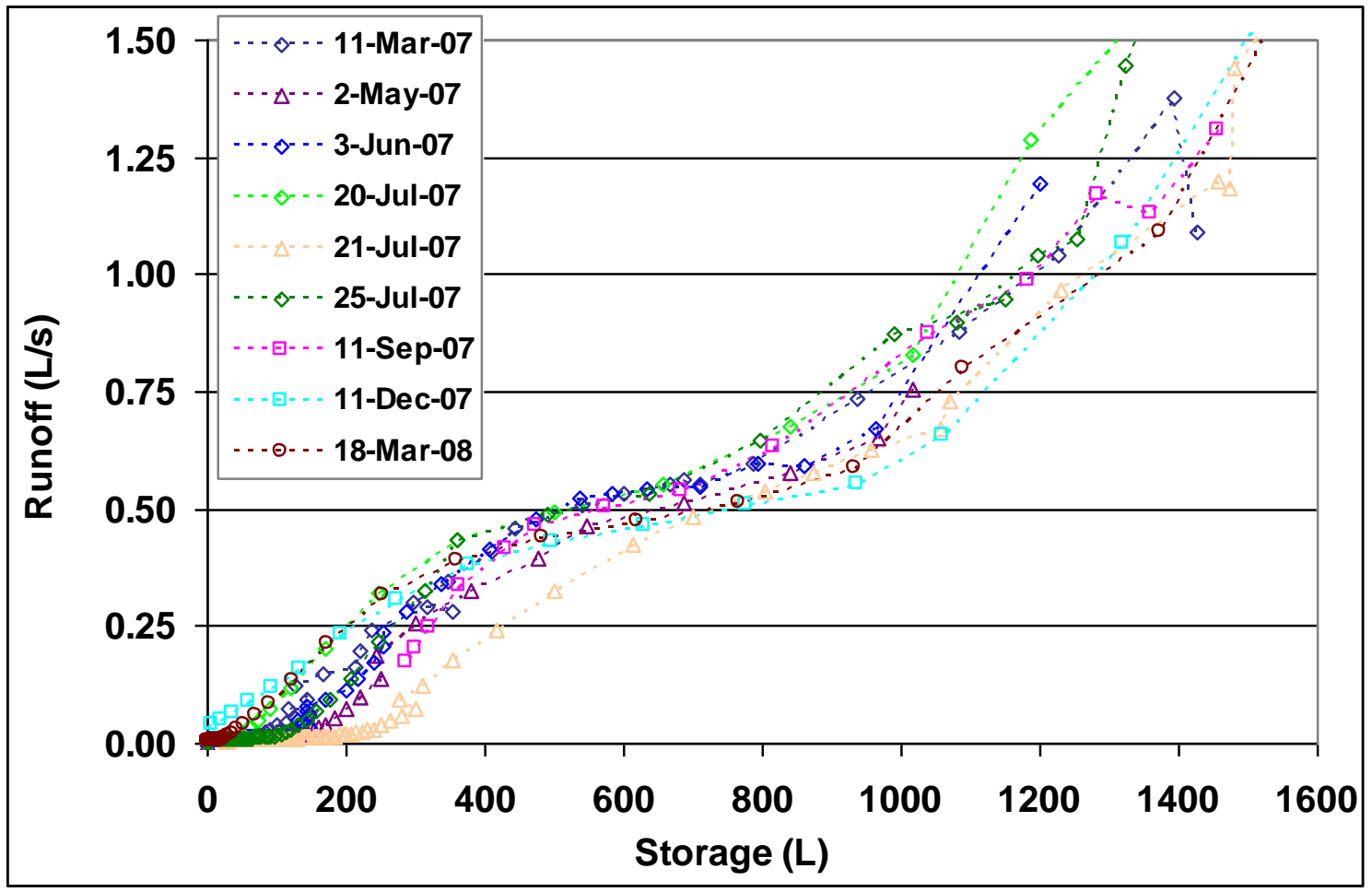

Figure 19: Drainage curves from large rain events

The inflection point of the drainage curves could possibly be used to estimate the hydraulic conductivity $(\mathrm{K})$ of the pavement. Darcy's Law equation and the inflection point flow rate could be used to solve to the hydraulic conductivity, as shown in the following calculations.

$$
\begin{aligned}
& \mathrm{Q}=\mathrm{K} \text { i A } \\
& \mathrm{Q}=\text { inflection point flow rate }=0.55 \mathrm{~L} / \mathrm{s} \\
& \mathrm{i}=\text { slope of roadway }=0.02 \\
& \mathrm{~A}=\text { cross-sectional area }=\text { length } \times \text { thickness }=60 \mathrm{ft} \times 4.1 \mathrm{~cm}=18.3 \mathrm{~m} \\
& \mathrm{~K}=3.67 \mathrm{~cm} / \mathrm{s}
\end{aligned}
$$


It is of interest that this value for hydraulic conductivity $(3.67 \mathrm{~cm} / \mathrm{s})$ is similar to the value measured for pavement cores from this site in the laboratory $(2.63 \mathrm{~cm} / \mathrm{s})$. Errors in the storage calculations could be attributed to time delay in readings due to the 5-minute measurement interval.

\subsection{STORM VARIABILITY}

Many factors can influence the pollutant concentrations in the runoff from a rain event. These factors include the duration of the event, total runoff volume, rain intensity, roadway traffic during the storm, antecedent dry period, and the previous rain event (Irish et al., 1995). However, the concentrations in the runoff samples can also be misrepresentative of a storm. If a sample is front-weighted, it is expected to have a higher concentration than the entire storm would have had since the first flush of a rain event is generally the dirtiest. Other factors can also attribute to unusual concentrations, such as debris or road kill on the roadway near the collection location.

The rain intensity is an important factor in runoff from PFC. The PFC overlay can only accommodate light to medium rain, and rain events with high intensities cause sheet flow over the roadway. The sheet flow runoff is untreated when it reaches the edge of pavement; therefore, rain events with high rain intensities may have higher concentrations of pollutants which are normally reduced by the PFC overlay.

Traffic is expected to have an adverse effect on pollutant concentrations in runoff from conventional pavement because of the splash and spray from the roadway that generates wash off from the vehicles. The reduction of splash and spray on PFC could be another explanation for the reduction of pollutants in the runoff. Multiple regressions were performed on the conventional pavement data from Site 2 in attempt to establish the significant variables that affect pollutant concentrations, specifically TSS. The variables 
tried were cumulative flow, duration, average intensity (calculated by dividing total rain by the duration), antecedent dry period, and average vehicles per hour during storm. The vehicles during storm values were calculated using the daily traffic diurnal curve developed for Loop 360 and summing the number of vehicles over the time span of the rain event. The average vehicles per hour values were calculated by dividing the vehicles during storm by the storm duration. The original analysis did not find any of the variables to be significant. The variables pertain to the entire storm; however, many of the sampled rain events were too large to be completely sampled by the passive samplers and only the first flush of the storm was collected. To account for this, storms with rainfall greater than one inch were removed from the analysis. This regression analysis found cumulative flow to be a significant predictor of TSS concentration with a P-value of 0.09. This result could be attributed to the passive sampler because larger flows in a composite sampler would probably cause a cleaner sampler. The regression equation for TSS versus cumulative flow (in Liters) is shown below.

$$
\text { TSS }=-16.9+0.06 *(\text { Cumulative Flow })
$$




\section{CHAPTER 5 SUMMARY AND CONCLUSIONS}

Porous asphalt overlays are becoming increasingly popular as the properties of the pavement are better understood. The interconnected voids in the overlay provide valuable wet driving safety benefits and reduction of road noise. Porous asphalt overlays also reduce the concentration of pollutants in stormwater runoff.

Site 1 on Loop 360 has been monitored for almost 4 years (since March 2004), which includes six months before the PFC overlay was applied (in October 2004). The runoff from the PFC overlay was compared to the conventional asphalt runoff. PFC significantly reduced the concentrations of pollutants in the particulate form, specifically total suspended solids, total phosphate, copper, lead and zinc. Most dissolved constituents were not significantly affected by the PFC, except for dissolved copper which significantly increased in the runoff from PFC. The only significant trends of increasing concentrations were for TSS, total copper and dissolved copper from the automatic sampler. However, the trend in TSS concentrations is due to one high concentration rain event and should be confirmed. A gradual decline in runoff water quality is expected as the overlay ages and the pores clog. The relationship between rainfall and runoff depth from the PFC at Site 1 revealed a runoff coefficient of 0.95 for the overlay.

Site 2 on Loop 360 was installed to provide direct comparison of runoff from conventional asphalt and PFC. The same significantly reduced constituents were found at this site as well as dissolved zinc. $\mathrm{NO}_{3}{ }^{+} / \mathrm{NO}_{2}$ and dissolved copper were found to be significantly greater in the runoff from PFC. The particulate and dissolved forms of the heavy metals were analyzed, and the particulate concentrations were consistently lower in the runoff from PFC. The dissolved concentrations make up the majority of the total 
concentrations found in the runoff from PFC. Copper, lead, and zinc are present primarily in the particulate form, and therefore, experience large overall reductions.

The longevity of water quality benefits is not yet determined and should be the focus of future research. This research should include continued monitoring at both sites to determine the functional life of the pavement. A larger data set would also be useful for finding significant predictors of pollutant concentrations in the runoff from PFC. The particle removal processes and other mechanisms for reduction of pollutant concentrations also require more understanding. Further analysis of the runoff hydrograph and the storage of the pavement could be used to establish a change in the hydraulic conductivity. Over time, a decline in hydraulic conductivity would indicate clogging, and therefore, the storage analysis could be used to analyze the degree of clogging in the pavement without coring. 


\section{Appendix A Time Series of Constituents at Site 1}

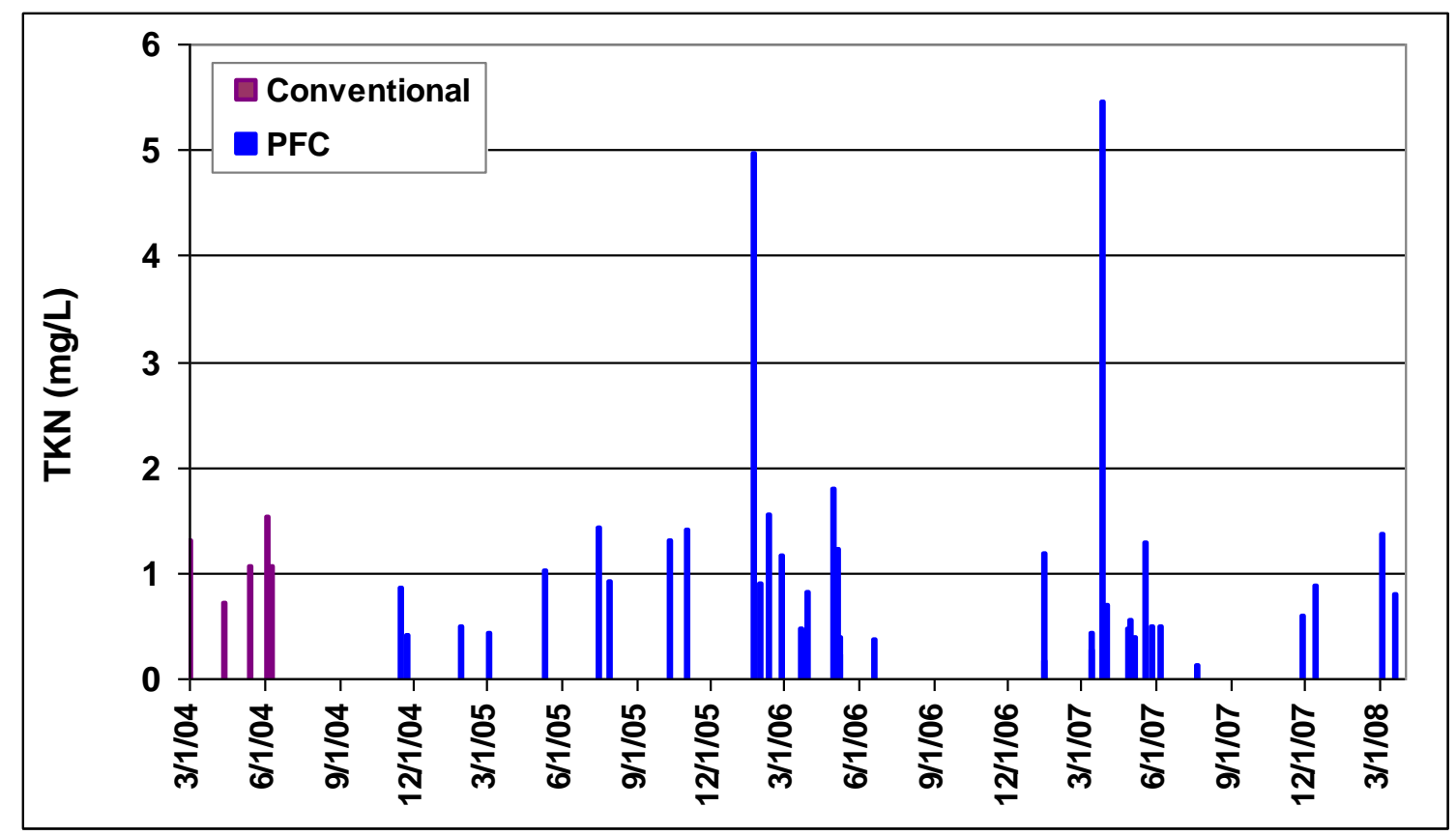

Figure A-1: TKN concentration over time at Site 1

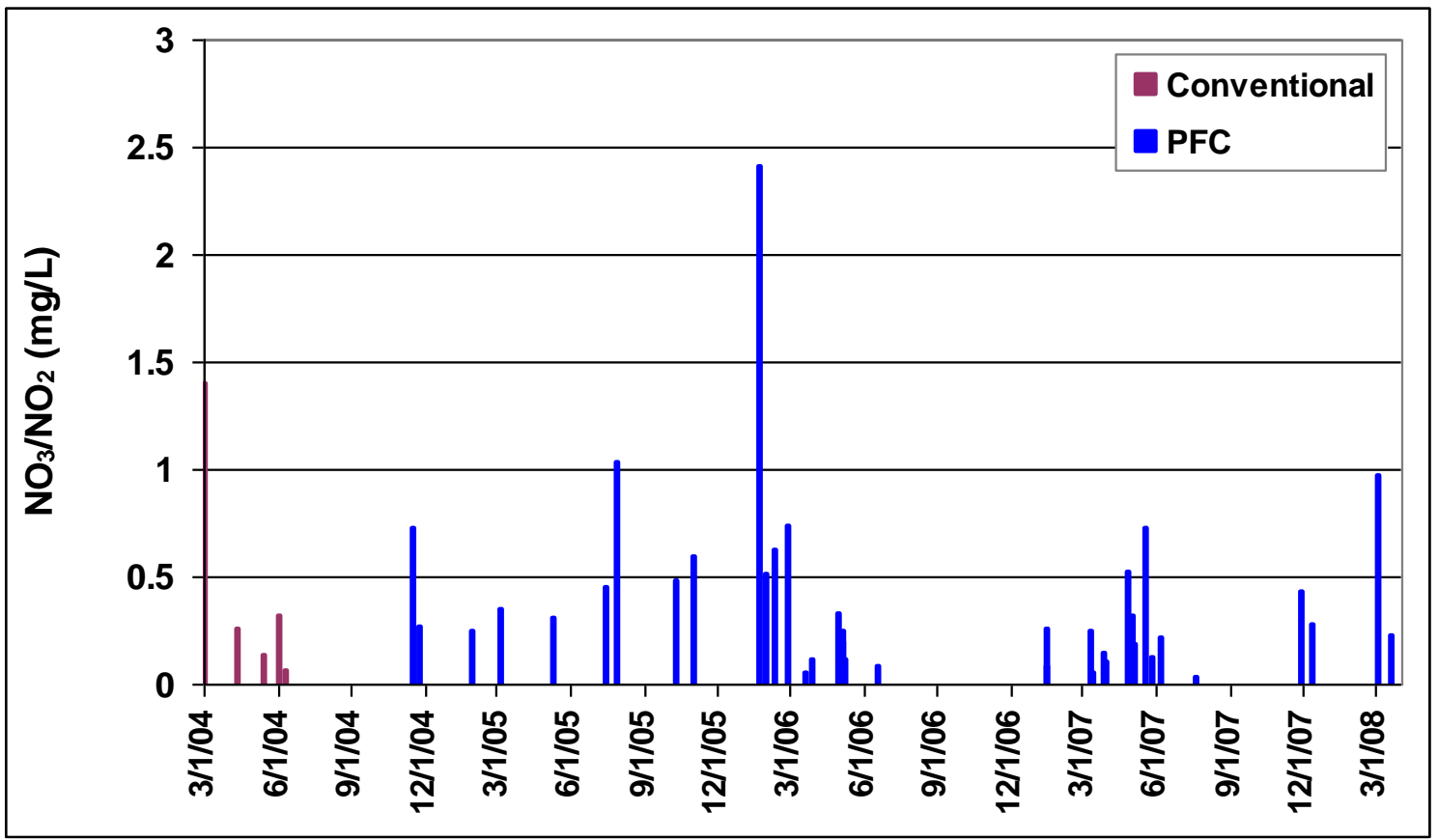

Figure A-2: $\mathrm{NO}_{3}{ }^{+} / \mathrm{NO}_{2}$ concentration over time at Site 1 


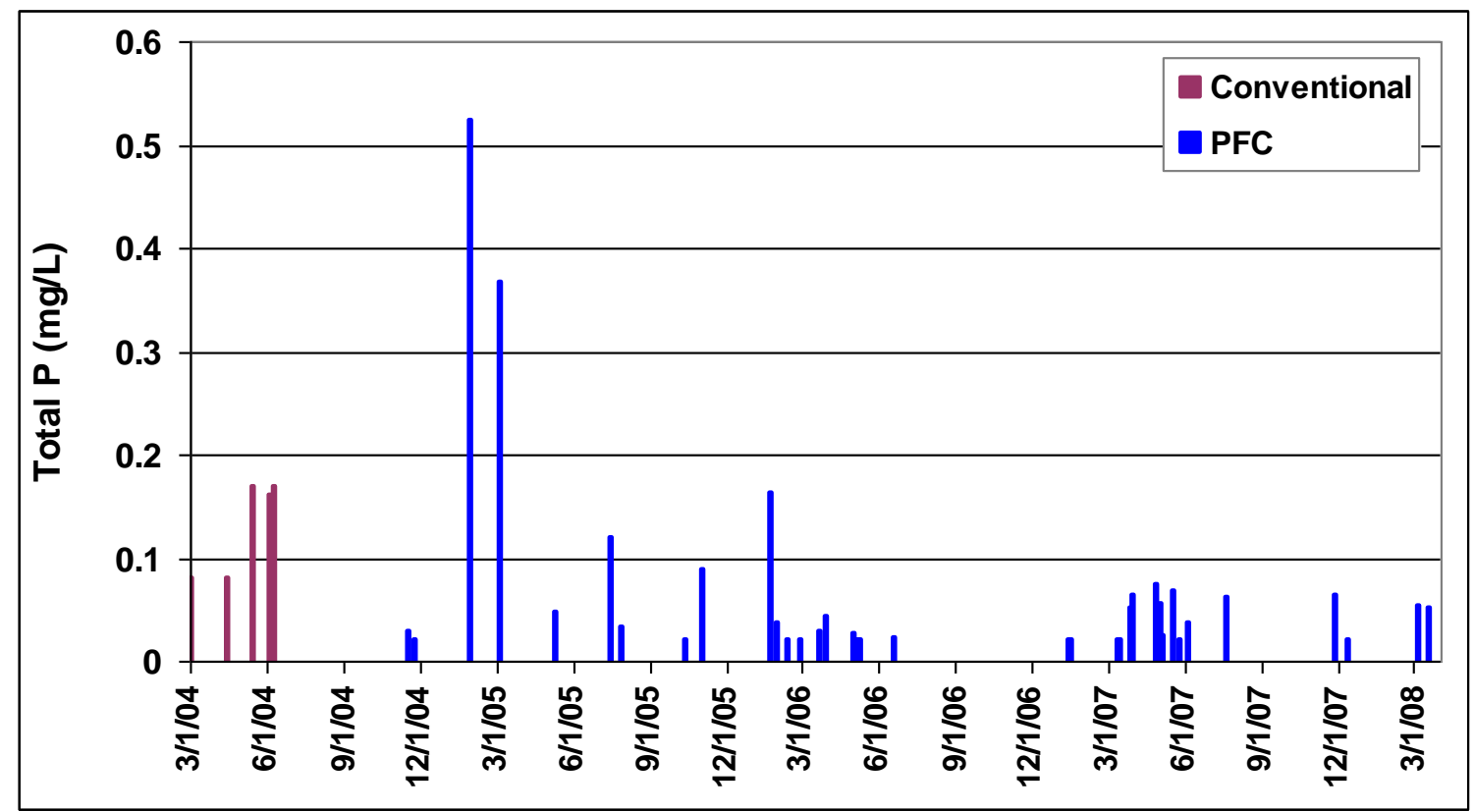

Figure A-3: Total $\mathbf{P}$ over time at Site 1*

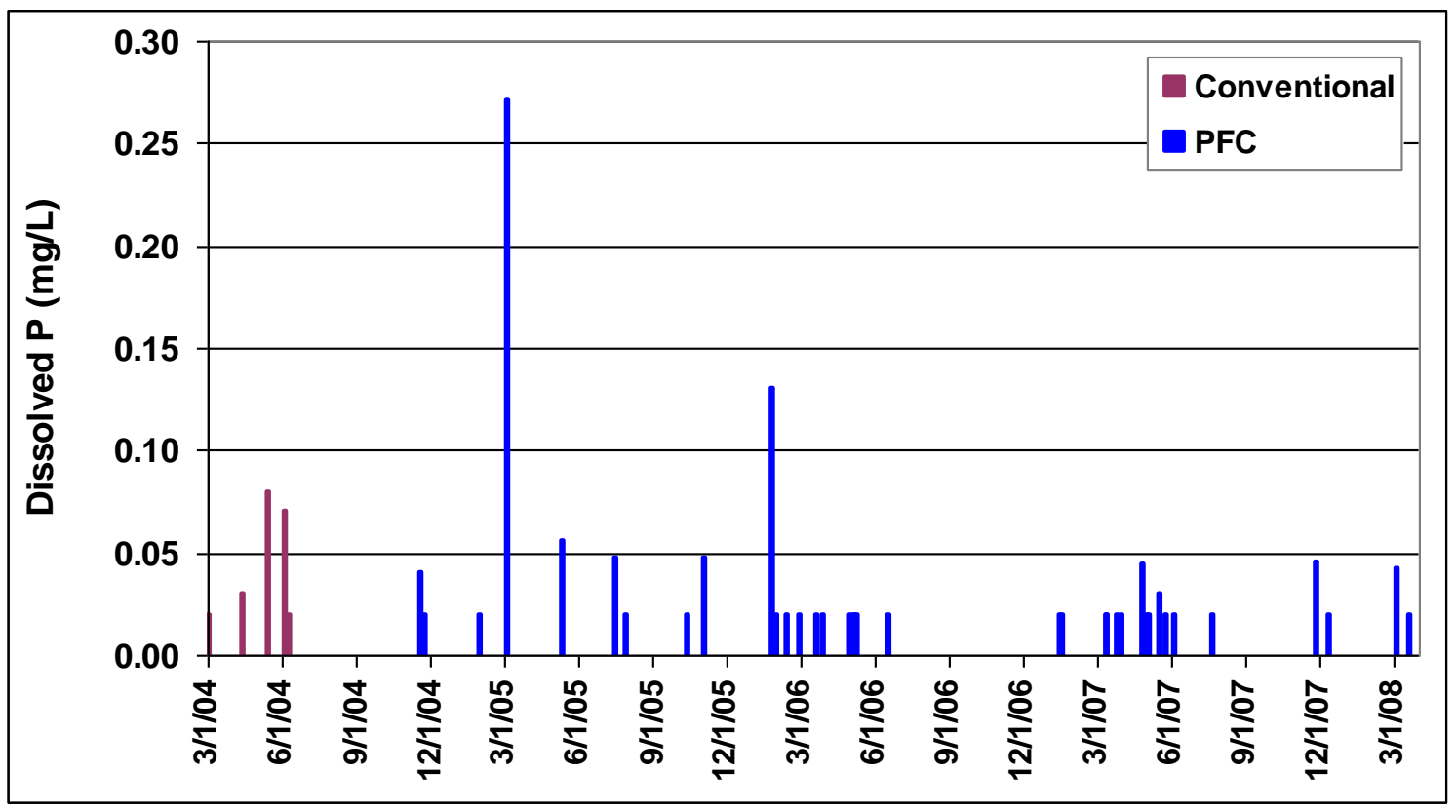

Figure A-4: Dissolved P over time at Site 1* 


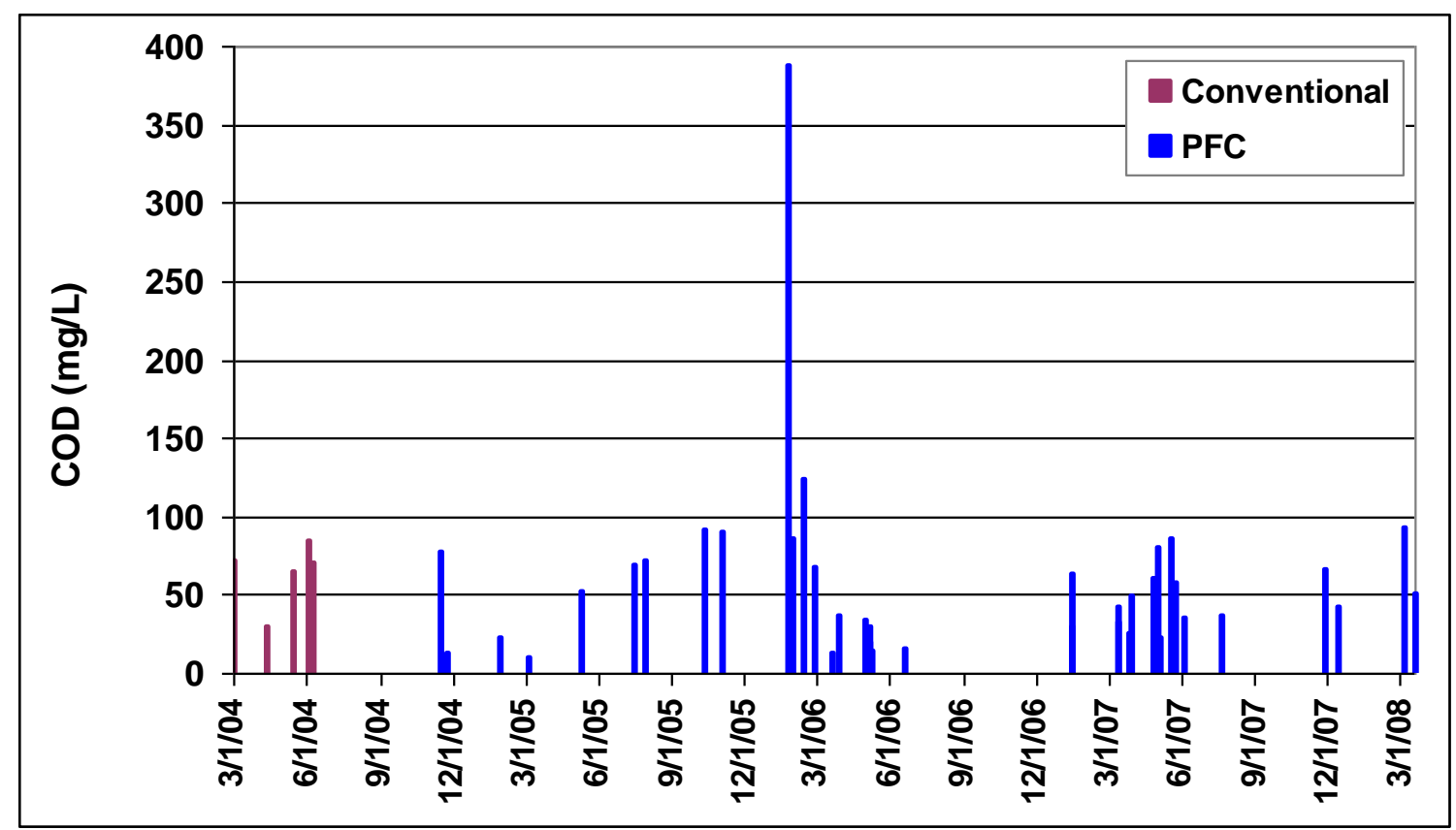

Figure A-5: Chemical oxygen demand (COD) over time at Site 1

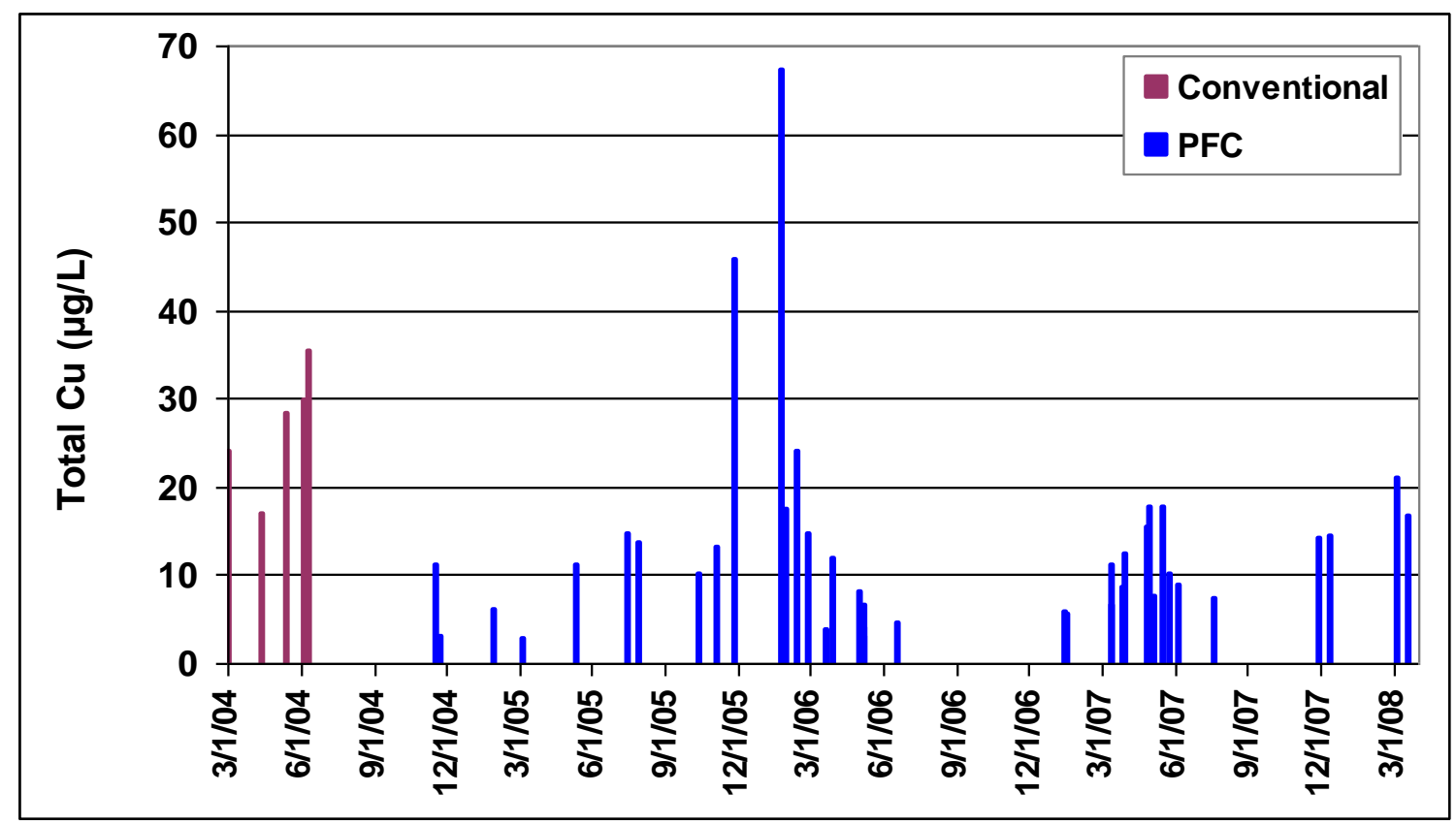

Figure A-6: Total copper over time at Site 1 


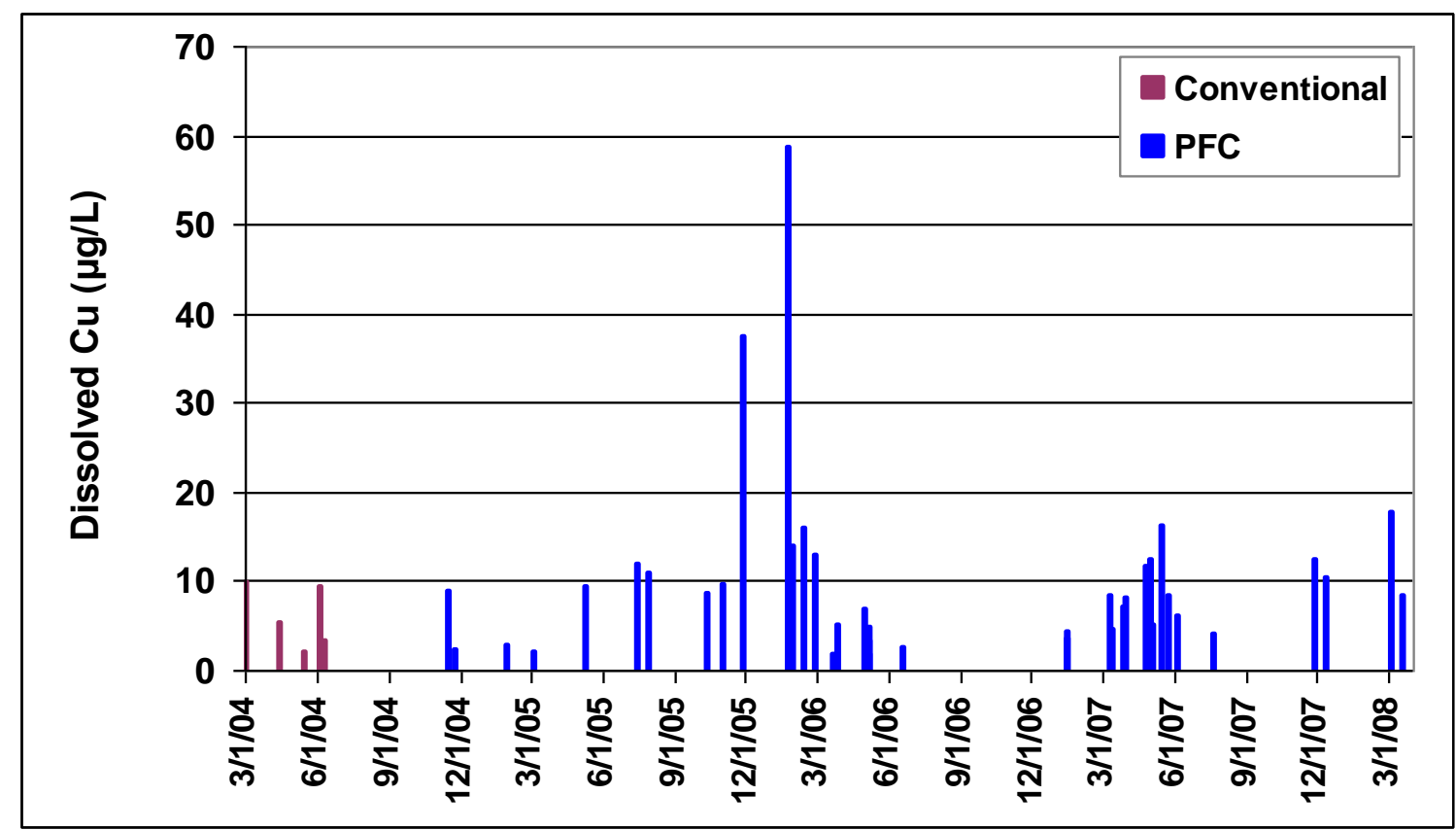

Figure A-7: Dissolved copper over time at Site 1

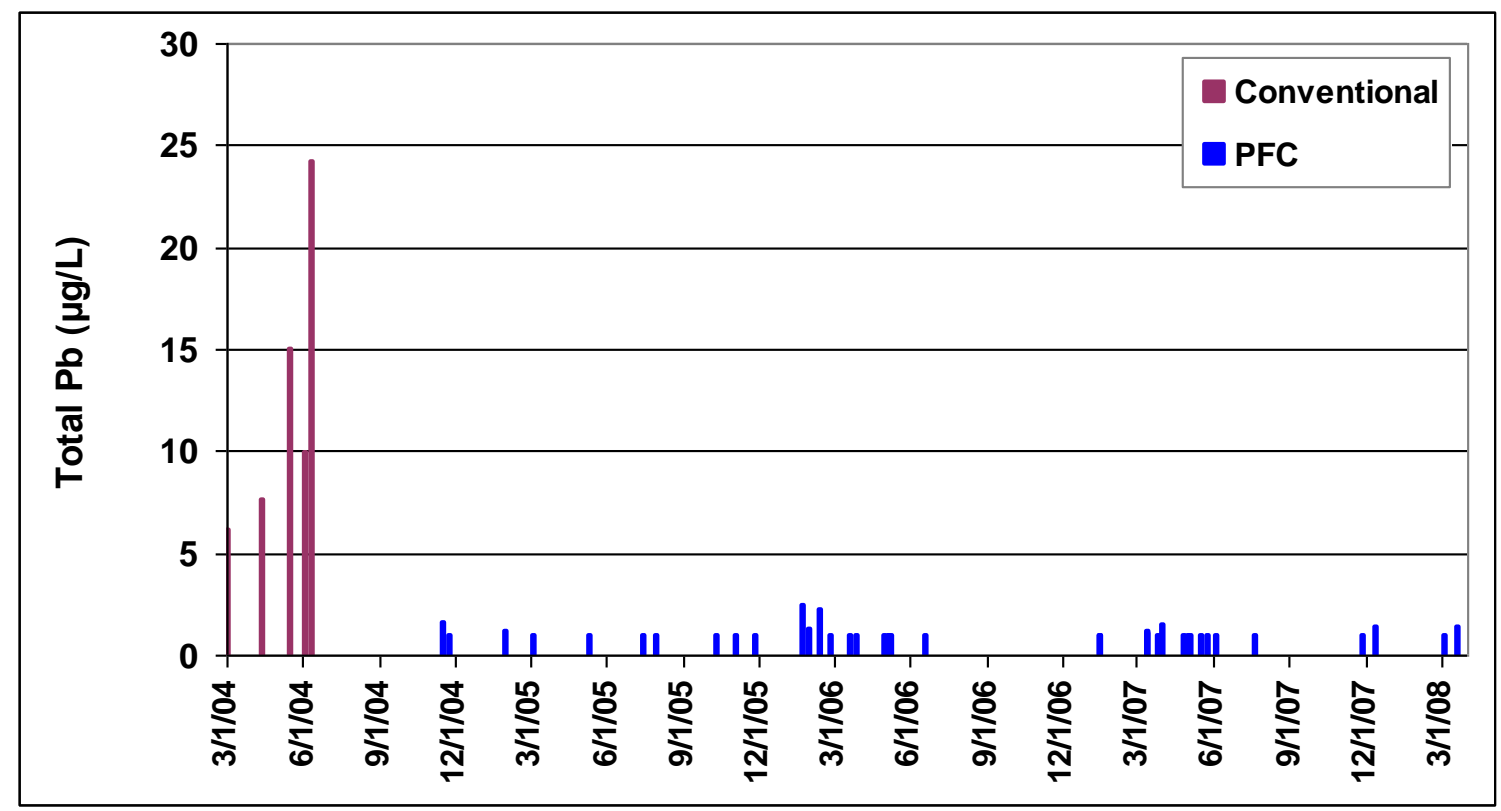

Figure A-8: Total lead over time at Site 1* 


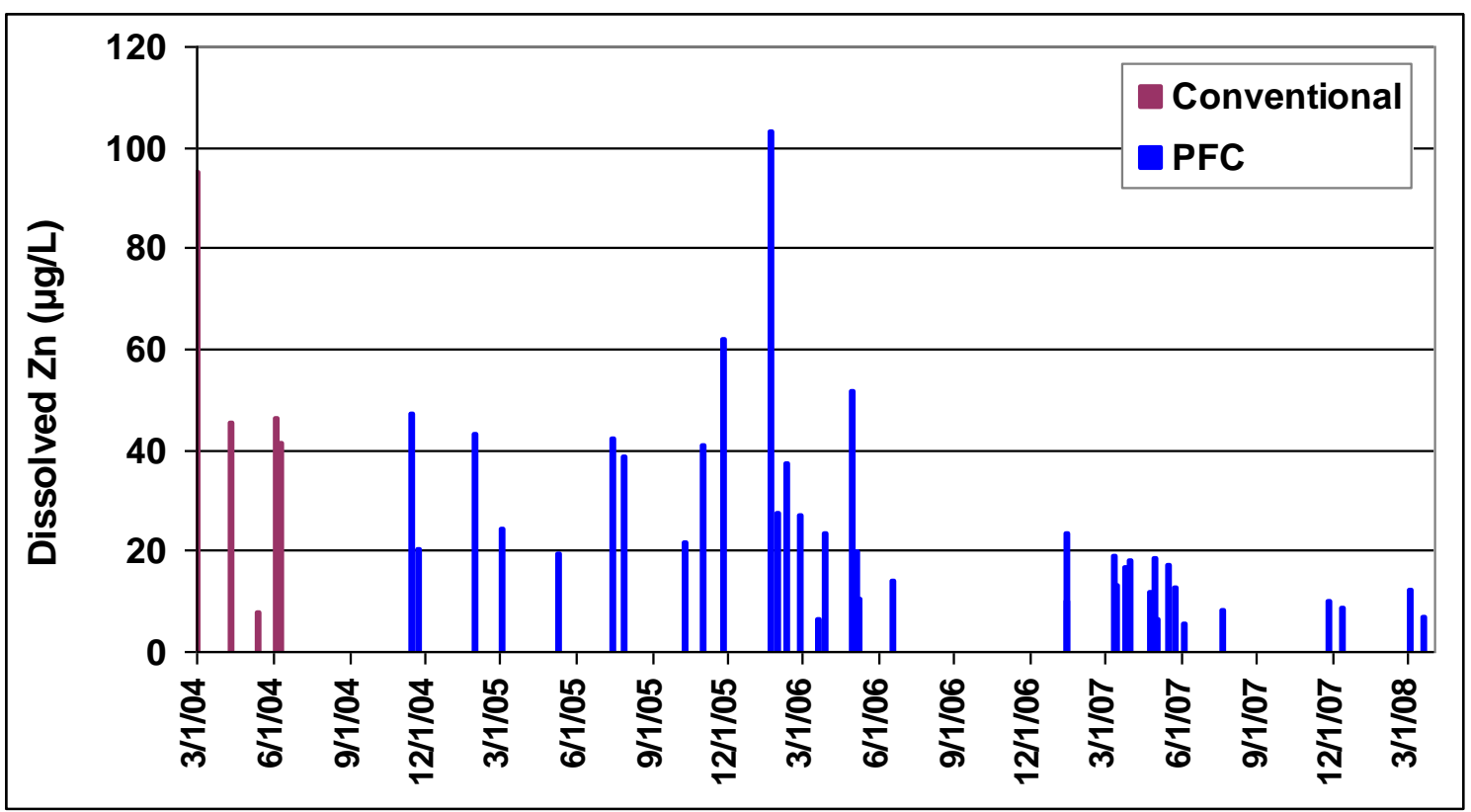

Figure A-9: Dissolved zinc over time at Site 1

*Not detected values are represented as detection limit in time series figures 


\section{Appendix B Significant Trends for Constituents at Site 1}

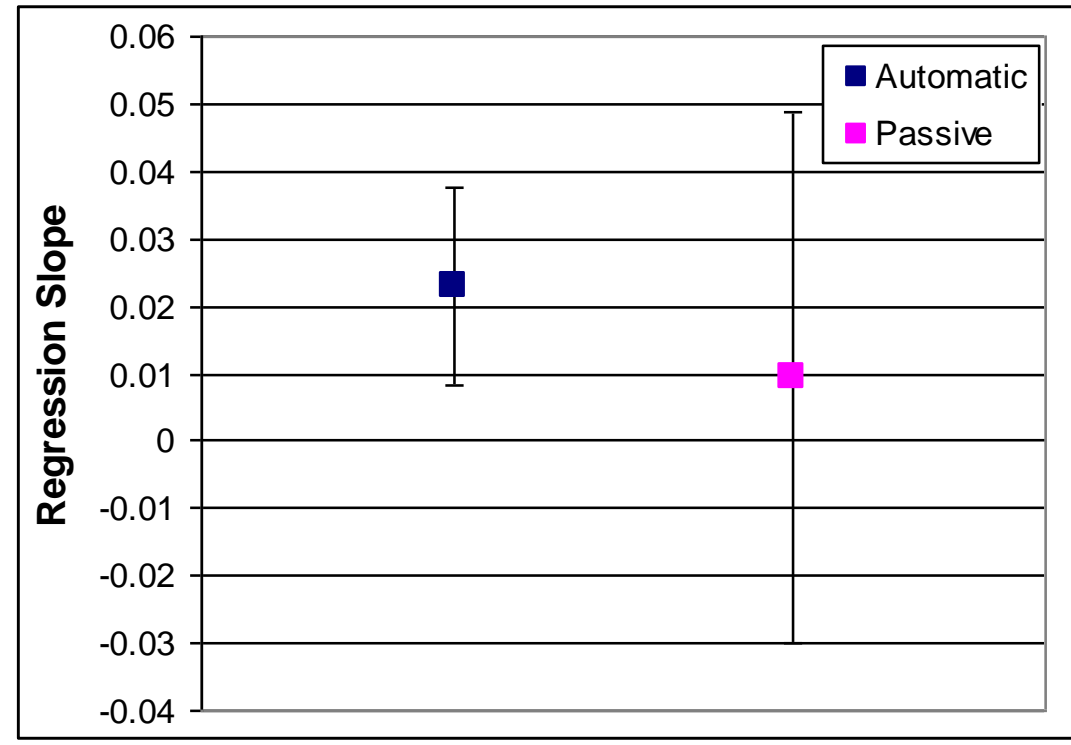

Figure B-1: 95\% confidence intervals for regression slopes of total copper

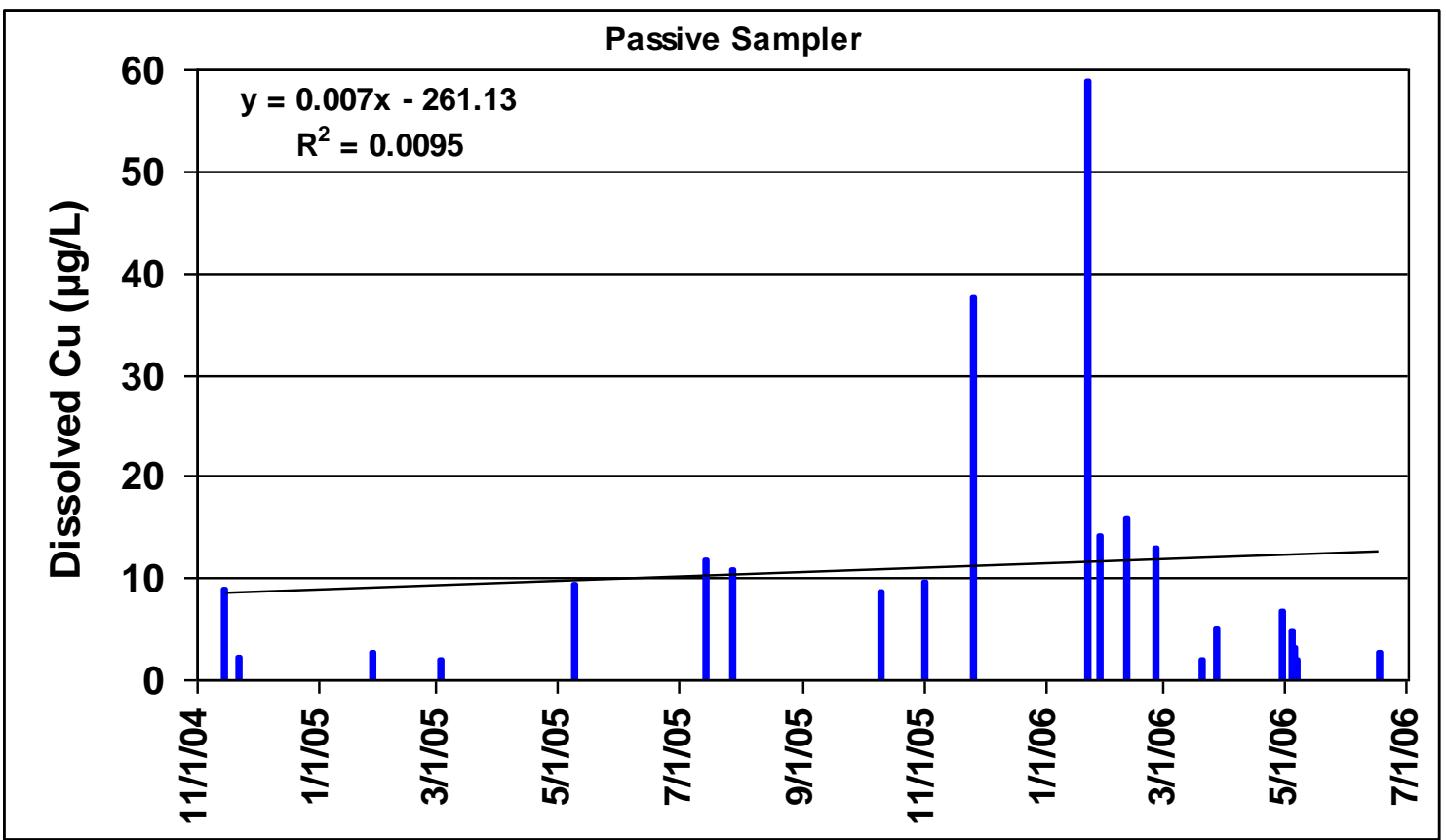

Figure B-2: Linear regression of dissolved copper concentrations from passive sampler of PFC at Site 1 


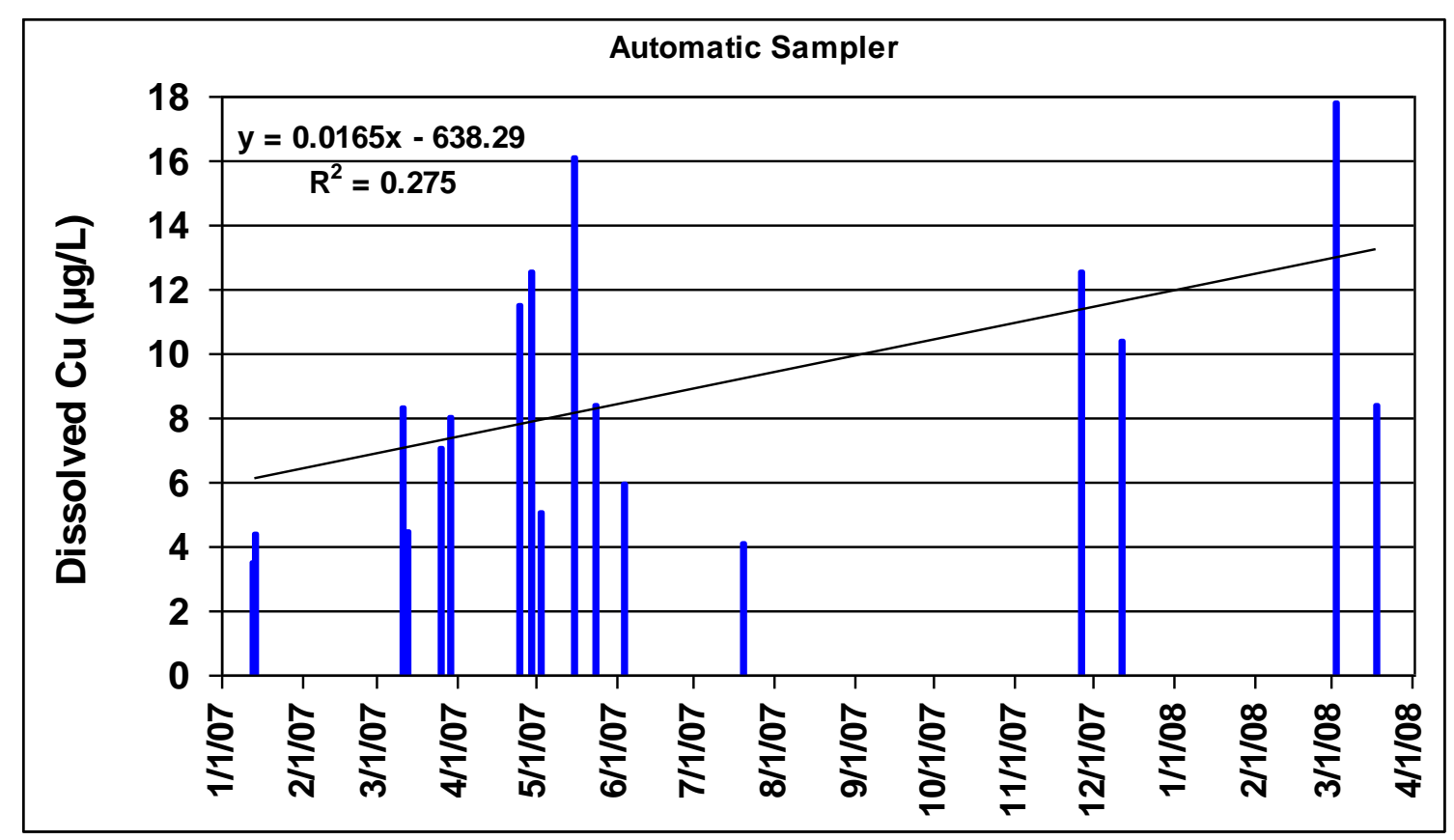

Figure B-3: Linear regression of dissolved copper concentrations from automatic sampler at Site 1

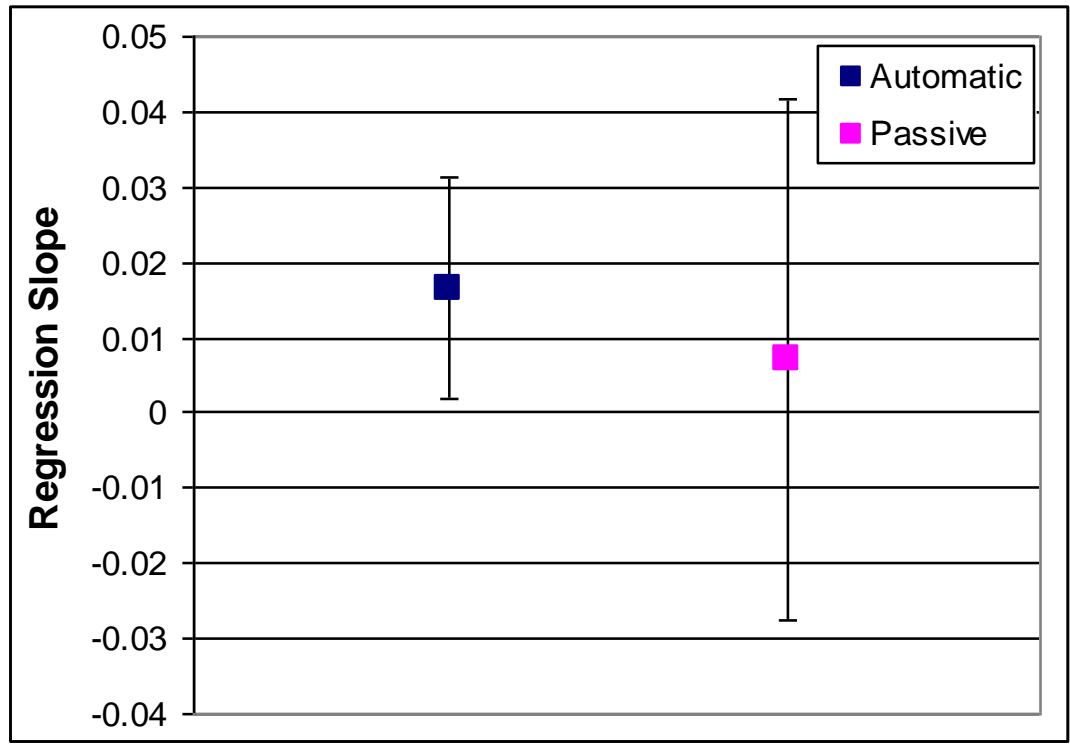

Figure B-4: 95\% confidence intervals for regression slopes of dissolved copper 


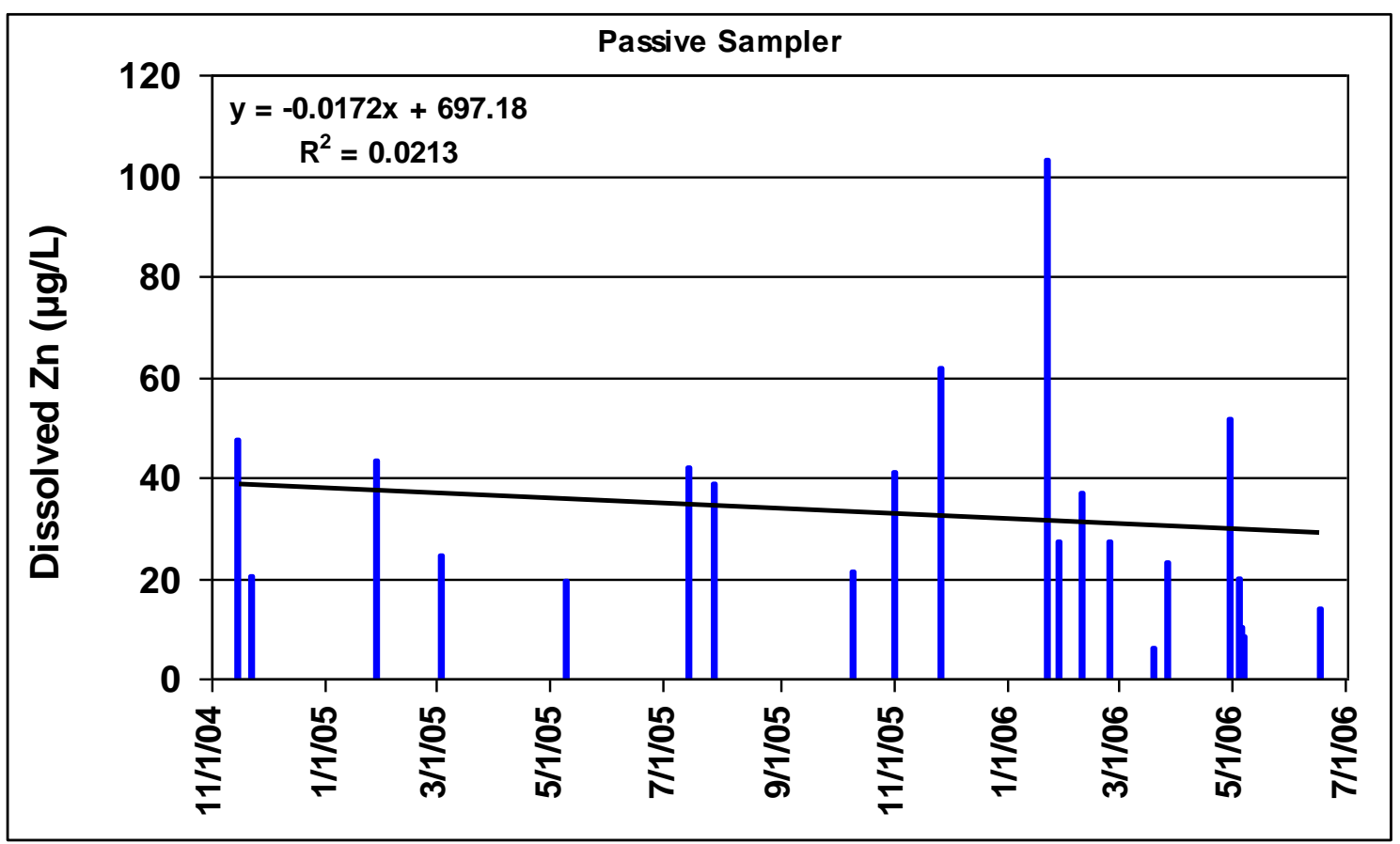

Figure B-5: Linear regression of dissolved zinc concentrations from passive sampler of PFC at Site 1

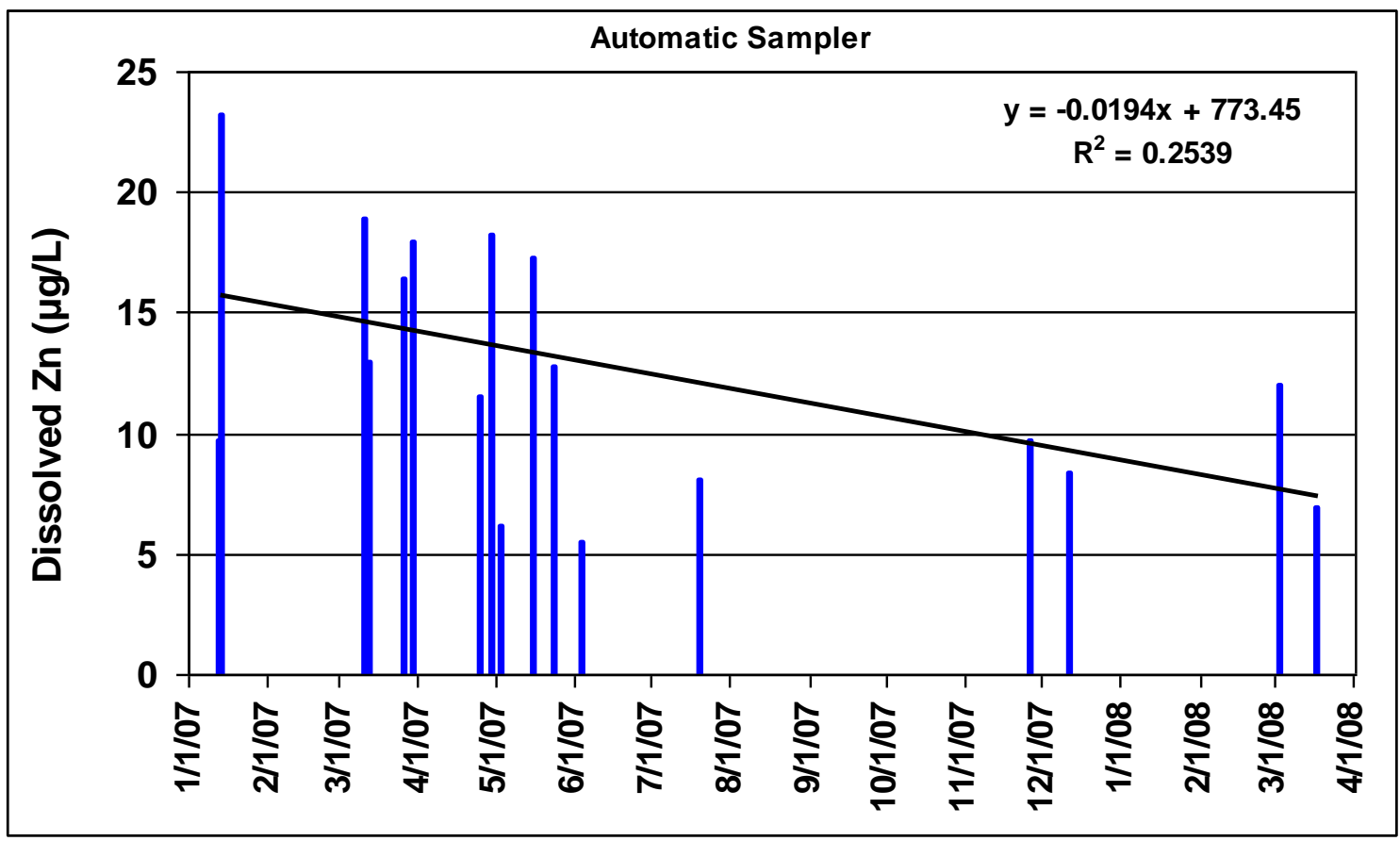

Figure B-6: Linear regression of dissolved zinc concentrations from automatic sampler of PFC at Site 1 


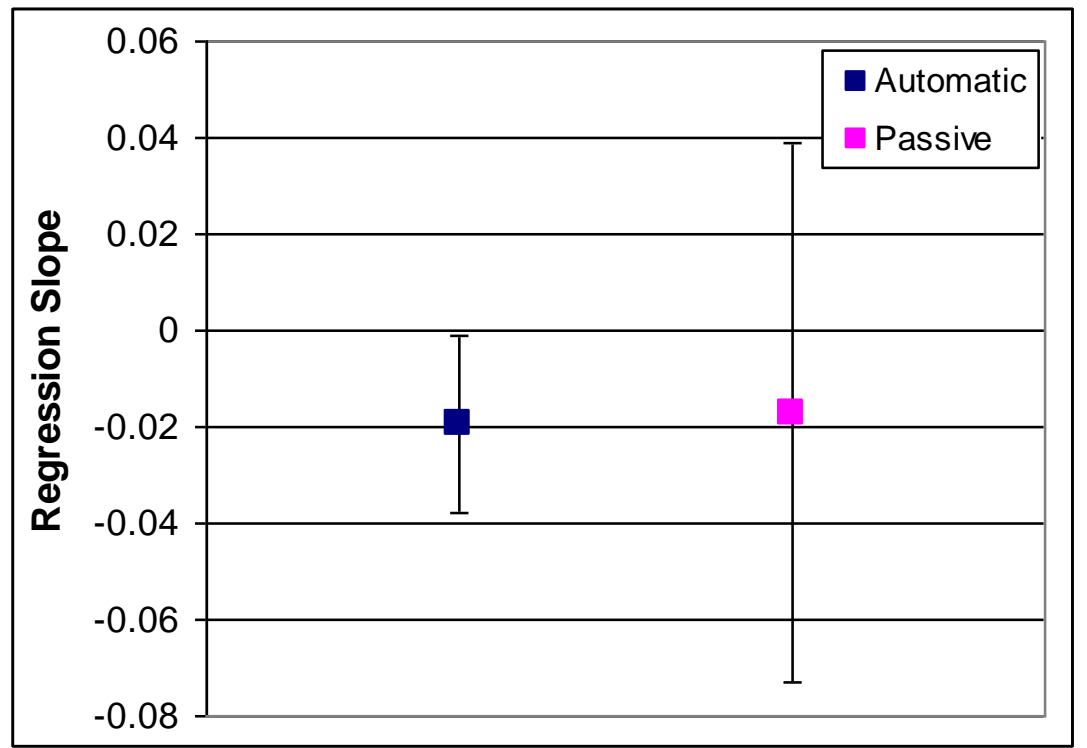

Figure B-7: 95\% confidence intervals for regression slopes of dissolved zinc 
Appendix C Hydrographs for Each Monitored Rain Event 
January 13,2007

Loop 360 near Bull Creek, Austin, Texas

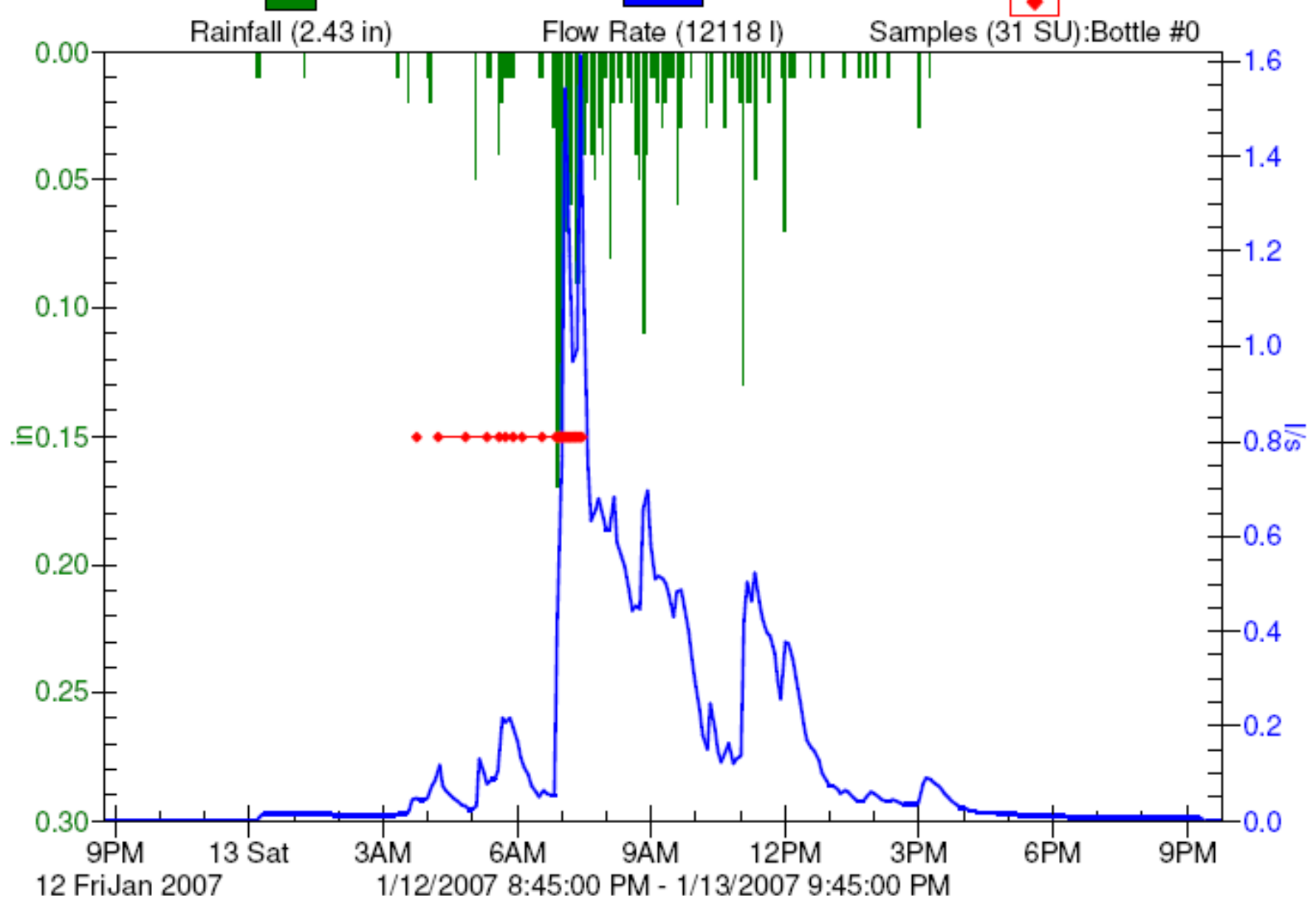


January 14, 2007

Loop 360 near Bull Creek, Austin, Texas

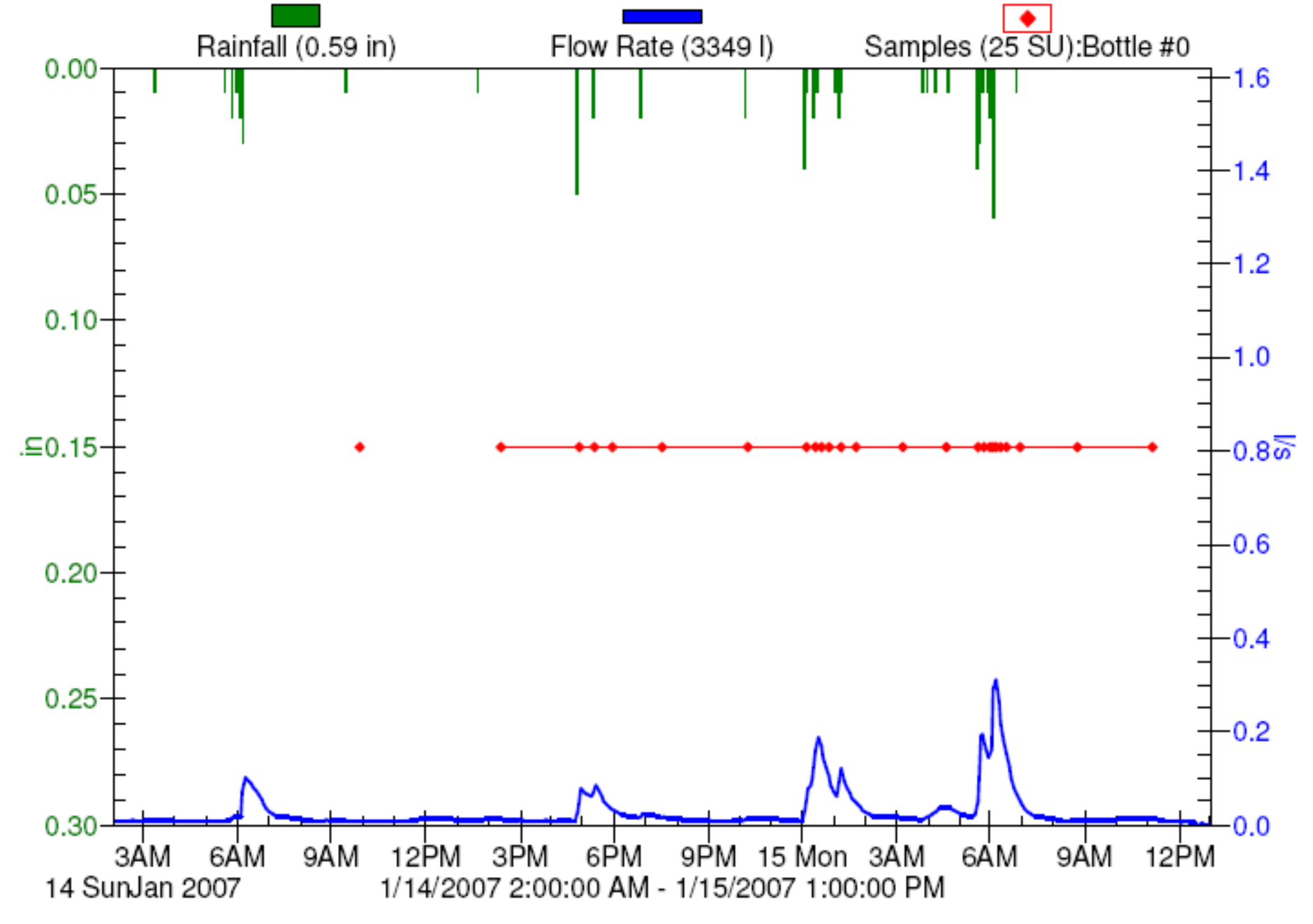


March 11, 2007

Loop 360 near Bull Creek, Austin, Texas

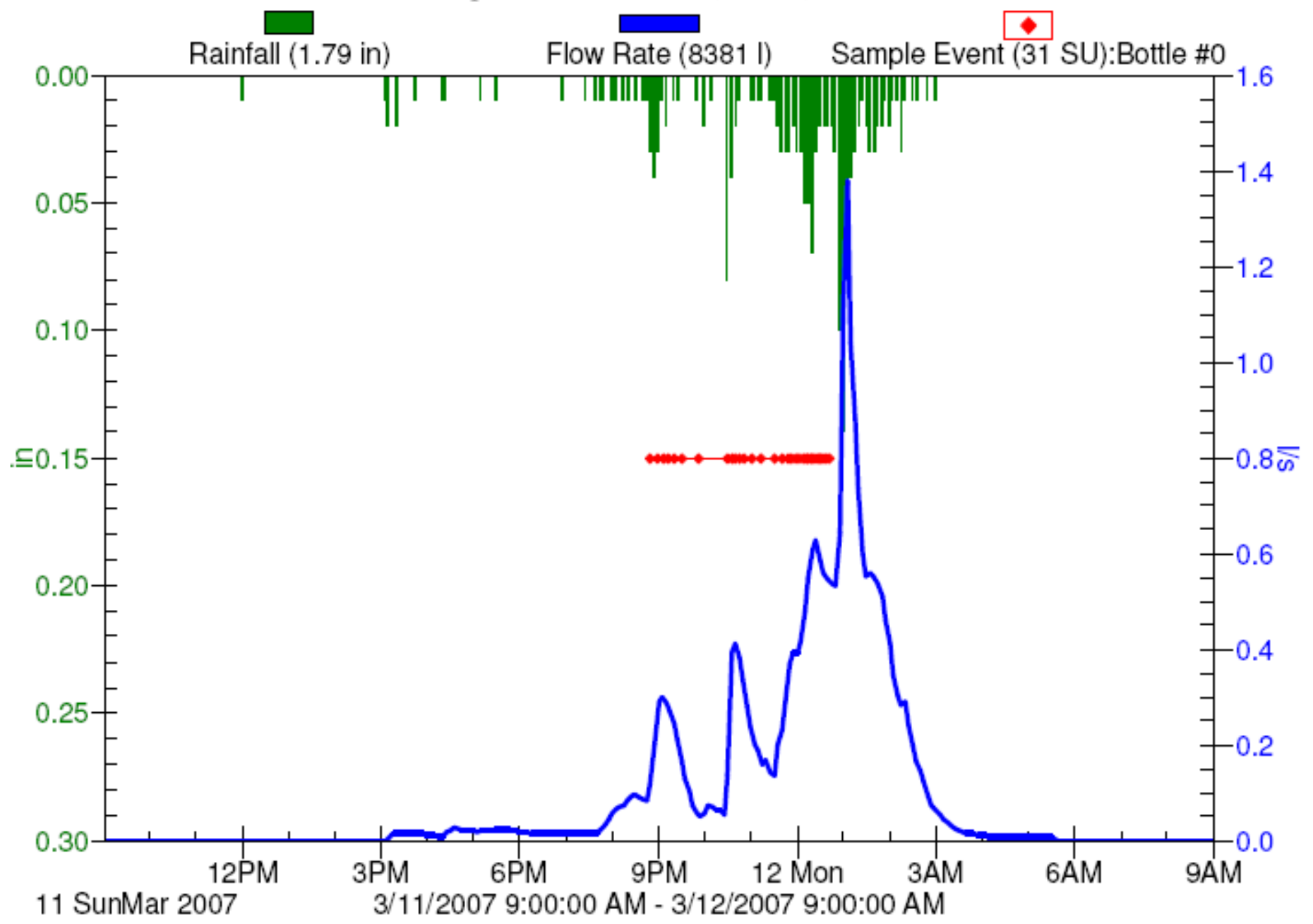


March 13, 2007

Loop 360 near Bull Creek, Austin, Texas

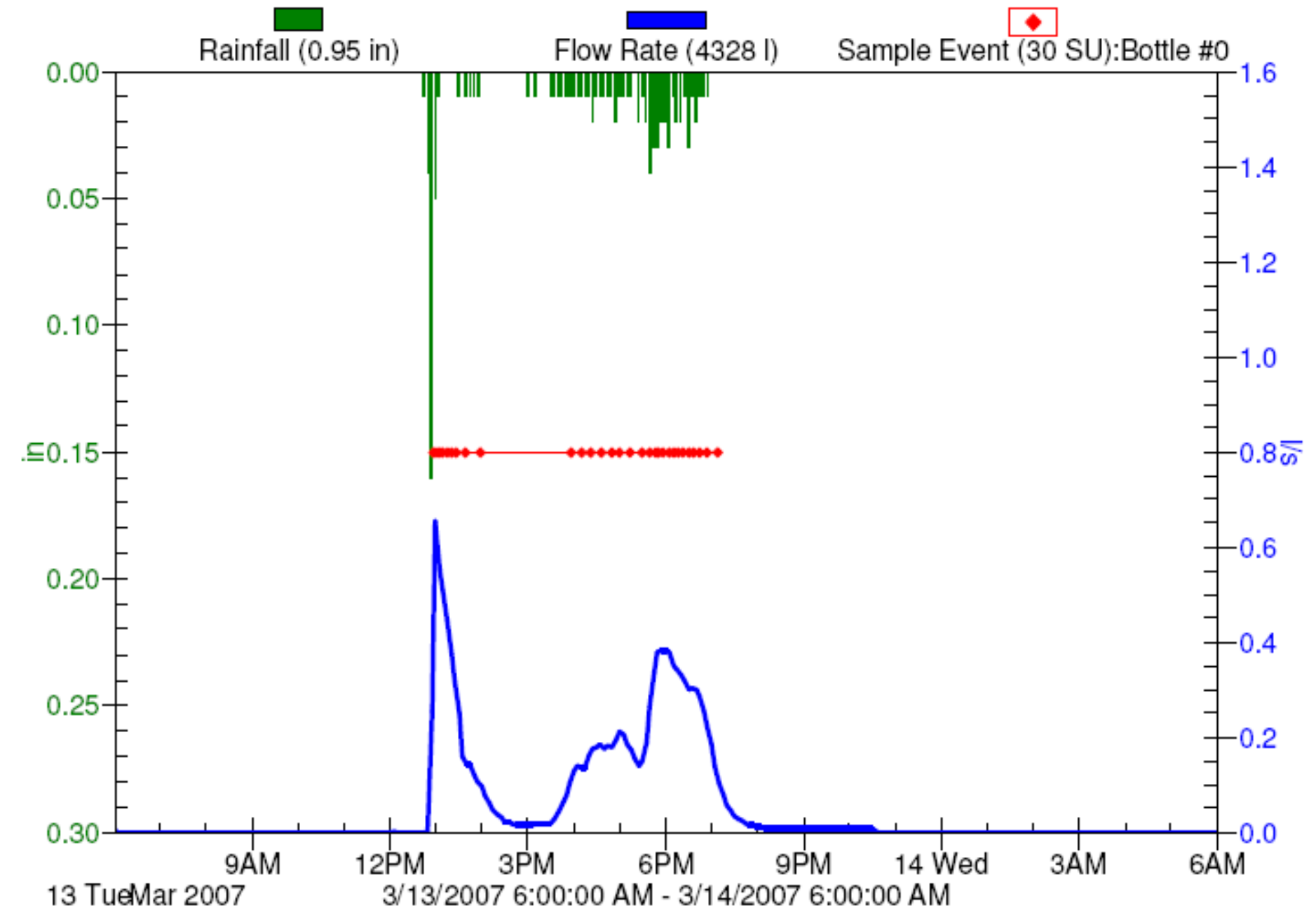


March 26, 2007

Loop 360 near Bull Creek, Austin, Texas

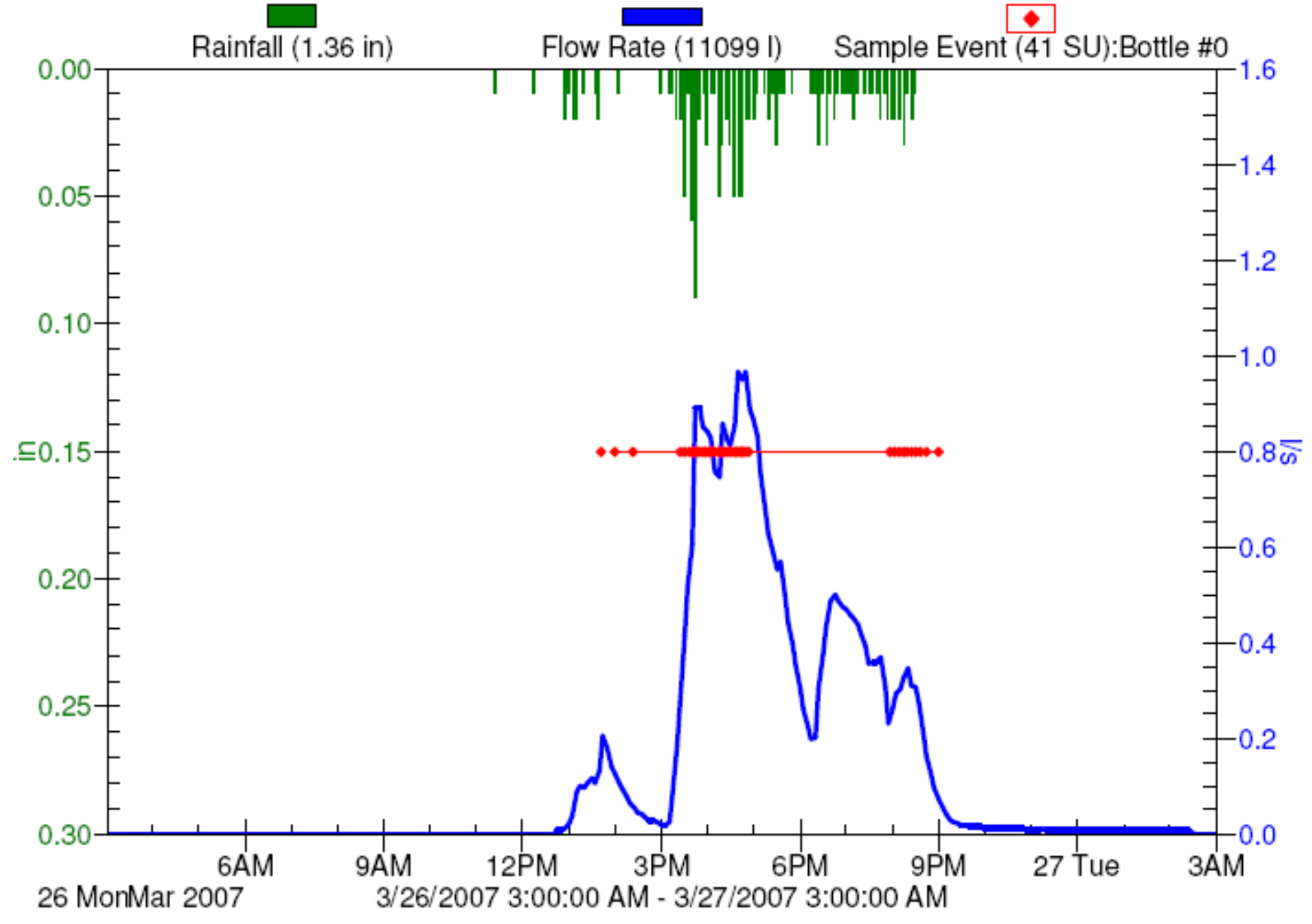


March 30, 2007

Loop 360 near Bull Creek, Austin, Texas

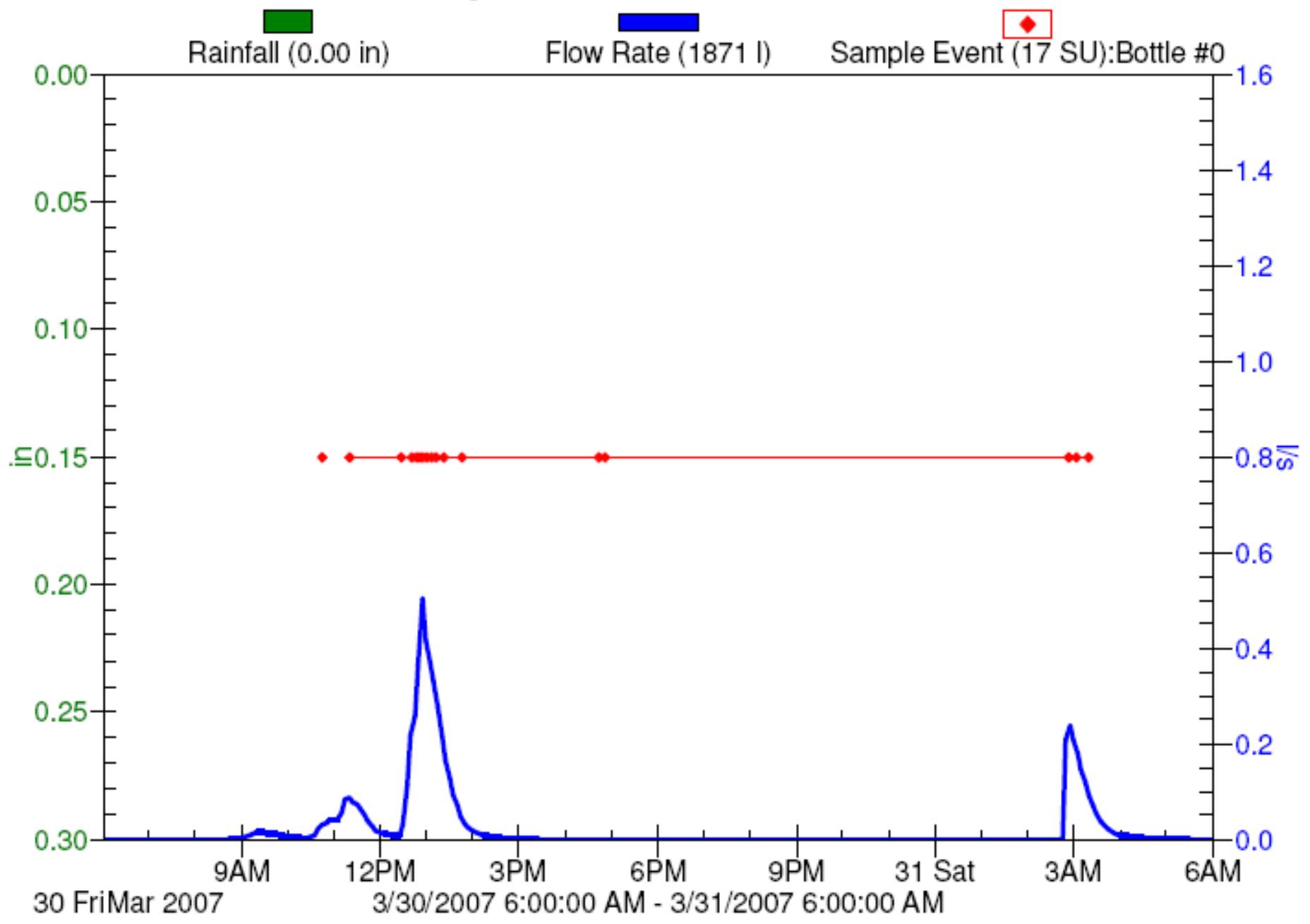


April 24, 2007

Loop 360 near Bull Creek, Austin, Texas

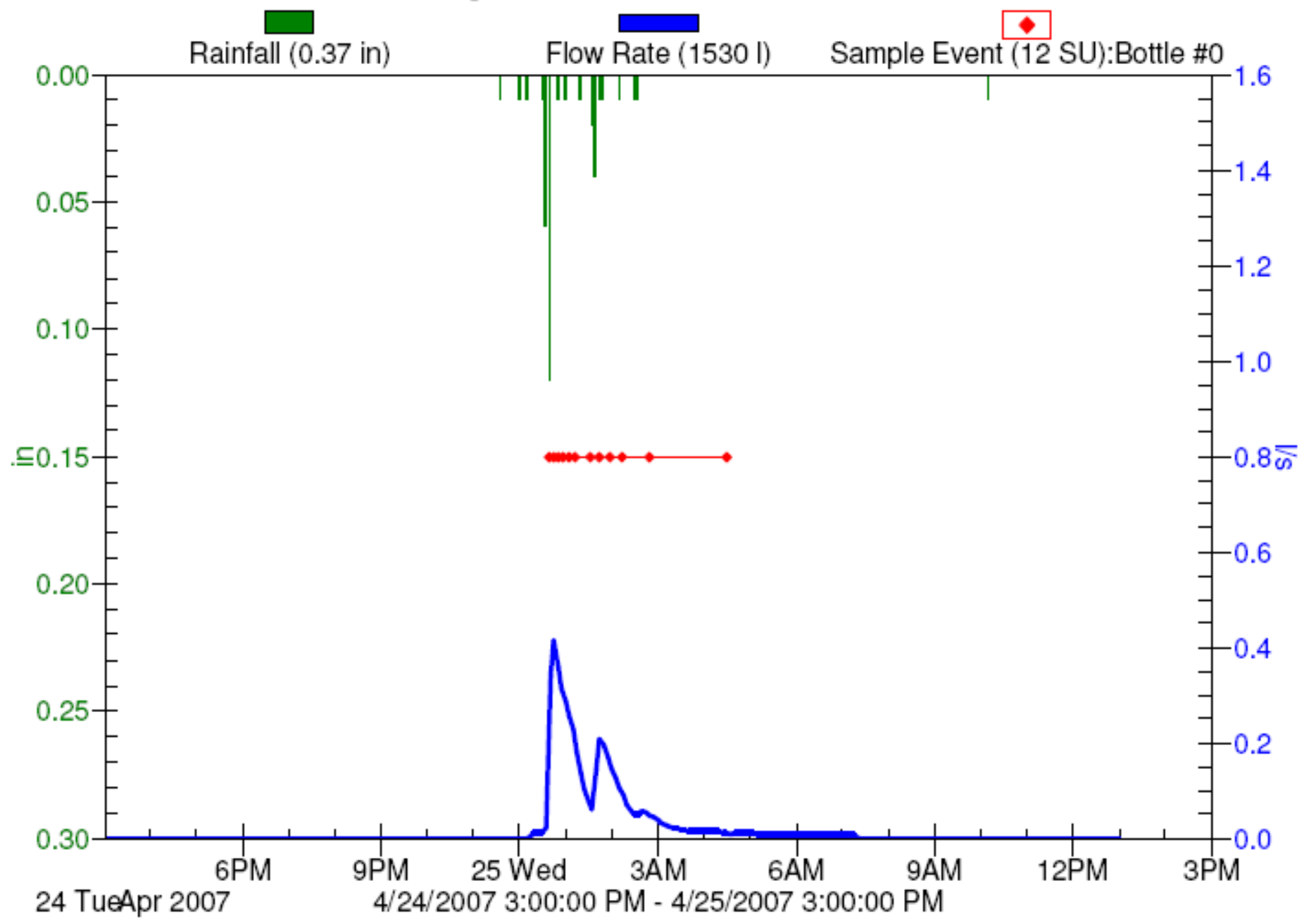


April 30, 2007

Loop 360 near Bull Creek, Austin, Texas

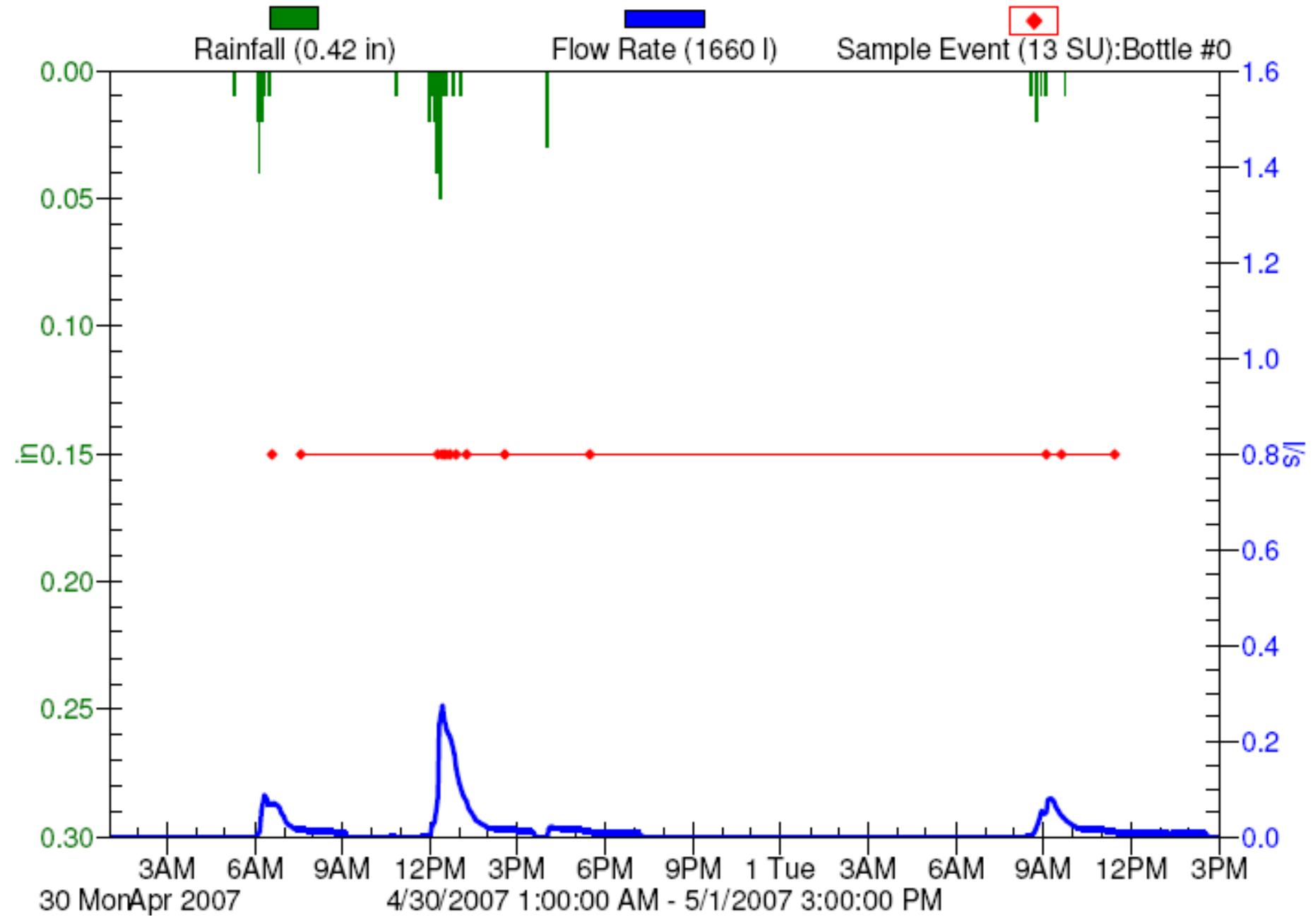




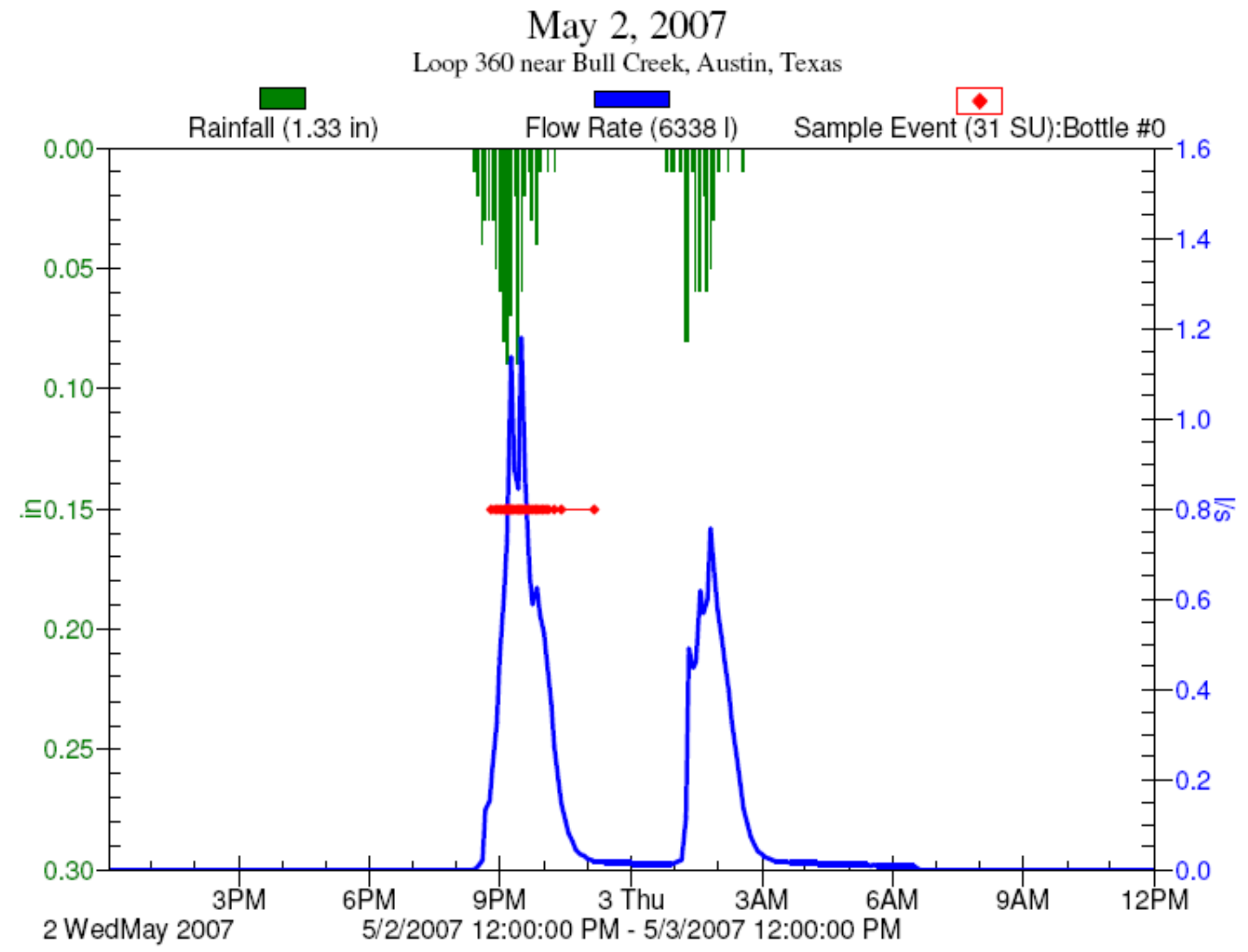


May 16, 2007

Loop 360 near Bull Creek, Austin, Texas

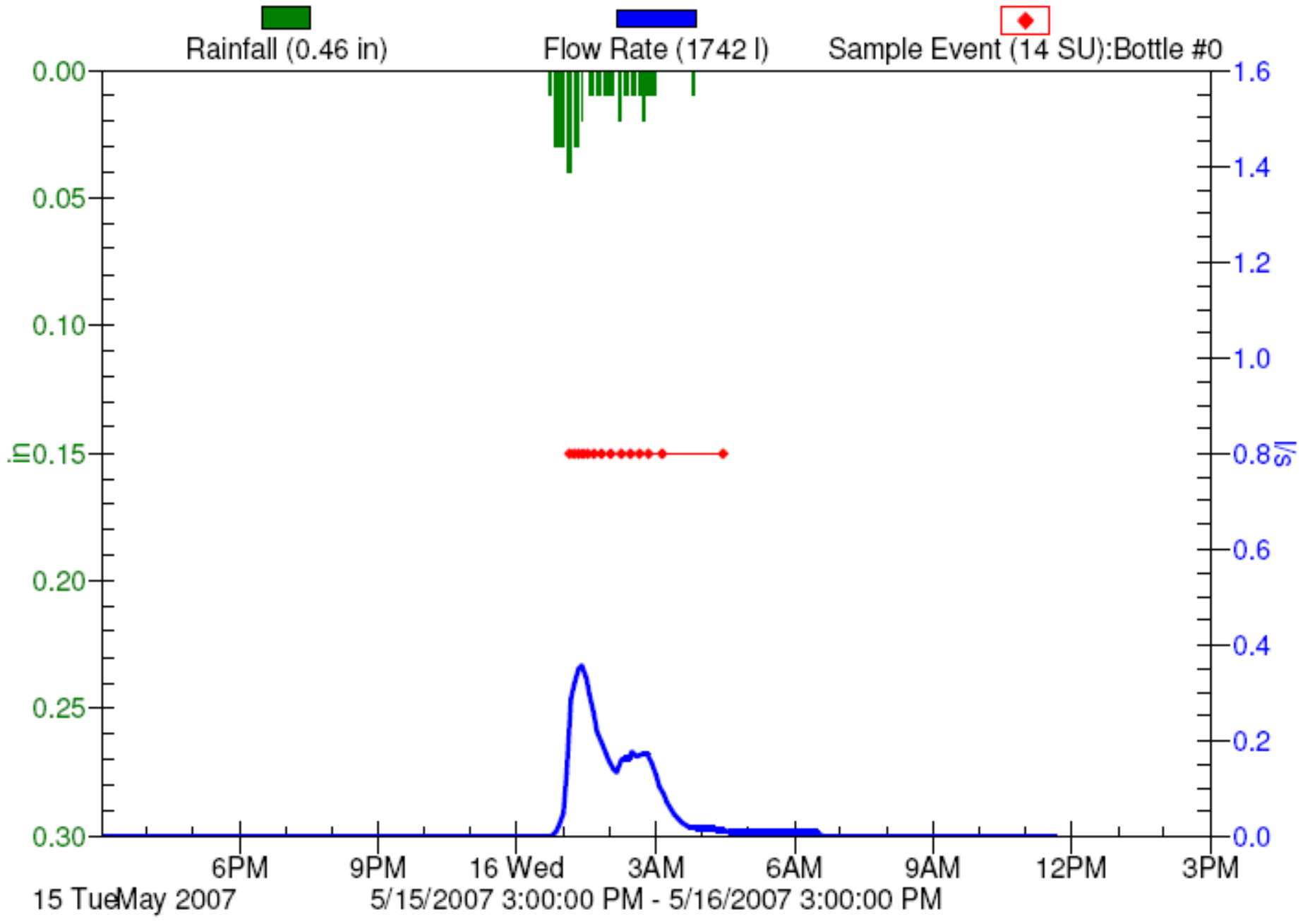




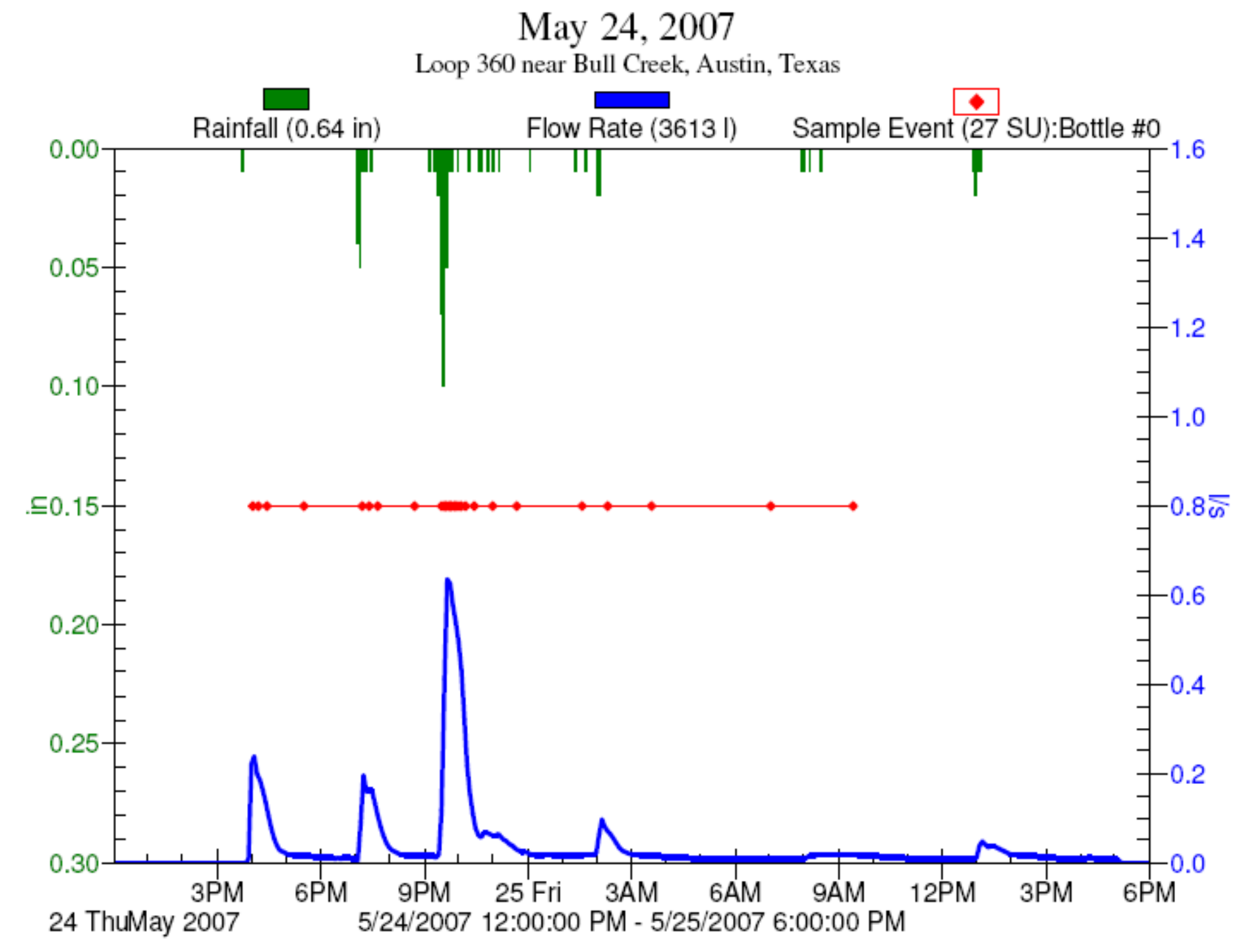


June 3, 2007

Loop 360 near Bull Creek, Austin, Texas

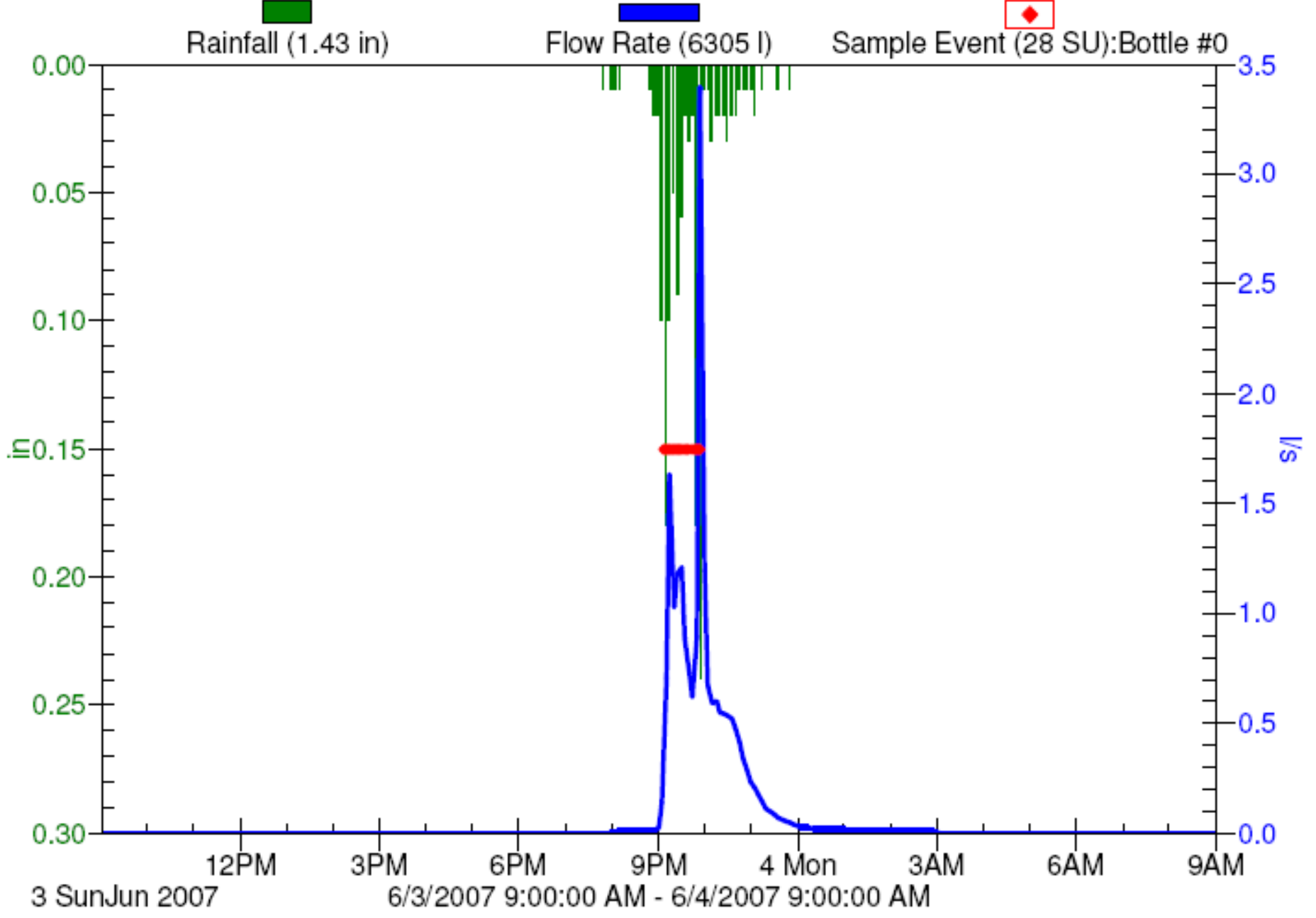


July 20, 2007

Loop 360 near Bull Creek, Austin, Texas

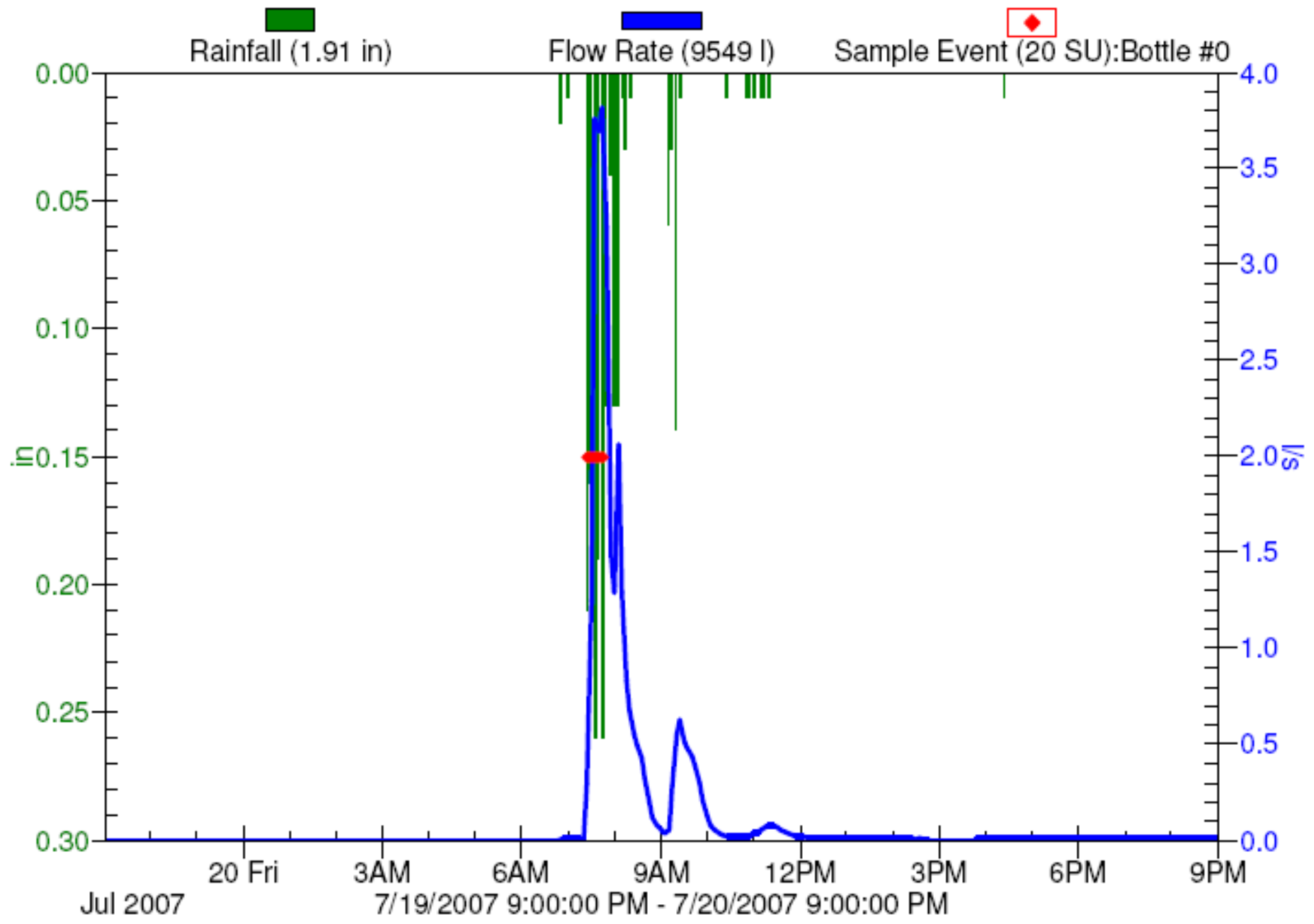


November 24, 2007

Loop 360 near Bull Creek, Austin, Texas

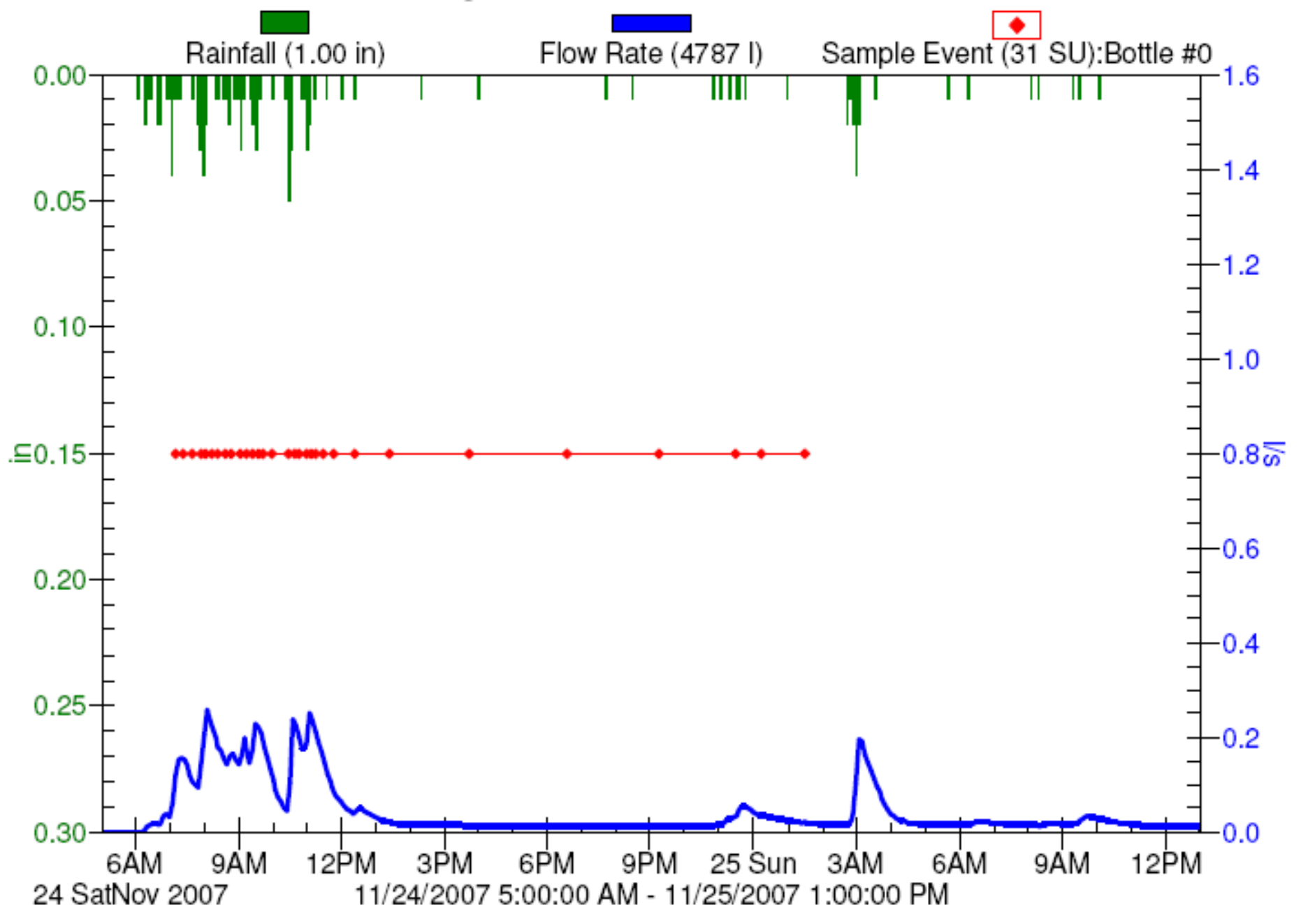


December 11, 2007

Loop 360 near Bull Creek, Austin, Texas

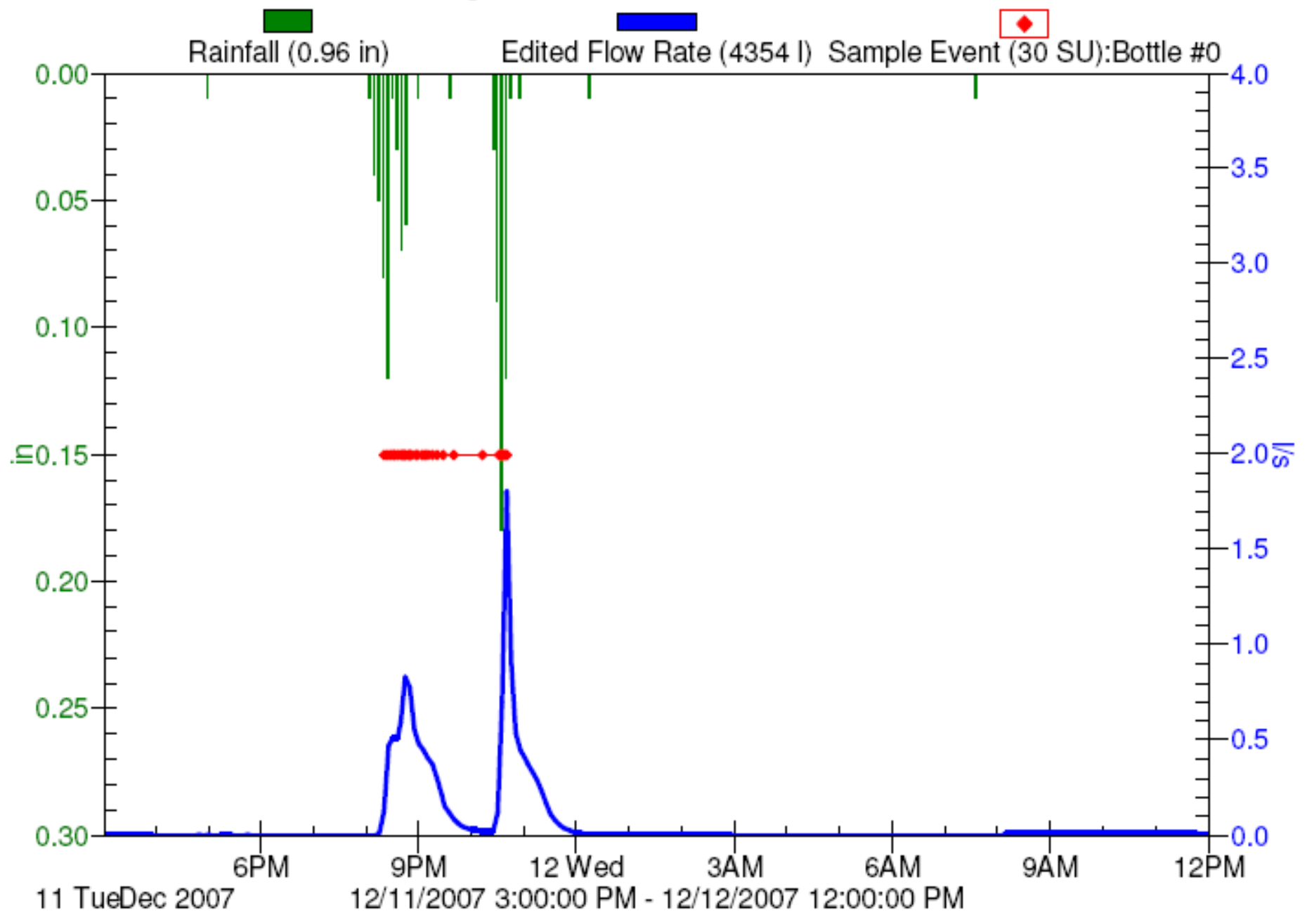




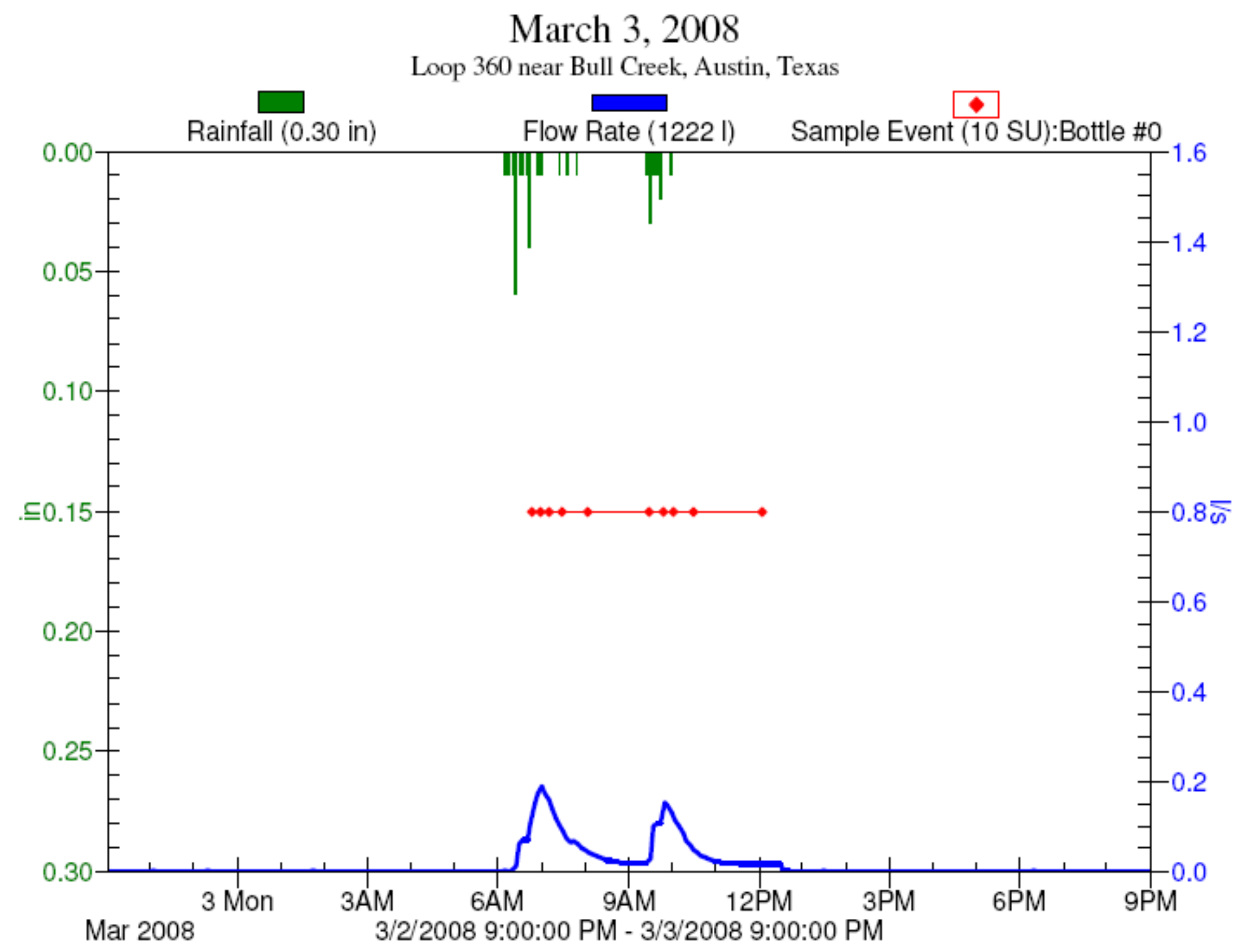




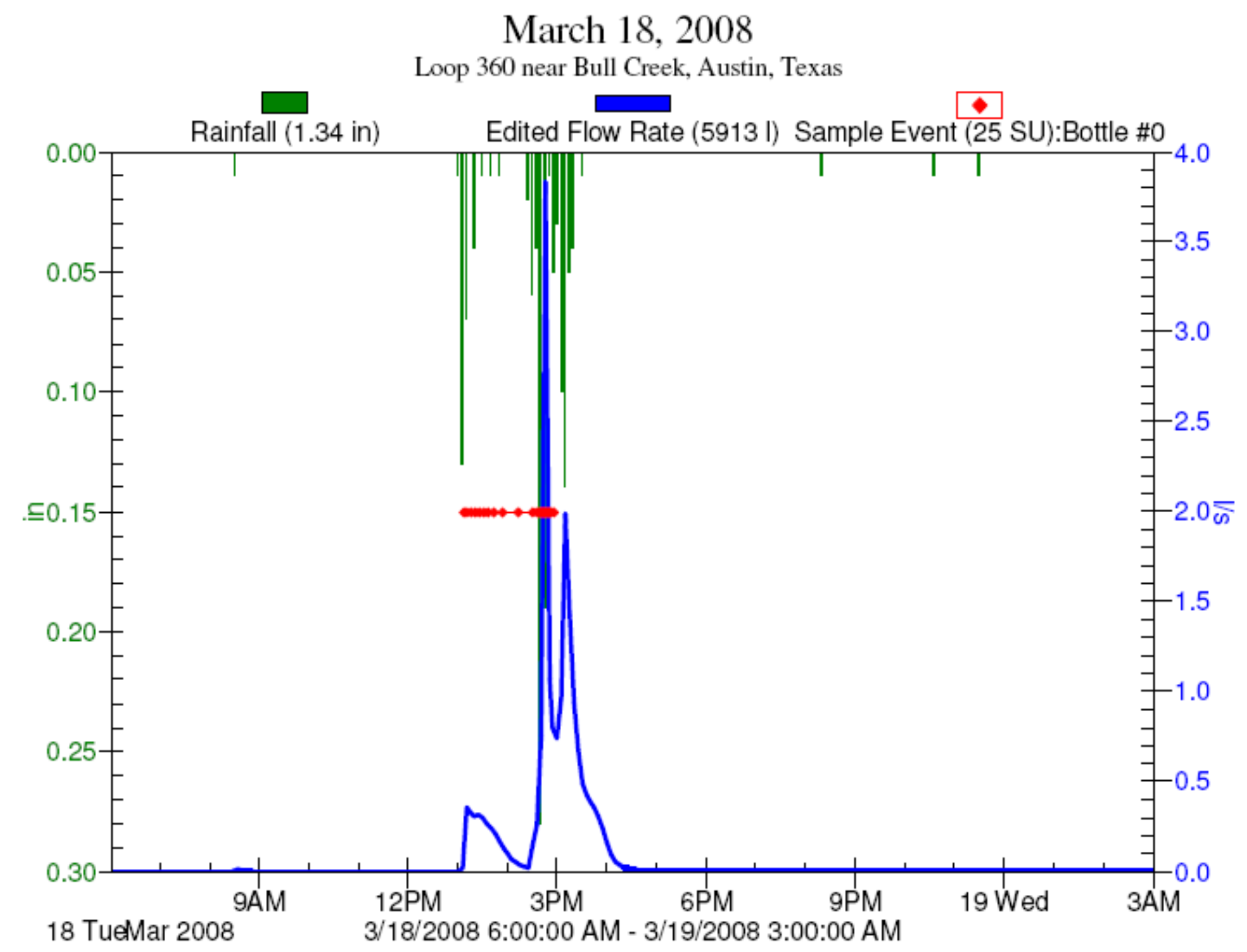




\section{References}

Barrett, M., Malina, J. and Charbeneau, R. (1995) Characterization of highway runoff in the Austin, Texas Area. Center for Research in Water Resources, The University of Texas at Austin, Austin, Texas.

Barrett, M. and Shaw, C. (2007) Benefits of Porous Asphalt Overlay on Storm Water Quality. Transportation Research Record: Journal of the Transportation Research Board, No. 2025, TRB, National Research Council, Washington, D.C., pp. 127-134.

Berbee, R., Rijs, G., de Brouwer, R., and van Velzen, L. (1999) Characterization and Treatment of Runoff from Highways in the Netherlands Paved with Impervious and Pervious Asphalt. Water Environment Research, Vol. 71, No. 2, pp. 183-190.

Capital Area Metropolitan Planning Organization (CAMPO). (2007) "TxDOT 5 County AADT Counts 1990-2005. www.campotexas.org/programs_rd traffic counts.php

Colandini, V., Michel, L. and Brosseaud, Y. (1995) Metallic Pollution in Clogging Materials of Urban Porous Pavements. Water Science Technology, Vol. 32, No. 1, pp. 57-62.

Fwa, T., Tan, S. and Guwe, Y. (1999) Laboratory Evaluation of Clogging Potential of Porous Asphalt Mixtures. Transportation Research Record: Journal of the Transportation Research Board, No. 1681, TRB, National Research Council, Washington, D.C., pp. 43-49.

Google Maps. (2007) Retrieved on February 11, 2008 from the Google Maps Website: http://maps.google.com/

Irish, L., Lesso, W., Barrett, M., Malina, J., and Charbeneau, R. (1995) An Evaluation of the Factors Affecting the Quality of Highway Runoff in the Austin, Texas Area. CRWR Online Report 95-9, Center for Research in Water Resources, The University of Texas at Austin, Austin, Texas. http://www.crwr.utexas.edu/online.shtml

ISCO. (2006) Isco Open Channel Flow Measurement Handbook. Ed. D. Walkowiak. 6th ed. Teledyne ISCO, Inc., Lincoln, Nebraska.

Kandhal, P. (2004) Asphalt Pavements Mitigate Tire/Pavement Noise. Hot Mix Asphalt Technology, March-April, pp. 22-31.

http://www.quietpavement.com/hotmixasphalt/docs/AsphaltPaveMitigateTirePav ementNoise.pdf 
Kearfott, P., Barrett, M. and J. F. Malina, Jr. (2005) Stormwater Quality Documentation of Roadside Shoulders Borrow Ditches. CRWR Online Report 05-02, Center for Research in Water Resources, The University of Texas at Austin, Austin, Texas. http://www.crwr.utexas.edu/online.shtml

Lower Colorado River Authority (LCRA). (2008) Hydromet Historical Reports. Gauge: Bull Creek at Loop 360, Austin. http://hydromet.lcra.org/hx/

Legret, M., Nicollet, M., Miloda, P., Colandini, V. and Raimbault, G. (1999) Simulation of Heavy Metal Pollution from Stormwater Infiltration through a Porous Pavement with Reservoir Structure. Water Science and Technology, Vol. 39, No. 2, pp. 119-125.

Legret, M. and Pagotto, C. (1999) Evaluation of Pollutant Loadings in the Runoff Waters form a Major Rural Highway. The Science of the Total Environment, Vol. 235, pp. 143-150.

Pagotto, C., M. Legret and Le Cloirec, P. (2000) Comparison of the Hydraulic Behaviour and the Quality of Highway Runoff Water According to the Type of Pavement. Water Resources, Vol. 34, No. 18, pp. 4446-4454.

Pacific Water Resources, Inc. (2004) Cross Israel Highway Stormwater Quality Study Phase II Monitoring Report.

Ranchet, J. (1995) Impacts of porous pavements on the hydraulic behaviour and the cleansing of water (in French). Techniques Sciences et Méthodes 11, pp. 869-871.

Stanard, C., Candaele, R., Charbeneau, R., and Barrett, M. (2008) State of the Practice: Permeable Friction Courses. Technical Report 0-5220-1. Center for Transportation Research, The University of Texas at Austin.

Stotz, G. (1987) Investigations of the properties of the surface water run-off from federal highways in the FRG. The Science of the Total Environment, Vol. 59, pp. 329337.

Stotz, G. and Krauth, K. (1994) The pollution of effluents from pervious pavements of an experimental highway section: first results. The Science of the Total Environment, Vol. 146/147, pp. 465-470.

Texas Administrative Code (TAC). (2005) Title 30, Environmental Quality, Chapter 213, Edwards Aquifer. Retrieved March 2, 2008 from the TCEQ Web Site: http://info.sos.state.tx.us/pls/pub/readtac\$ext.ViewTAC.

Texas Department of Transportation (TxDOT). (2004) Item 342 Permeable Friction Course (PFC) Standard Specifications for Construction and Maintenance of Highways, Streets, Bridges, Austin, Texas. pp. 312-328. Retrieved August 7, 
2007 from the TxDOT Web Site:

http://www.dot.state.tx.us/business/specifications.htm

Van der Zwan, J., Goeman, T., Gruis, H., Swart, J. and Oldenburger, R. (1990) Porous Asphalt Wearing Courses in the Netherlands: State of the Art Review, Transportation Research Record: Journal of the Transportation Research Board, No. 1265, TRB, National Research Council, Washington D. C., pp.95-110. 